\title{
WHEN LIFE HANDS YOU LEMONS, MAKE LEMONADE
}

by

\section{Catrina Pastore}

A thesis submitted to the Faculty of Graduate and Postdoctoral

Affairs in partial fulfillment of the requirements for the degree of

Degree in

Master of Architecture

Carleton University

Ottawa, Ontario

(C) 2018

Catrina Pastore 


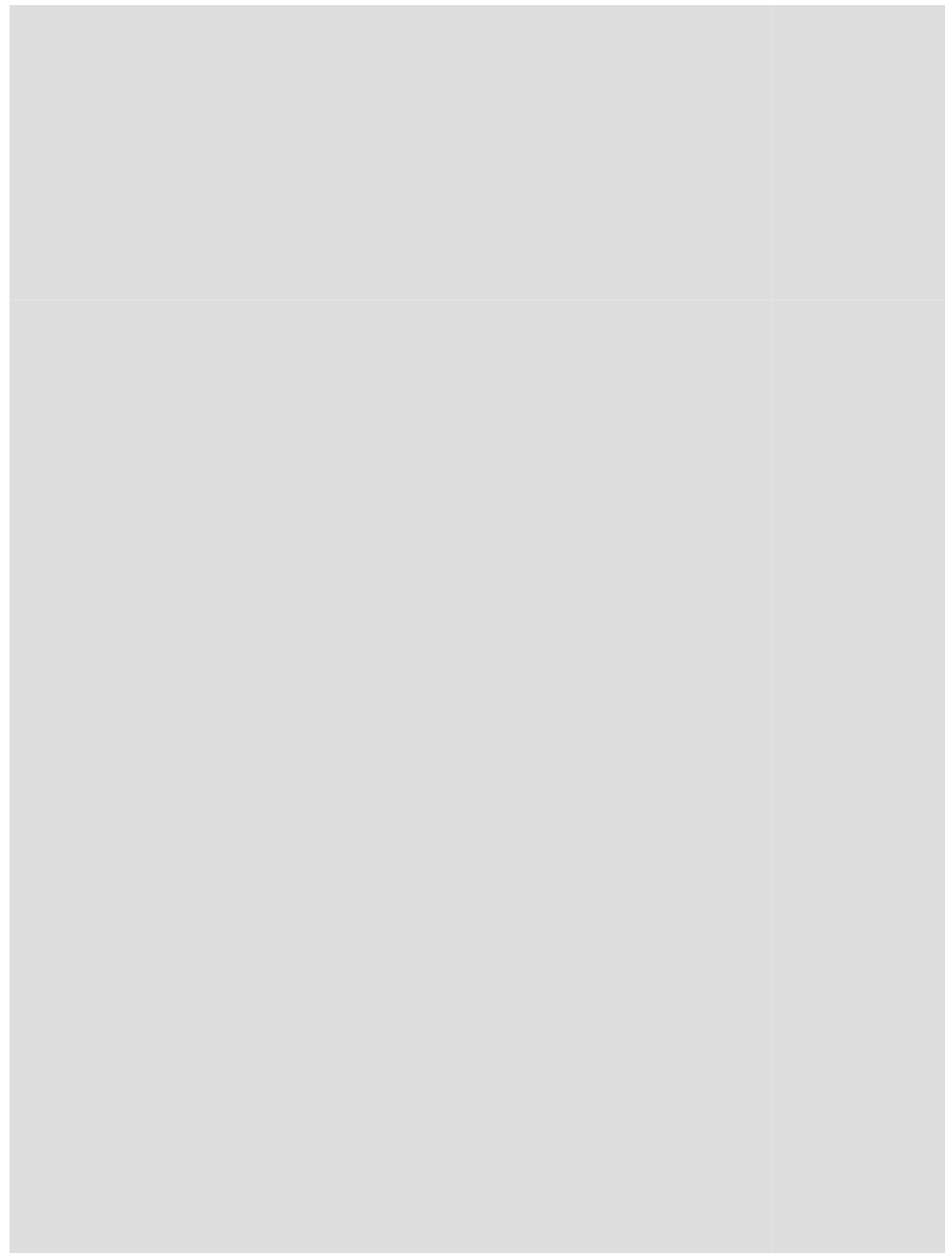




\title{
WHEN LIFE HANDS YOU LEMONS, MAKE LEMONADE
}

\author{
by
}

Catrina Pastore

A thesis submitted to the Faculty of Graduate and Postdoctoral

Affairs in partial fulfillment of the requirements for the degree of

Degree in

Master of Architecture

Carleton University

Ottawa, Ontario

(C) 2018

Catrina Pastore 


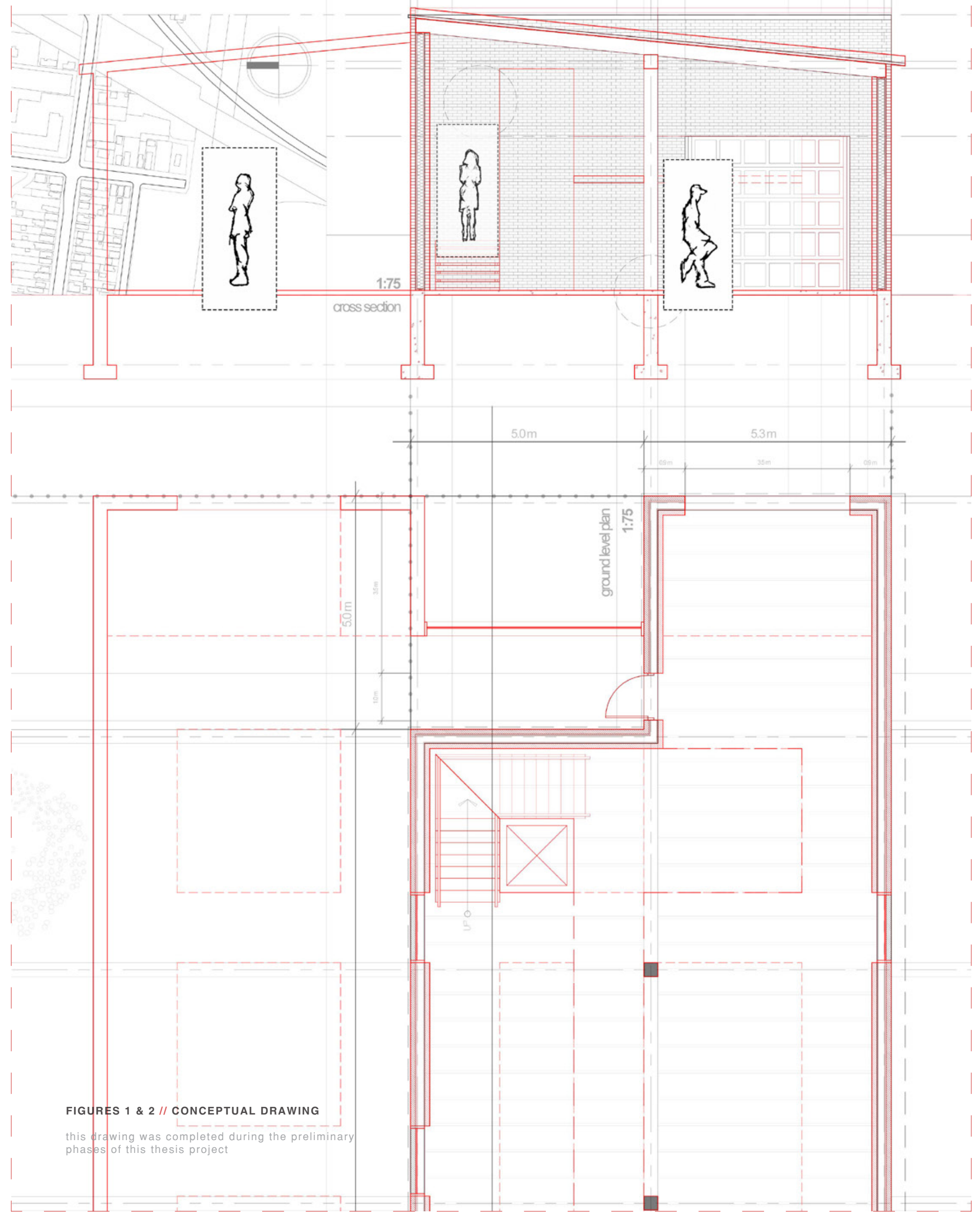




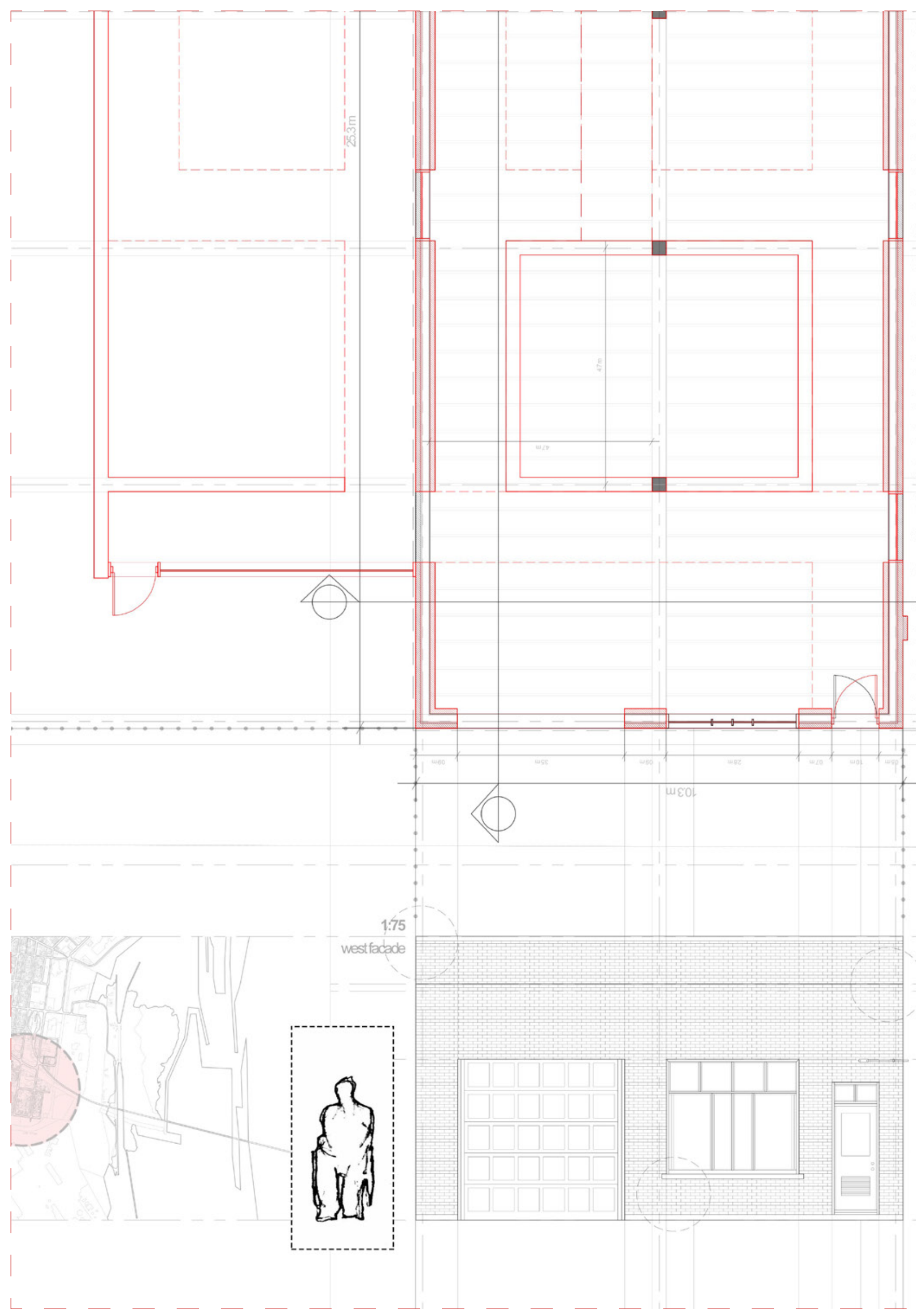




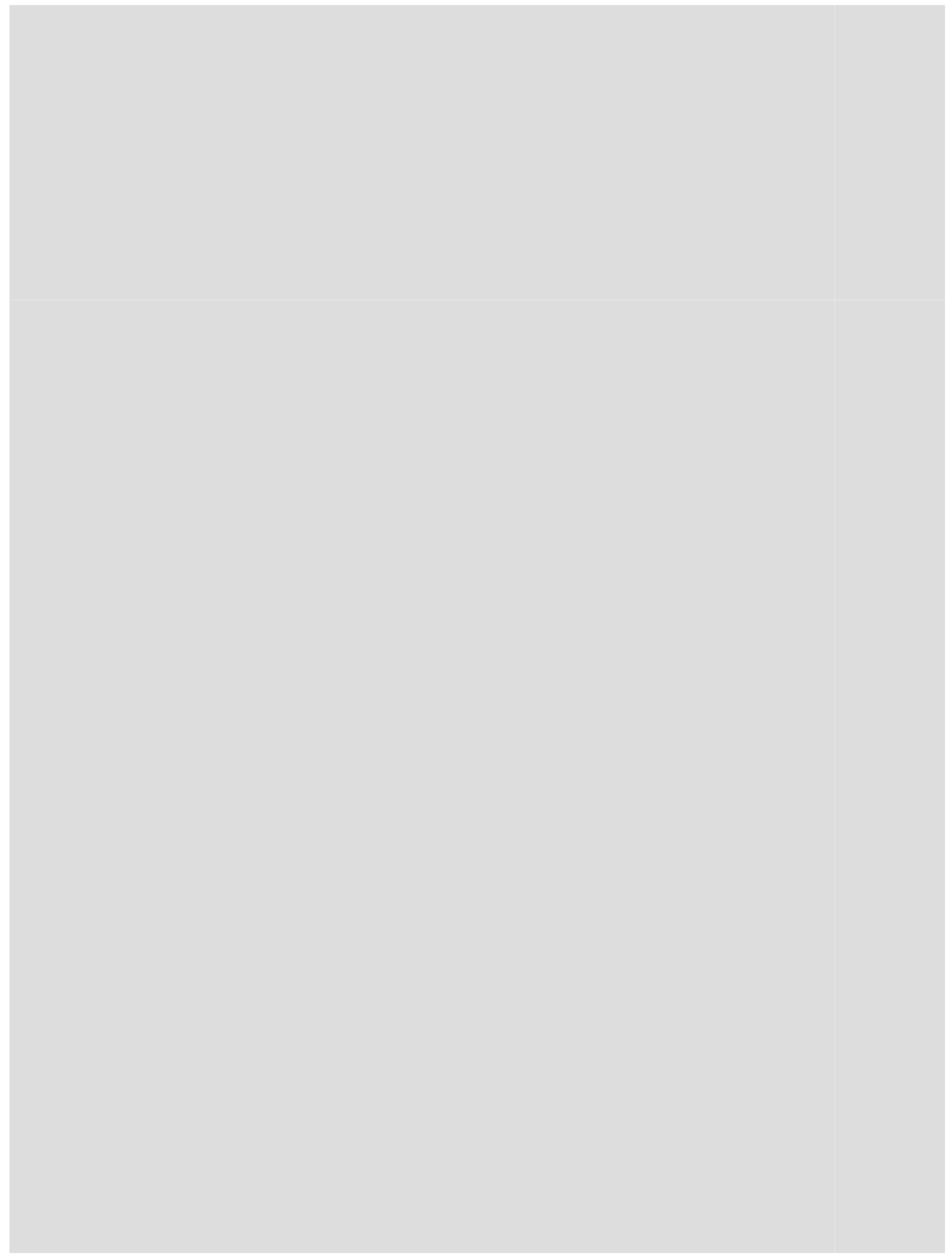




\section{ABSTRACT}

Interviews with key players in the City of Sault Ste. Marie have revealed that one of the main hindrances to the rejuvenation of the downtown core is the opioid crisis. The negative stigma associated with drug addiction is having an extremely negative impact on the quality of life in the city. Plastic surgery will not heal the problem. The disease needs to be addressed head-on.

The city needs a better and more holistic plan for the delivery of rehabilitation services. This thesis proposes a network of rehabilitation spaces as a new, necessary and positive institution in the city. Combining rehabilitation clinics with additional programs that can help patients to establish drug free lifestyles is an opportunity to educate the public regarding addiction disease. The intention is not only to rehabilitate the individual, but indirectly the community and built environment as well.

Three existing buildings in three different neighbourhoods of Sault Ste. Marie will be adaptively reused to accommodate the clinic requirements and an additional job training/lifestyle program. Drug rehabilitation strategies will be reinterpreted as design strategies for addressing the existing deteriorating fabric. 


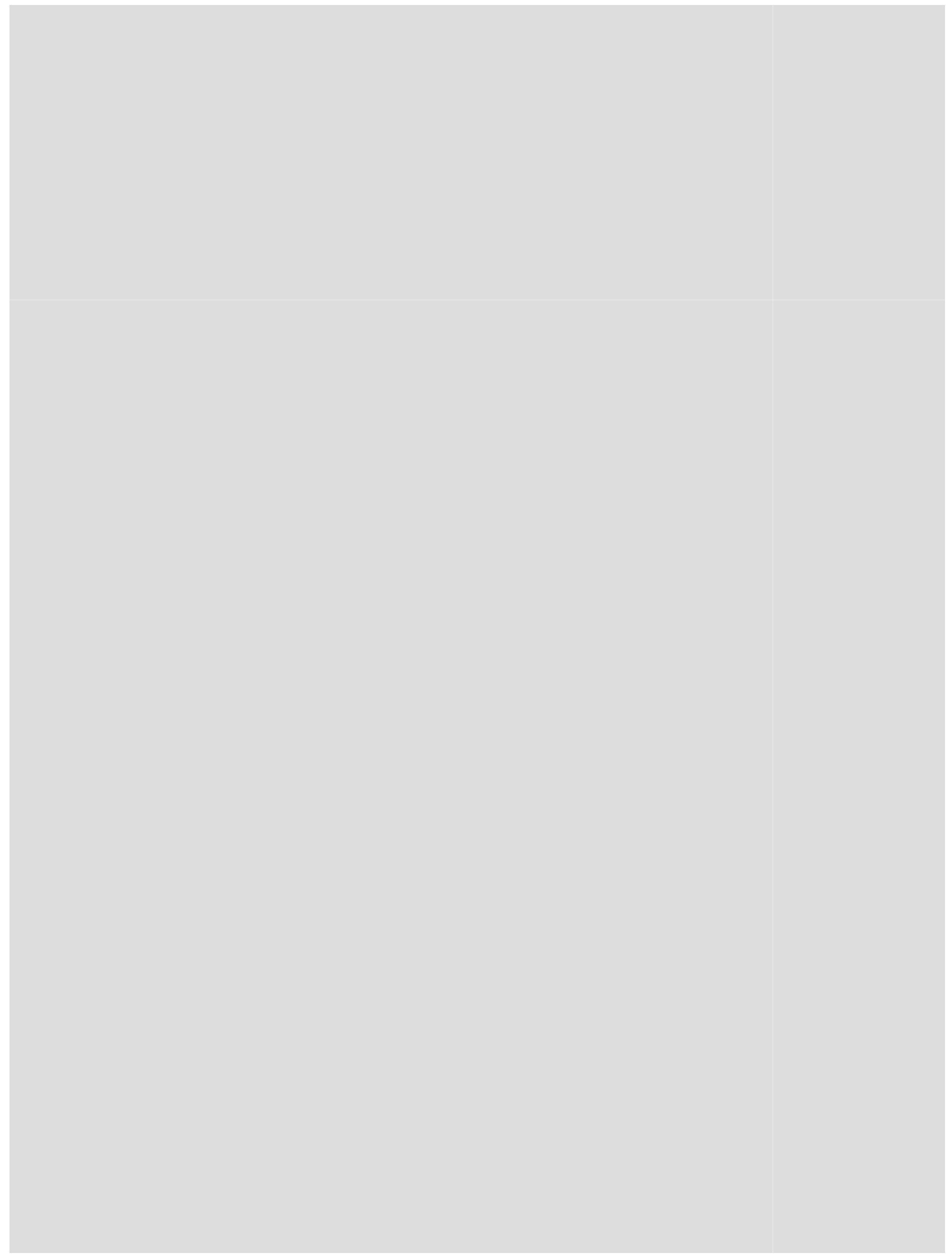




\section{ACKNOWLEDGEMENTS}

For my advisor Lucie, for being an ongoing support and encouraging me to always think outside the box

For those who assisted me in the development of this thesis, for your time and openness

For my parents Franco and Maria, for being my core

For my sisters Olivia and Daniella, for always making me smile

For the rest of my family and friends, for keeping me balanced

Thank you.

For those struggling or recovering from addiction, you are not alone. 


\section{CONTENTS}

\begin{tabular}{r|r} 
ABSTRACT & $\mathbf{V I}$ \\
\hline ACKNOWLEGEMENTS & $\mathbf{V I I I}$ \\
CONTENTS & $\mathbf{X}$ \\
\hline LIST OF ILLUSTRATIONS & $\mathbf{X I I}$ \\
LIST OF APPENDICES & $\mathbf{X V I}$ \\
FOREWARD & $\mathbf{1 8}$ \\
INTRODUCTION & $\mathbf{2 4}$ \\
STEELTOWN DOWN & $\mathbf{2 6}$
\end{tabular}

PEOPLE, PROFILE, PERSPECTIVE

THE FABRIC \& THE HUMAN CONDITION

CASE STUDIES VI VIII $\mathbf{X}$

XII XVI 18 24 26 8

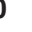




\begin{tabular}{|r|r|}
\hline DESIGN METHODOLOGY & $\mathbf{8 3}$ \\
\hline DRAWING METHODOLOGY & $\mathbf{9 1}$ \\
\hline INTERVENTION & $\mathbf{1 0 4}$ \\
\hline $\begin{array}{r}\text { west end community kitchen } \\
\text { gore street theatre }\end{array}$ & \\
\hline country club wellness & \\
\hline cONCLUSIONS & $\mathbf{1 2 5}$ \\
\hline BIBLIOGRAPHY & $\mathbf{1 3 0}$ \\
\hline APPENDICES & $\mathbf{1 3 4}$
\end{tabular}




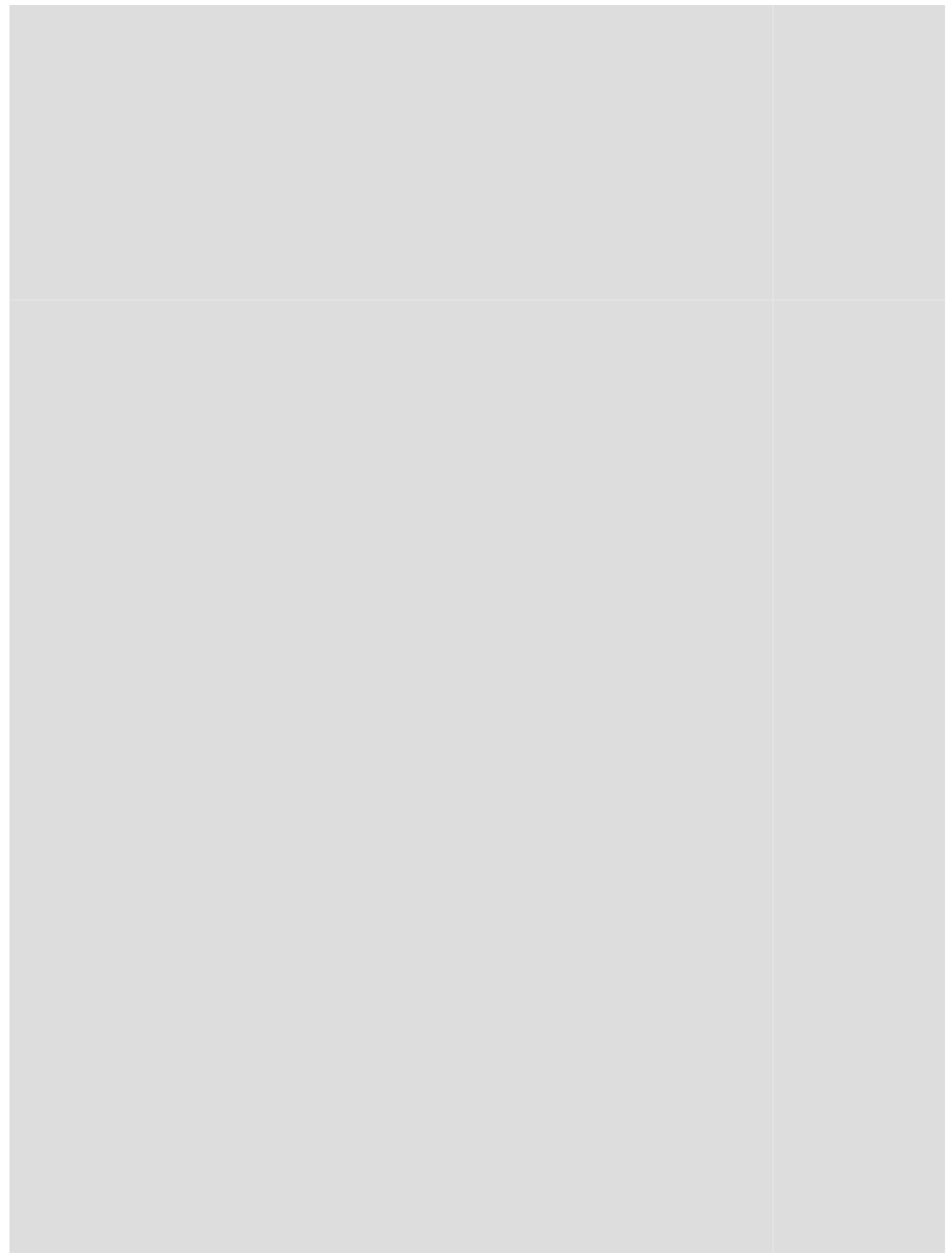




\section{LIST OF ILLUSTRATIONS}

Figures 1 \& 2 // Conceptual Drawing

Figure 3 // Site Visit Map 19

Figures 4 - 9 // Gore Street Before \& After

// 'Before' \& 3rd 'After' photograph(s) sourced from: http://saultstemarie.ca/City-Hall/City-Departments/Community-Development-Enterprise-Services/Planning-Enterprise-Services/Strategic-Long-Range-Planning/Downtown-Development/Gore-Street.aspx

Figure 10 // "Before I Die ..."

// Sourced from: https://www.ctvnews.ca/video?clipld=1323609

Figure $11 / /$ Algoma Steel

// Sourced from: https://hiveminer.com/Tags/algomasteel,sunset

Figure 12 // People, Profile, Perspective

// Sourced from: http://www.futuressm.com/category/reality-check/

Figure $13 / /$ Gore Street Courtyard

Figure 14 // Downtown Methadone \& Suboxone Clinic

// Sourced from: https://www.sootoday.com/local-news/downtown-gets-another-methadone-clinic-271067

Figure $15 / /$ Gore Street

Figure 16 // West End Community Plaza

35

Figure 17 // Case Studies: The Hungry Heart Documentary

// Sourced from: http://thehungryheartmovie.org/

Figure 18 // Narrative : The Hungry Heart

// Sourced from: http://thehungryheartmovie.org/

Figure 19 // Small City Reinvention : Flint Michigan

// Sourced from: https://www.flintarts.org/

Figure 20 // Breaking The Stigma : Psychiatric Centre

// Sourced from: https://www.competitionline.com/en/projects/51317

Figure 21 // Layered Context Model 0

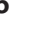

7

9

41

3


Figure 22 // Contextual Analysis: Demographics

Figure 23 // Contextual Analysis : Demographics

Figure 24 // Contextual Analysis : Existing Facilities

Figure 25 // Contextual Analysis : Existing Facilities

Figure 26 // Contextual Analysis : Site Selection

Figure 27 // Contextual Analysis : Site Selection

Figure 28 // Program Distribution

Figure $29 / /$ West End Community Site Collage

Figure 30 // West End Community Birds Eye View of Context

Figures 31 \& 32 // West End Community Historical Photographs

Figure 33 // West End Community Contextual Analysis

Figures 34 - 36 // West End Community Site Photographs

Figure 37 // West End Community Existing Floor Plan

Figure 38 // West End Community Selected Building

Figures $39 \& 40 / /$ West End Community Selected Building

Figure $41 / /$ Gore Street Site Collage

Figure 42 // Gore Street Birds Eye View of Context

Figures 43 \& 44 // Gore Street Historical Photographs \& http://search.ontariojewisharchives.org/Permalink/descriptions 273853

Figure 45 // Gore Street Contextual Analysis

Figures 46 - 48 // Gore Street Site Photographs

Figure 49 // Gore Street Existing Floor Plans 
Figures 51 \& 52 // Gore Street Selected Building

Figure 53 // Country Club Site Collage

Figure 54 // Country Club Birds Eye View of Context

// Base image sourced from: Google Earth

Figures 55 \& 56 // Country Club Historical Photographs

// Sourced from: http://www.saultgolfclub.ca/course.html

Figure 57 // Country Club Contextual Analysis

Figures 58 - 60 // Country Club Site Photographs

78

Figure $61 / /$ Country Club Existing Floor Plans

79

Figure 62 // Country Club Selected Building

80

Figures 63 \& $64 / /$ Country Club Selected Building

Figure 65 // Parti Diagrams

82

Figure 66 // Design Methodology : Body \& Building

Figure 67 // Design Methodology : Circulation

Figure 68 // Design Methodology Circulation : West End Community

Figure 69 // Design Methodology Circulation : Gore Street

Figure 70 // Design Methodology Circulation : Country Club

Figure 71 // Drawing Methodology

Figure 72 // Drawing Methodology

Figure 73 // Drawing Methodology

Figure 74 // Drawing Methodology: West End Community Base Drawing

Figure 83 // Drawing Methodology : Gore Street Base Drawing

Figures 84 - 87 // Drawing Methodology : Gore Street Base Drawing

Figures 88 - 91 // Drawing Methodology : Gore Street Base Drawing 
Figure 92 // Drawing Methodology : Country Club Base Drawing

Figures 93 - 96 // Drawing Methodology : Country Club Base Drawing

Figures 97 - 100 // Drawing Methodology : Country Club Base Drawing 102

Figure $101 / /$ Intervention Conceptual Drawing 103

Figure 102 // Final Drawing Composition : West End Community Kitchen 105

Figures 103 \& 104 // Spatial Sketches: West End Community Kitchen 107

Figures 105 \& $106 / /$ Section Sketches : West End Community Kitchen 107

Figure 107 // Wall Section : West End Community Kitchen 107

Figure 108 // Wall Section : West End Community Kitchen 108

Figure 109 // Floor Plans Ground Level : West End Community Kitchen 109

Figure 110 // Floor Plans Upper Level : West End Community Kitchen 110 Figure 111 // Final Drawing Composition : Gore Street Theatre 111

Figures 112 \& $113 / /$ Spatial Sketches : Gore Street Theatre 113

Figures 114 \& 115 // Section Sketches: Gore Street Theatre 113

Figure 116 // Wall Section : Gore Street Theatre 113

Figure 117 // Wall Section : Gore Street Theatre 114

Figure 118 // Floor Plans Ground Level : Gore Street Theatre 115

Figure 119 // Floor Plans Lower Level : Gore Street Theatre 116

Figure 120 // Floor Plans Upper Level : Gore Street Theatre 117

Figure $121 / /$ Final Drawing Composition : Country Club Wellness 118

Figures 122 \& 123 // Spatial Sketches : Country Club Wellness 120

Figures 124 \& 125 // Section Sketches : Country Club Wellness 120

Figure 126 // Wall Section : Country Club Wellness 120

Figure 127 // Wall Section : Country Club Wellness 121

Figure 128 // Floor Plans Ground Level : Country Club Wellness 122

Figure 129 // Floor Plans Upper Level : Country Club Wellness 


\section{LIST OF APPENDICES}




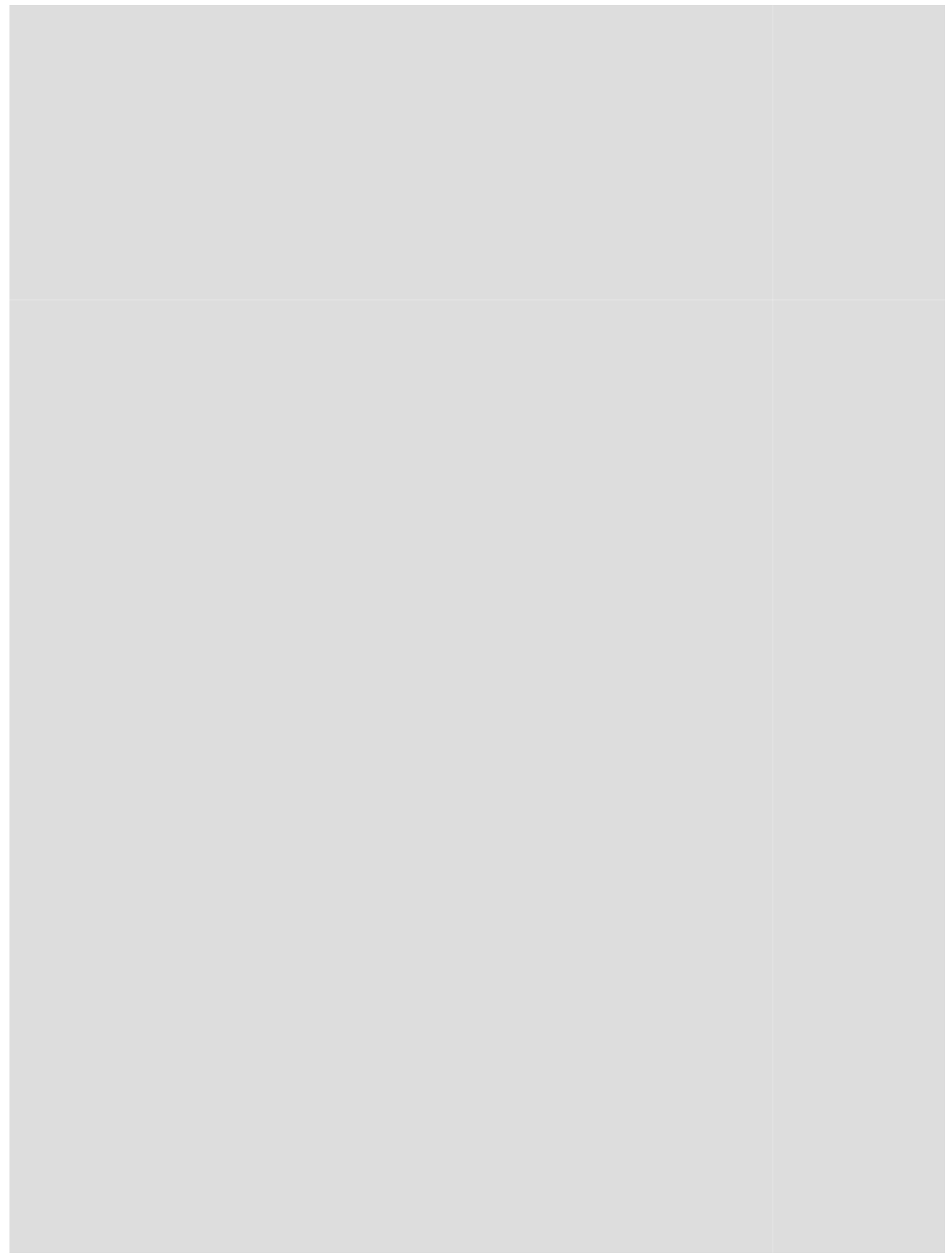




\section{FOREWORD}

Growing up as a teenager in my hometown of Sault Ste. Marie, Gore Street meant 3 things: drugs, prostitution, and insecurity. In contrast, when my parents were teenagers, the street had a whole other meaning: arts, ethnic heritage, and community. What happened? How did one street, a $100 \mathrm{~m}$ long road that carries significant value within the downtown core, transform so drastically within roughly 20 years? More importantly, what does that mean for the rest of the city?

It's hard not to feel a bit of hesitation taking on a project of such sensitive content. The realization that your city is stuck in a kind of limbo can be a hard pill to swallow.

As I was driving through the city deciding the best way to record my selected sites, I could not help but be consumed with the concern of safety. Two of my sites being in unsafe parts of town raised caution. As much as I did not want to acknowledge my prejudice, the reality was that I could not visit two sites without the company of someone else. I asked that my cousin join me while I visited each site to photograph and record the context and selected existing buildings.

The first visit was to the West End Community, a small plaza that is currently home to the local soup kitchen, social housing, a small number of locally owned commercial businesses, and adjacent to the city's main industrial site. Personally I have always felt a sense of comfort within this area because of its history and intent to assist those in need. Although this is the case, the issue of safety was still a concern because of the lack of activity within the area. My first observation upon arrival was the number of vehicles parked in the plaza. There were two. My second observation was the number of vacant buildings. Only two out of the ten buildings in the plaza were occupied by either owners or tenants. So much underutilized potential. Why were there no people on the street? This entire area is predominantly residential, a community unto itself. Where were these people hiding? An almost abandoned neighbourhood, visually unoccupied, felt unsafe. 


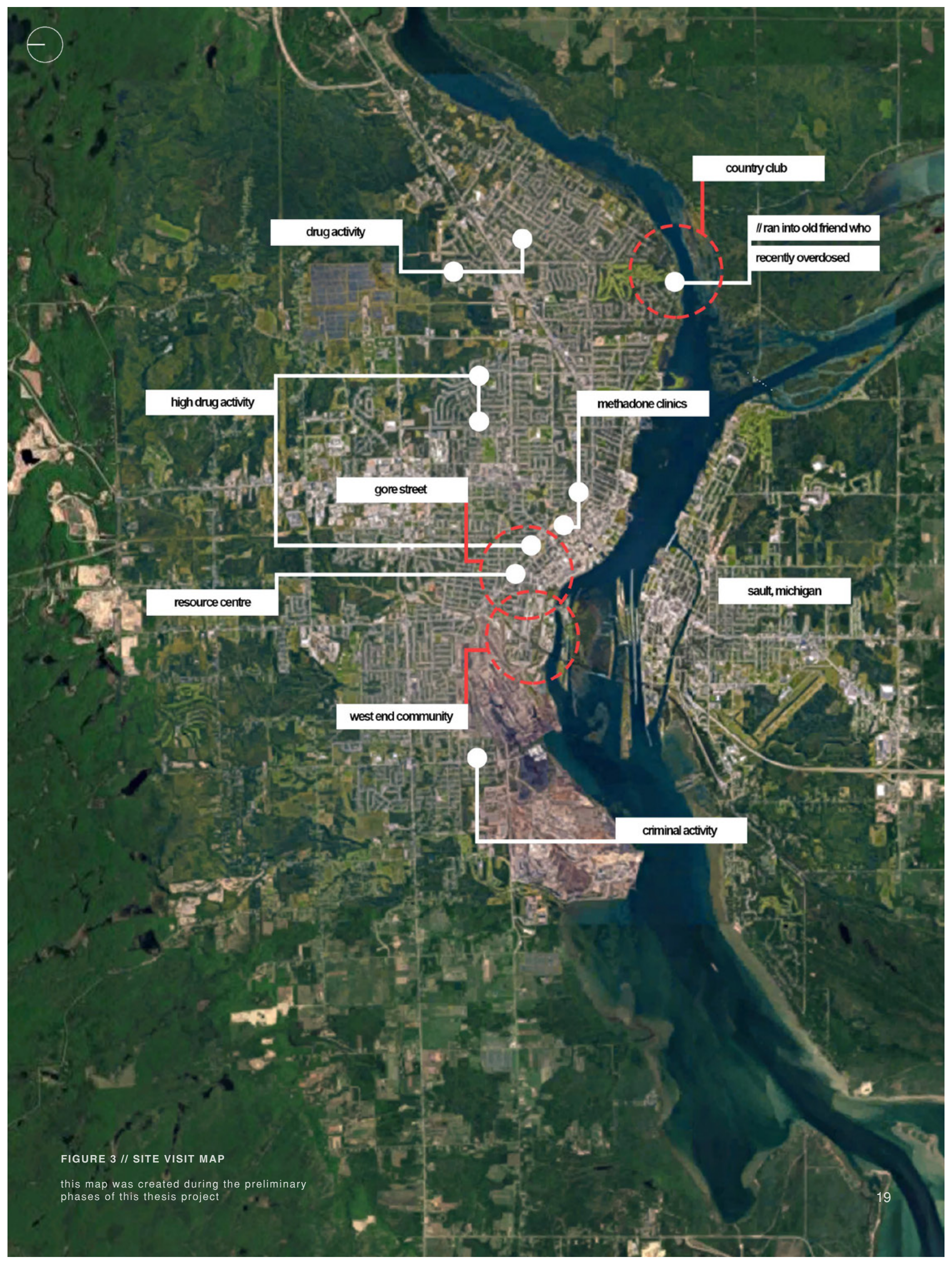


My second visit was to the Country Club Golf Course, located in the East end of the city. The site is an immense parcel of green space located at the heart of an upper middle class area of town. In the past year the property, along with the existing building situated on site, has been put on the market for sale. Logically it would make most sense to visit the Country Club last considering it was in the opposite end of town and directly beside my house, but there was a certain curiosity inside me that wondered how I would feel in a very exposed, occupied part of town, in direct contrast to the West End Community that I had just visited. Arriving back in the East End of the city I already felt back at home. Regardless of the fact that my home was located only five houses down the street from where I stood, it was the environment that made me feel comfort. The waterfront, the open green space, the accessibility and close proximity to the rest of the city, this was what Sault Ste. Marie was about. After an easy hour of recording I then walked back to my car, about to leave and ironically ran into an old friend from high school, a friend who overdosed on oxycontin just a year ago.

Driving back to the West End of the city from the Country Club brought me along Queen Street, a direct route to Gore Street. The 5 - 10 minute drive brings you right through our downtown core. This time I was extra observant of the conditions of the downtown. On a regular day I pass through the downtown almost three times, and that's just as a transit route. A citizen visits the downtown as a destination an average of two times a week, almost three times less than what was estimated five years ago. Just thinking of this brought about an overwhelming sadness. I looked around to find both successful and unsuccessful businesses, realizing that the most successful one was a methadone clinic with regulars overflowing onto the sidewalk, sitting and smoking in the cold fall weather. Despite this, the most overwhelming experience of the day was visiting Gore Street.

The last stop on my excursion through the city was the infamous Gore Street, Many consider this to be the 'cancer to the downtown core'. I grew up informed about the conditions of Gore Street and its role within Sault Ste. Marie's downtown. As a child it was the street we took every Sunday to get to my Nona's. As a teenager it was an area I was told to avoid at all costs because it was unsafe. As an employee of the city's planning division it was a revitalization project that no one knew how to address. Now, it is just one piece in an extremely complicated puzzle.

I arrived and parked next to the neighbourhood watch program that recently moved to Gore Street just in the last year. My cousin and I got out of the car to begin our walk along the street. We started at the South End of the street because it seemed to be where most of the pedestrian traffic was occurring that day. Standing at the intersection of Queen and Gore I looked down the rest of the street to notice almost total abandonment. We began to make our way towards it, each step approaching emptiness. One block in, I noticed the change in aesthetics. The Corporation of the City of Sault Ste. Marie had recently spent a large amount of money on improving the dynamic of the street by landscaping, adding public spaces, and improving the quality of a number of storefronts. 

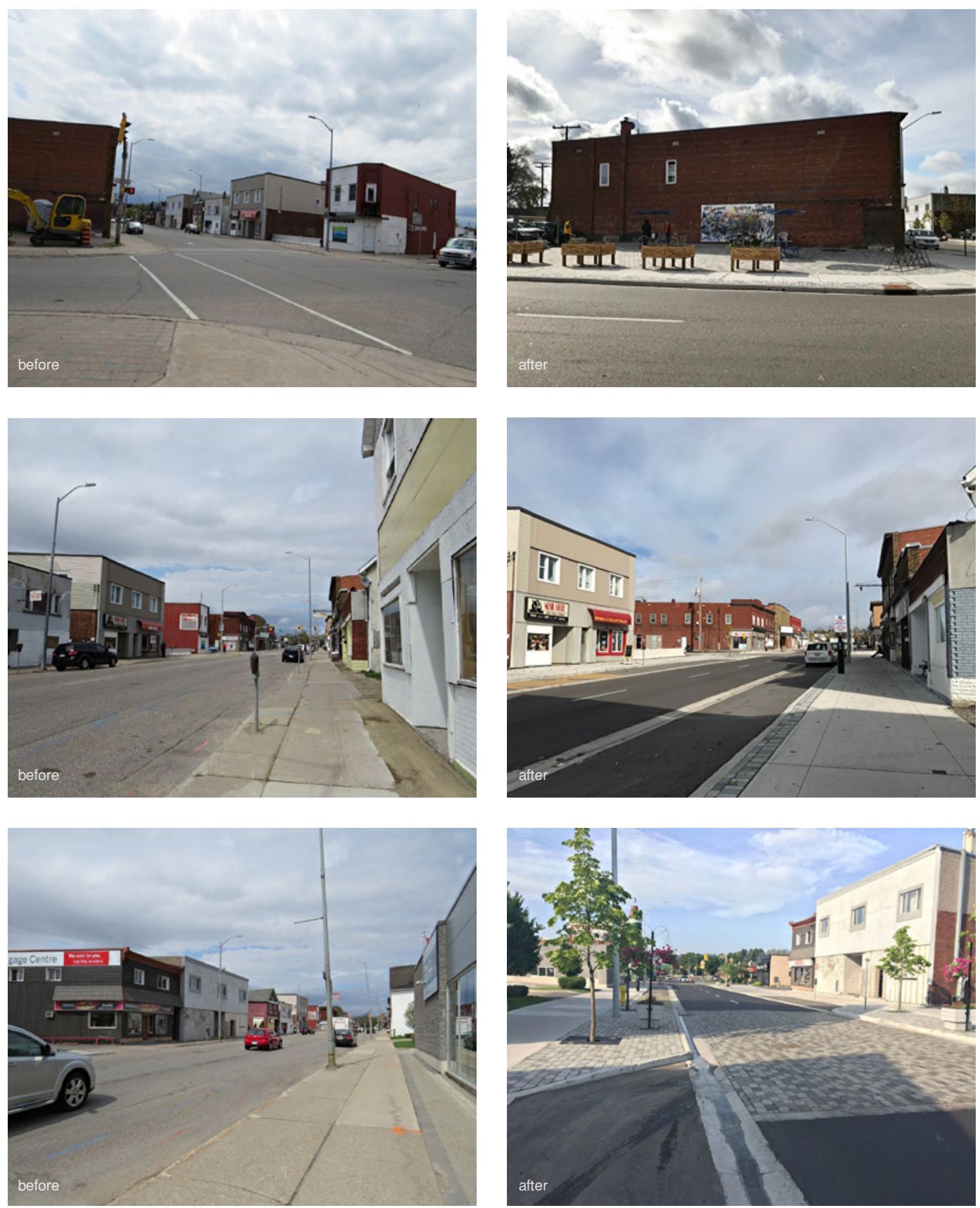
While the City did just this, they failed to acknowledge the human dimension. The streets were physically cleaner but remained dirty in a sense that drug deals were still happening right in front of my eyes. We reached one of these public spaces (and by public space I mean a corner lot of newly paved ground and the insertion of modern designed picnic tables), to find a group of five people: a policeman and woman, an elderly woman, a middle-aged woman and middle-aged man. As we approached the area we quickly picked up on the serious conversation that was being had between the officers and middle aged couple. The elderly woman remained seated at a table experiencing serious respiratory problems that fazed no one else but my cousin and myself. It was hard to decipher what exactly was occurring at that very moment but it was obvious enough that the middle-aged couple were being questioned about a drug deal that had taken place just minutes before we arrived. I could only hear bits of the conversation being exchanged between the officers and the couple but that was all irrelevant, it was only three words that mattered: "I need help".

Despite all of the aesthetic fixes and maintenance that the city had put into trying to improve Gore Street, it still remained an area in need of help. After minutes of pretending to photograph the surrounding spaces, specifically the old theatre building that I have selected as my third site, my cousin picked up that the woman in the couple was the same woman he had recently had an encounter with while working security in our shopping centre. Just days prior to this, the same woman was unfortunately removed from the centre for asking vendors in the cafeteria for food. As he was telling me this, the woman either recognized him or was uncomfortable with our presence and began pointing and yelling. It was at this point that we left and continued our walk back to the vehicle.

Drug addiction within Sault Ste. Marie is a real issue. These are real people, real problems, and real environments. They affect all of us in one way or another and it is our obligation as a community to help those who cannot help themselves.

By growing up in this city I have formed a part of its history. There is value in the things that are and in the things that were. The human condition exists everywhere, as do buildings. They simultaneously cohabitate with one another to make up the fabric of our city. In this case rehabilitation is as much part of growth as building new is. What is the link between the rehabilitation of people and buildings? Is it possible to restore a sense of place by rehabilitating both using the same methods? 


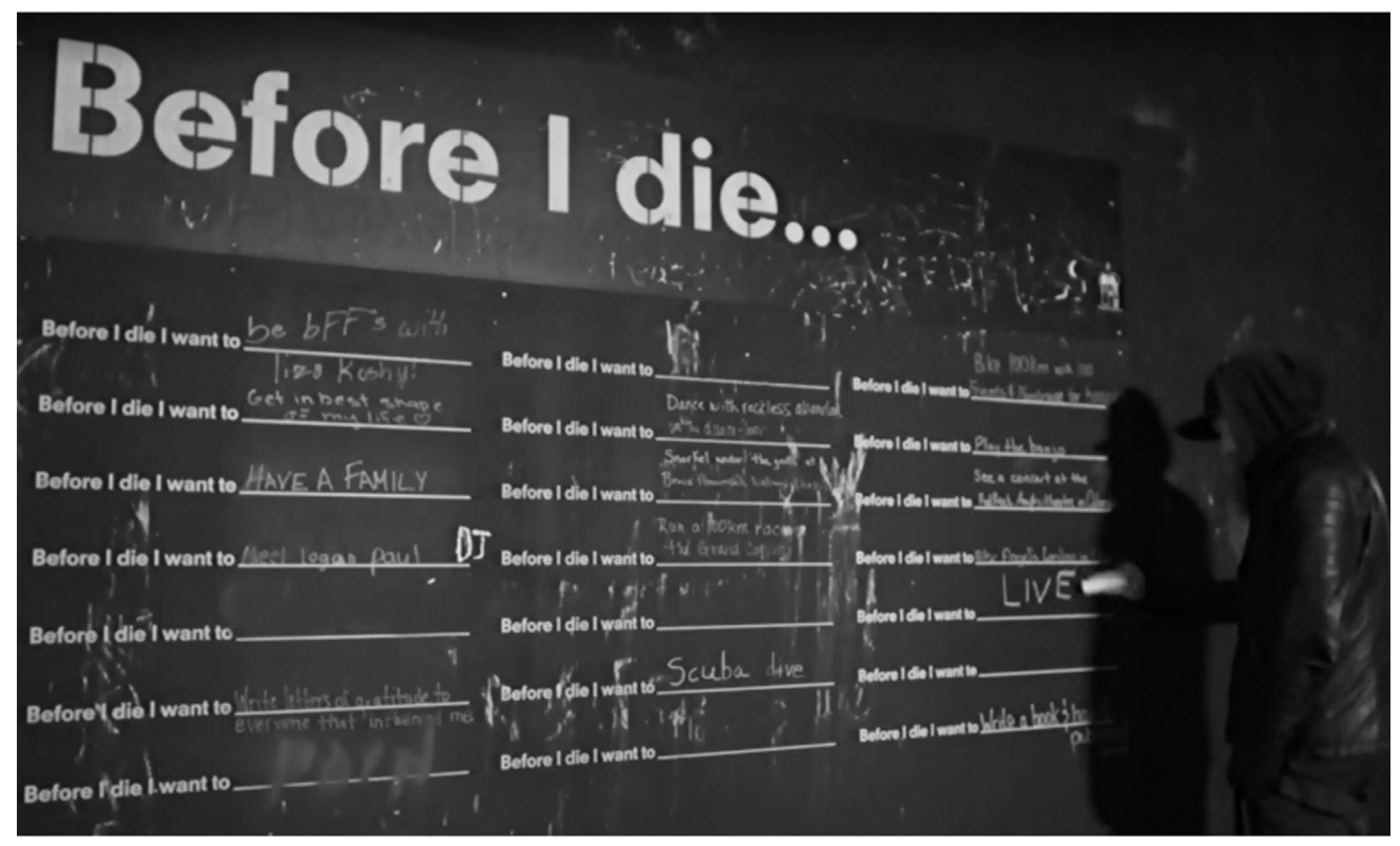




\section{INTRODUCTION}

Drug addiction is a disease, it is not a moral failing. Like diabetes and heart disease, the DNA of one person makes them more susceptible to the disease than another. One person may take painkillers after simply having their wisdom teeth removed and inadvertently become addicted to pain medication. However once addicted, the resulting lifestyle is often devastating, as people resort to illegal activities in order to feed their addiction. They lose those close to them and ultimately they lose themselves. The negative stigma associated with addiction is related to these nefarious activities and the destitution of the addicted individuals. These people have lost everything and are caught in a downward spiral as they constantly try to fund their addiction. In recent years, over prescribing of pain medication by physicians has contributed to opioid addiction reaching epidemic levels in North America. Today, more people die from addiction than from motor vehicle accidents. Death rates caused by overdose are about to surpass deaths caused by the aids crisis. ${ }^{1}$ The reality is that it is only because addiction is now prevalent in all socio-economic sectors of the population that attention is being paid to this disease.

Recovery is possible however, but it is going to require a very different approach. Addiction has to be brought from the dark unspoken domain, condemned and hidden from view, into a visible world that encourages people to seek help and offers hope for a better future. Treatment has to be made readily available to people from all walks of life, from the homeless to the upper middle class teenager. This disease has to be made public and addressed in an open way in order to prevent an increase in overdose deaths.

As architects I believe that we have the ability to create positive environments by responding to negative human conditions. There are parallel conditions found between a substance user and an abandoned existing building. Much like someone struggling with drug addiction, existing buildings are either erased or forgotten about when they can no longer properly function and serve the community. In the case of both addiction recovery and building rejuvenation, rehabilitation is as much a part of growth as starting new is.

How can we benefit from treating buildings (micro) and urban fabric (macro) with the same regard as the human being? What is the link between the rehabilitation of people and buildings? Is it possible to restore a sense of place by rehabilitating both using the same methods?

1 Steeltown Down. Documentary. Produced and Directed by Vice Canada. Released February 10, 2018. 


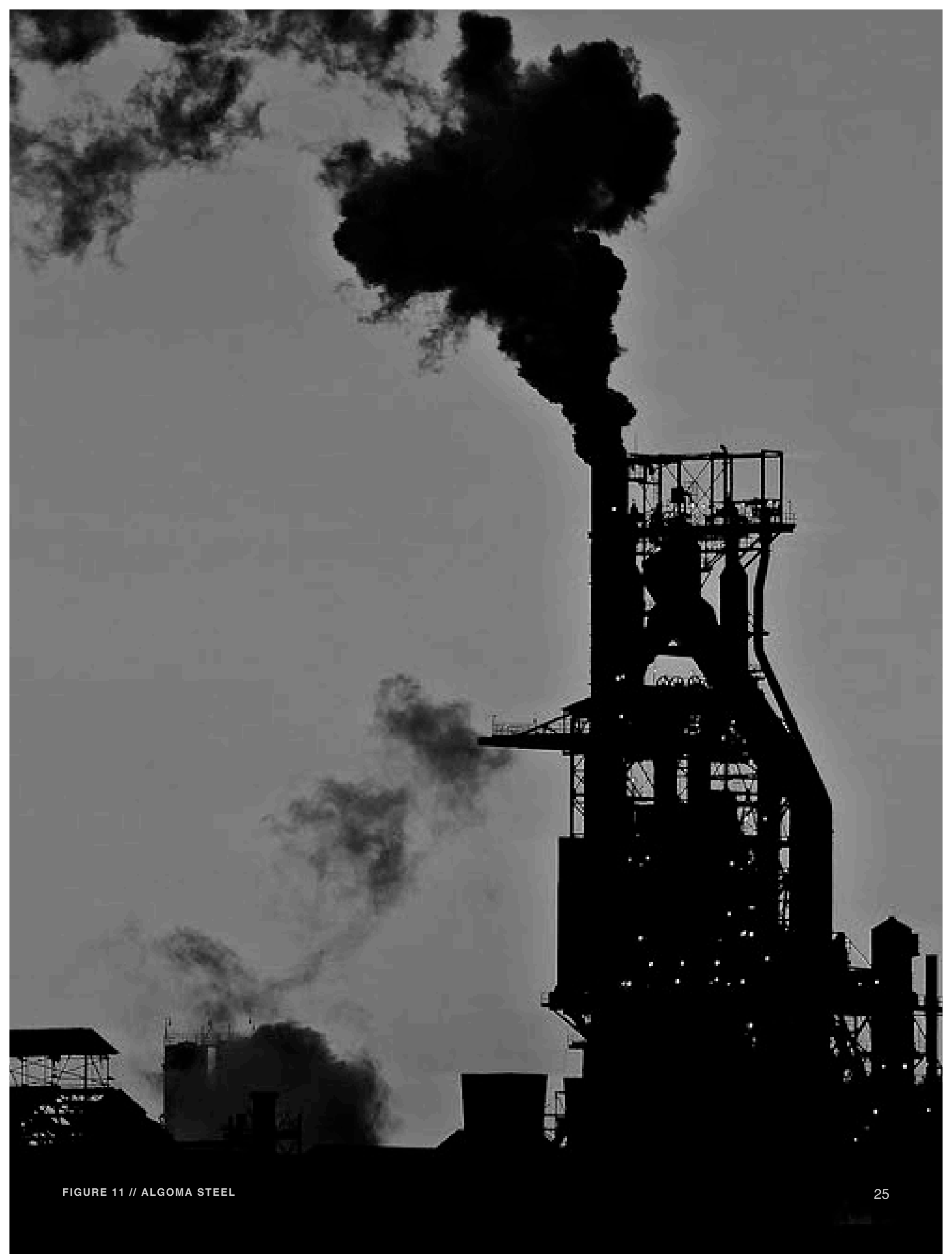




\section{STEELTOWN DOWN}

Sault Ste. Marie is a remote Northern Ontario community of approximately 75,000 people. It defines itself as an industrial border city at the heart of The Great Lakes. The city was originally settled with the intention of acting as a central hub between 3 major bodies of water: Lake Superior, Lake Huron, and Lake Michigan. Considering its geographical location, it provided great opportunity for transportation access, which ultimately led to the city's successful steel and paper industry, the trigger to the Soo's initial strong economic and social growth.

American born businessman Francis Clergue actualized the potential of the city when he built an electric-power plant and pulp mill in the early 1900's. After years of business and new ownership The Algoma Steel Company became Canada's second largest steel producer. ${ }^{2}$ Although Algoma Steel, now Essar Steel Algoma, continues to be a major economic force in the area, it is struggling. At its peak Essar Steel employed up to 10,000 workers, but with changes in the economy, technology, and restructuring of its current payroll, falls just short of $3000 .^{3}$

Over recent years the city has unfortunately transitioned into a state of socio-economic decline. Essar Steel has recently gone into bankruptcy protection and fears that the recent proposed tariffs on imported steel will essentially make it obsolete as it is the essential driver of the city's economy. The city has yet to find a way to sustain itself without relying on the steel plant and so the city as a whole is feeling those struggles. There is a reluctance to invest in the community. As a result of this the city has begun to experience a number of added stresses. The Soo suffers from serious out-migration due to the lack of opportunity and resources available to graduating students and young professionals. The urban core has ultimately reached a point of depreciation. Local business owners are moving out of the downtown core and relocating to the northern area of the city where property taxes are lower, but even more importantly, because of the safety concerns associated with presence of drugs that have recently become very problematic. The city footprint continues to increase but the population decreases. It is obvious that today's city is now a shadow of its former self. It has yet to embrace the notion of resiliency. $\begin{array}{ll}2 & \text { Kemp, D. D. "Sault Ste Marie". The Canadian Encyclopedia. Accessed March 03, } 2018 . \\ 3 & \text { lbid. }\end{array}$ 

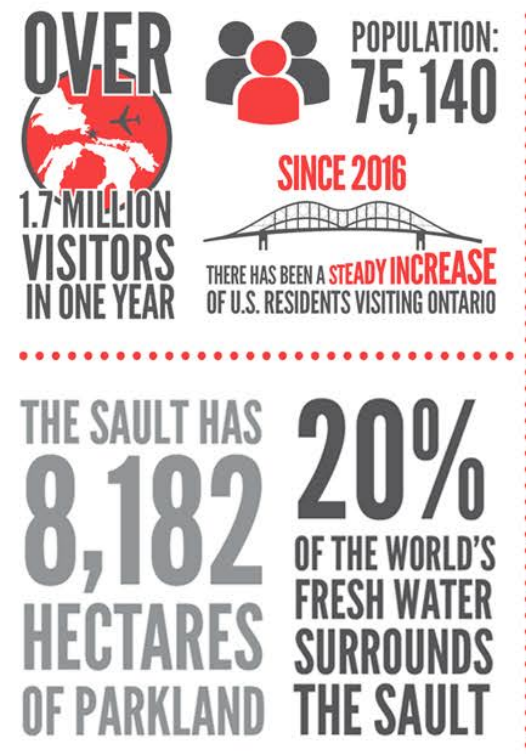

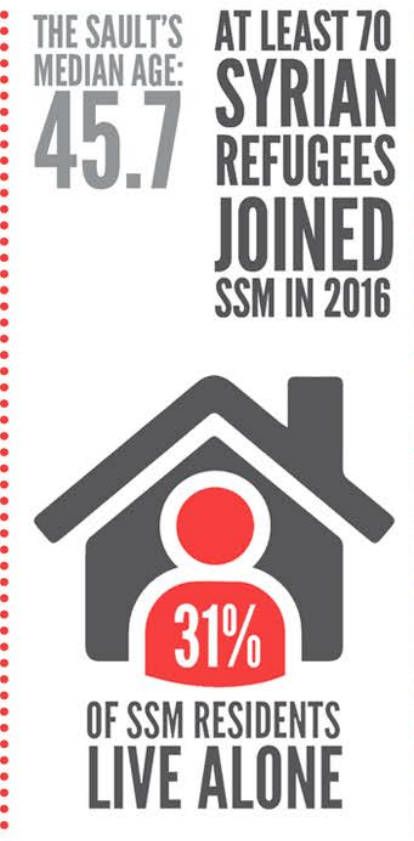

SAULT STE. MARIE (in)
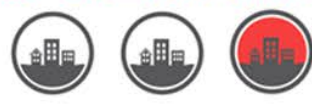

IS ONE OF THE FOUR CITIES IN NORTHERN ONTARIO TO HAVE BOTH A COLLEGE \& UNIVERSITY

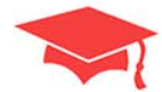

IN 2015-16

OVER 200

YOUTH \& ADULTS

RE-ENGAGED

IN EDUCATION

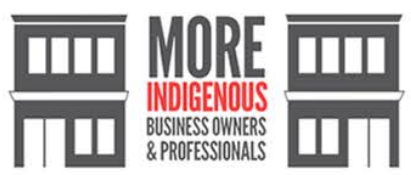

ARE ESTABLISHING STOREERONTS IN SAULT STE MARIE

IVET0

BUINIESSES

\& ORGANIZATIONS

IN DOWNTOWN

G1

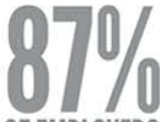

OF EMPLOYERS

HAVE LESS

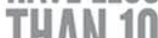

STPOOYES

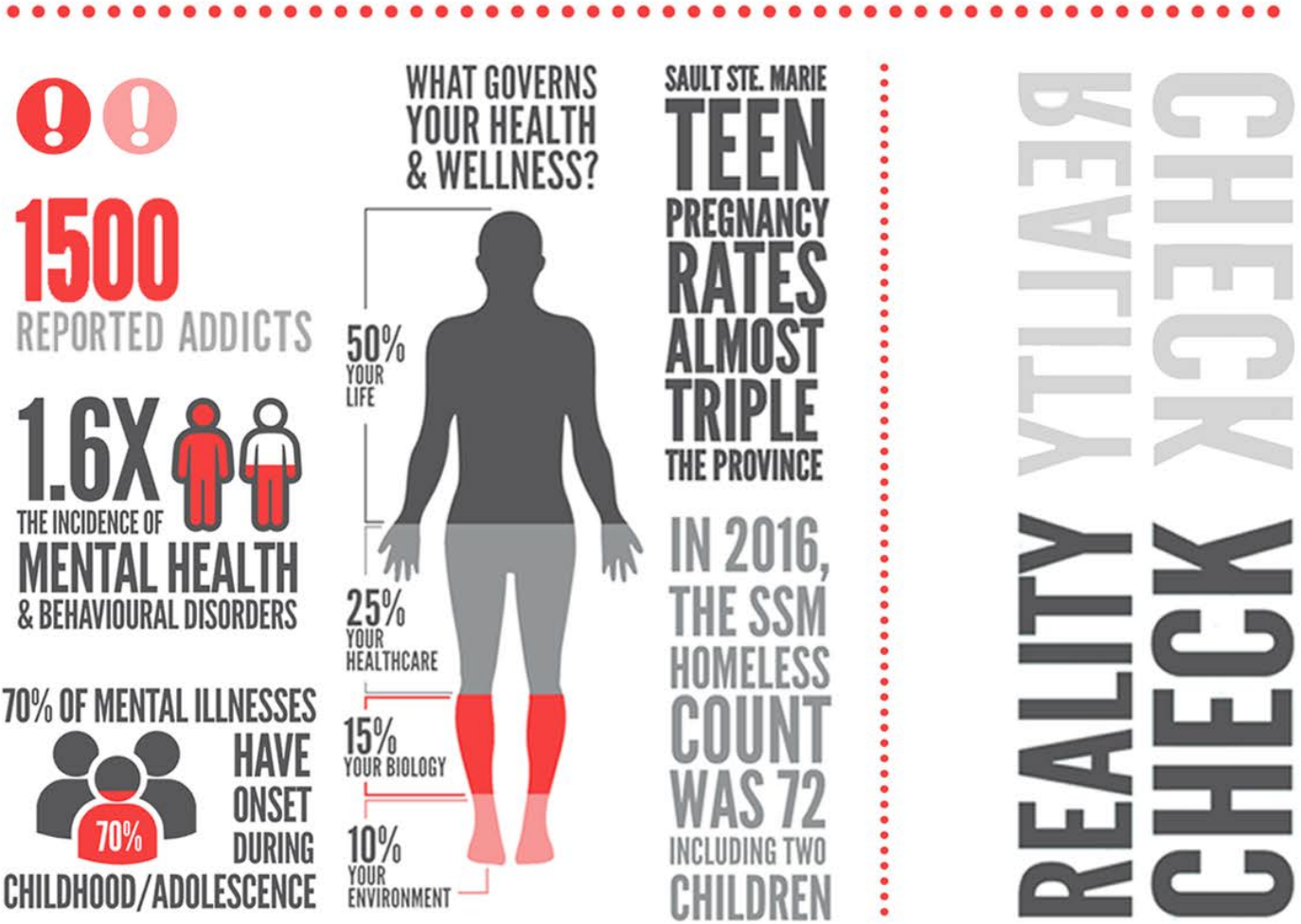

FIGURE 12 // PEOPLE, PROFILE, PERSPECTIVE REALITY CHECK 


\section{PEOPLE, PROFILE, PERSPECTIVE}

Earlier in the summer, I had discussions with a cross section of members within the community in order to gain an understanding of how people felt about Sault Ste. Marie and what they felt were issues that needed to be addressed for the city to flourish. I interviewed city planners, architects, project coordinators, business owners, nurses, social workers, academics faculty and administration. I posed the same 5 questions to each in hopes of attaining a variety of perspectives. Most of the responses were positive but each emphasized negative realities occurring in the city. Most importantly each person mentioned the drug addiction problem scattered throughout the city and the impact it has on their daily lives.

In addition I had conversations with the mayor and a number of council members. I learnt how the municipality prioritizes the current realities of the city and what is planned in order to address them. Throughout this exercise, the one common thread was the effort put into dancing around the issue of drug addiction. There appeared to be a blindness to the recent developments in the city. Only recently, with the CTV documentary of January... is there an acknowledgement that this problem needs to be addressed directly. 


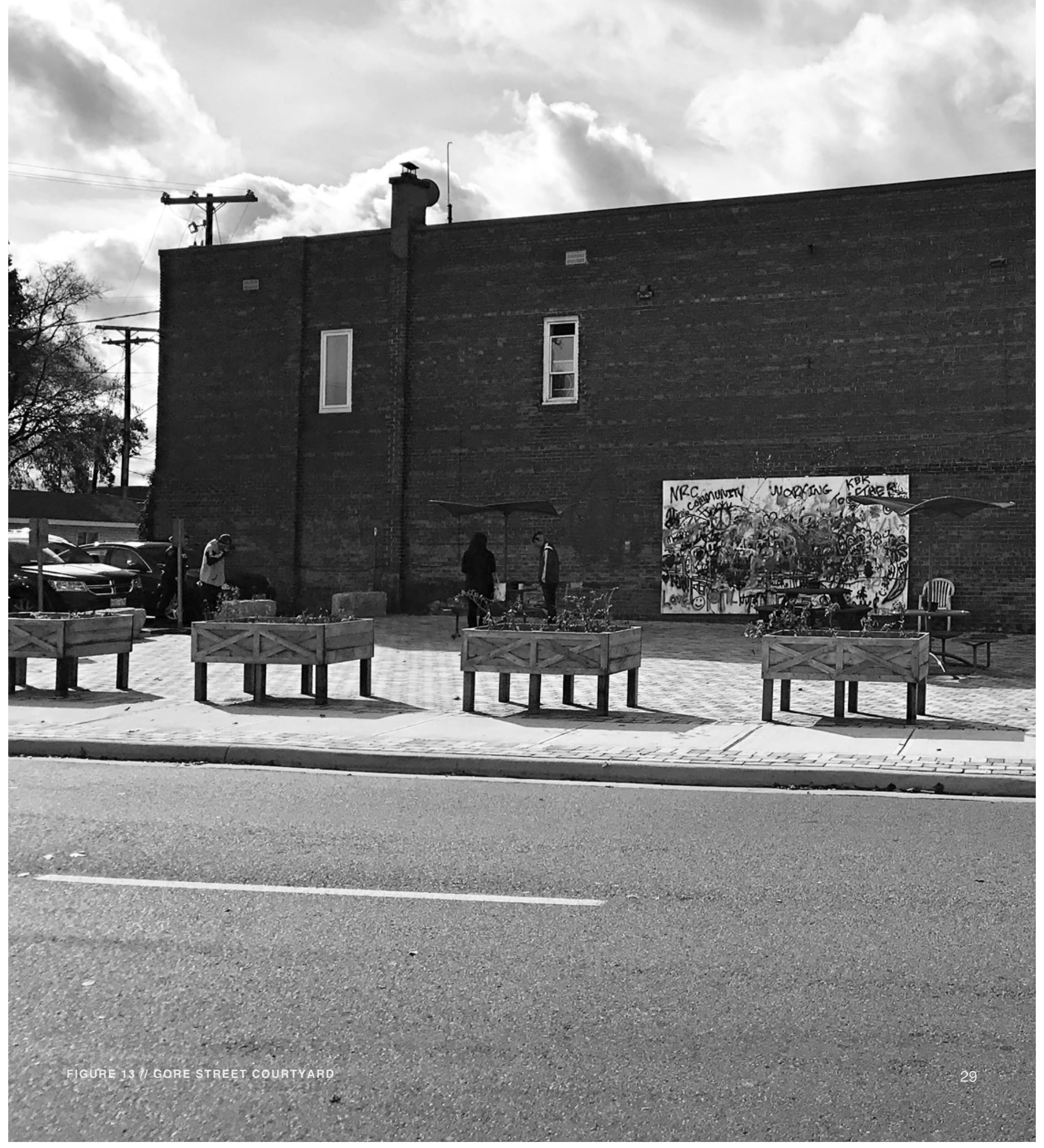




\section{CONFRONTING STIGMA}

Overdoses in Sault Ste. Marie are rising and occur daily. Between 2010 and 2015, Sault Ste. Marie has lost 11 people attributed to opiate overdose. ${ }^{4}$ This number continues to grow. There are approximately 1500 reported addicts within the city, 250 of them being under the age of $25 .{ }^{5}$ In the month of September there were a reported 50 calls of drug overdoses and 22 in the span of 10 days. It is not uncommon for the The Sault Ste. Marie Drug Strategy Committee to hear of at least 5 overdoses a day. ${ }^{6}$ A struggling addict revealed overdosing twice in only 36 hours is commonplace. Mental health and drug addicted patients continue to clog up the emergency rooms of the local hospital with the intention to have a shelter and a bed for the night. The drug addiction counsellor staff at the Sault Area Hospital is witness to addiction deaths occurring each week. ${ }^{7}$ These numbers are only the reported incidents, and in reality comprise about only $50 \%$ of the incidents happening within the city. ${ }^{8}$

The negative stigma the community has associated with drug addiction has caused segregation, creating major problems within the city. In some cases, local business owners have even resorted to investing in downtown property in order to avoid the insertion of a methadone clinic adjacent to them. The "not in my backyard" phenomenon is alive and well. However there is a sense that this situation may be changing.

Until recently, drug addiction has been associated with a lower socio-economic group. This has enabled the assignment of a negative stigma to this group of sufferers. However the opioid pain medication epidemic is a relatively new phenomenon that is affecting families in all socio-economic groups. Until now, it has been relatively easy for people to avoid the issue as "not their problem," but now that their brother, daughter, co-worker etc. is affected, there is an opportunity for the community as a whole to reassess the situation.

4 Ougler, Jeffrey. "Sault Ste. Marie and Area Drug Strategy Committee..." Sault Star, January 31, 2017. Accessed October 02, 2017.

5 Crosier, Stephanie. "Opioid Drug Abuse on the Rise Locally". Sault Star, August 29, 2017. Accessed October 02, 2017.

Kelly, Brian. "Drug Overdoses Climbing. Sault Star, March 18, 2017. Accessed October 02, 2017.

$\begin{array}{ll}7 & \text { Steeltown Down. Documentary. Produced and Directed by Vice Canada. Released February 10, } 2018 . \\ 8 & \text { Kelly, Brian. "Drug Overdoses Climbing". Sault Star, March 18, 2017. Accessed October 02, } 2017 .\end{array}$ 


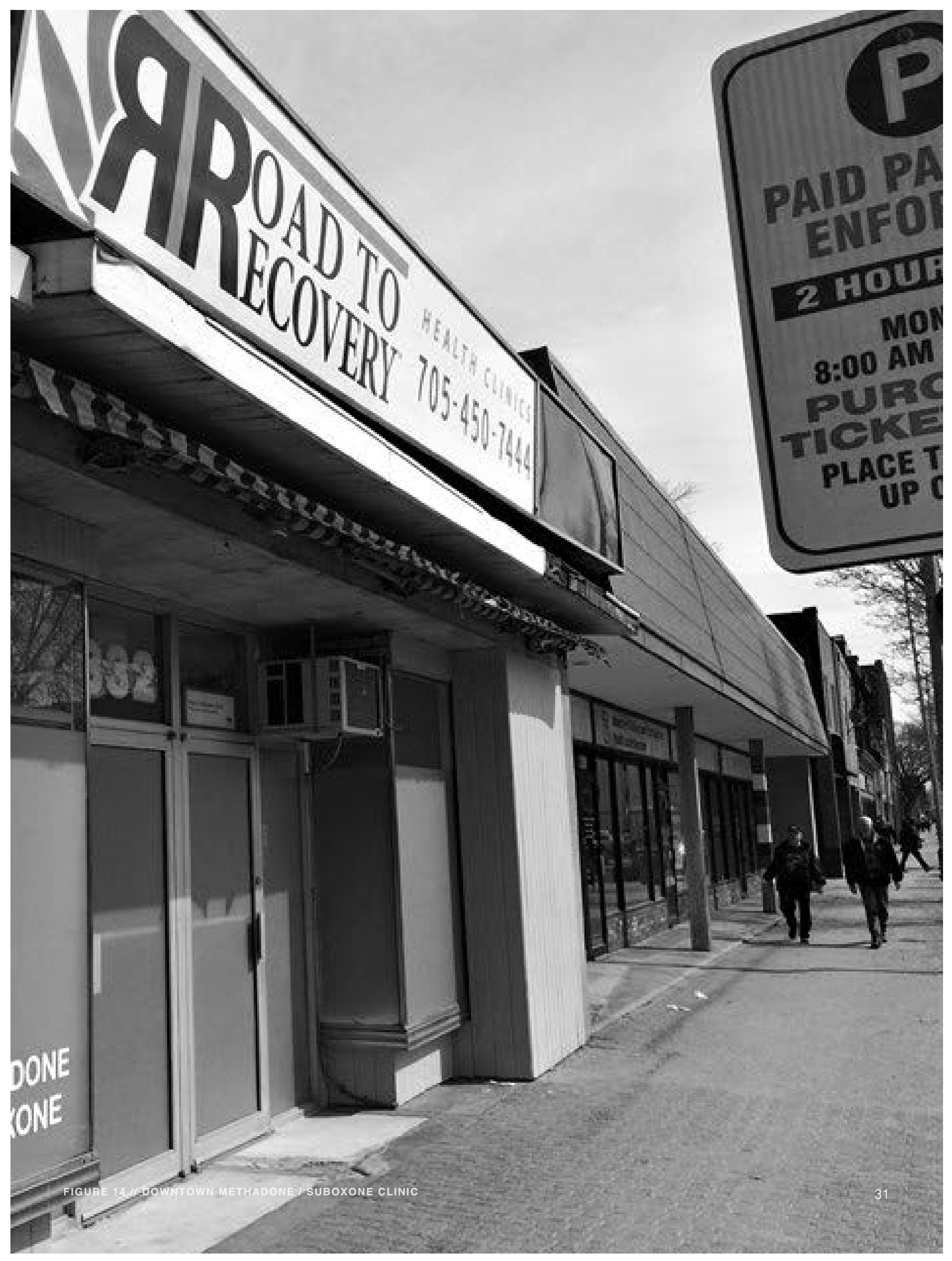


Drug addiction must not be stigmatized. It is a disease (much like diabetes or heart disease) that has a genetic component to it. It is embedded within our DNA and can happen to anyone regardless of their socio-economic situation. Addiction can be caused by many factors. In many cases over-prescription of pain medication by doctors and dentists (postoperative or post injury) combined with the genetic predisposition of the individual has resulted in individuals finding themselves unwillingly falling into a downward spiral. Families, friends and loved ones become a part of this misfortune. When we live in an environment steeped in shame and stigma it makes it that much easier for people to turn to drugs in order to feel a part of something. Individuals suffering from drug addiction did not choose that life.

Architecturally speaking, I believe there is an opportunity to reinvent the facilities that are needed to address addiction illness. The hidden "back alley" clinics need to come out from the community shadows. Given proper facilities, most addicts will choose a more stable lifestyle in which they do not need to resort to illegal activities to maintain their addiction. 


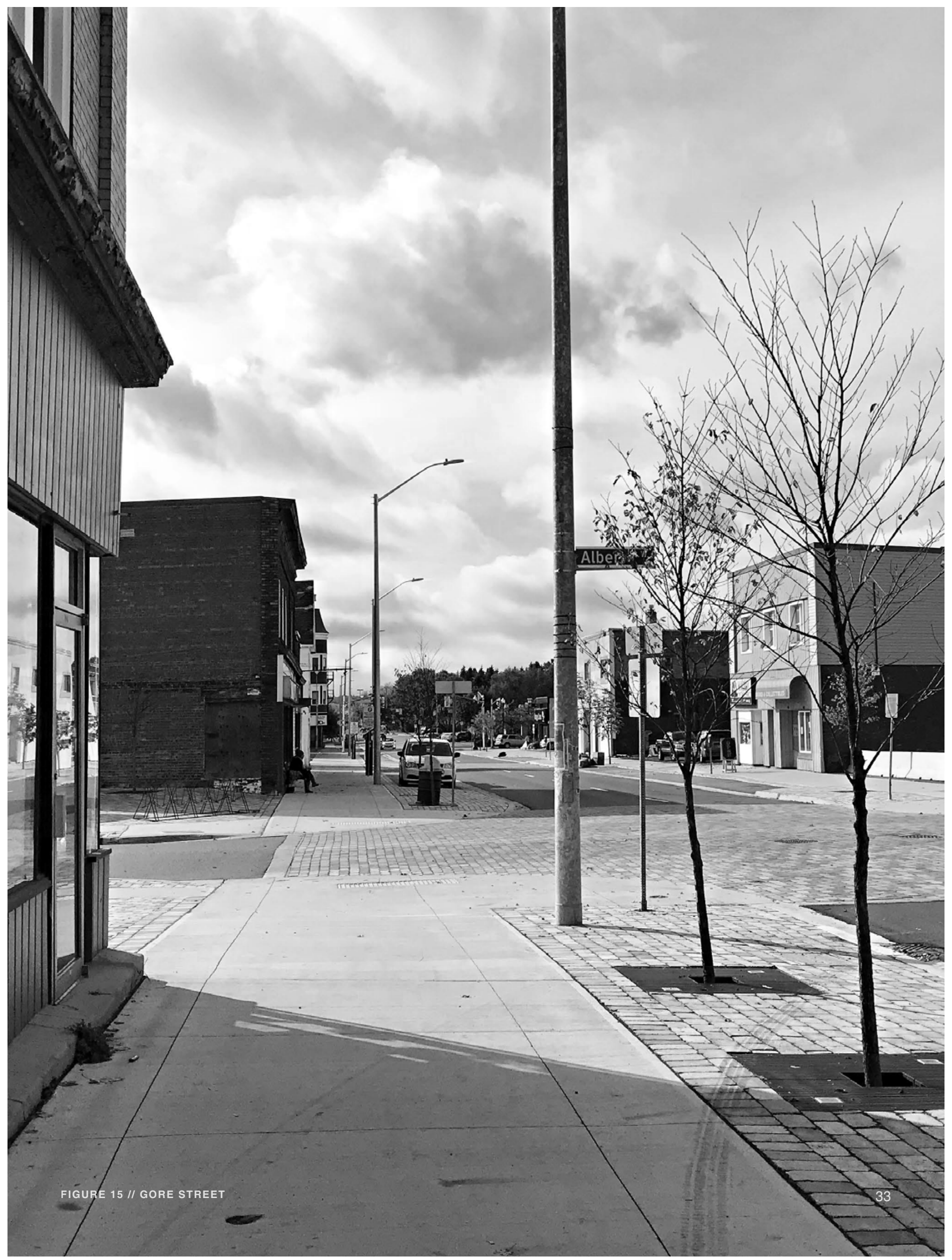




\section{THE FABRIC \& THE HUMAN CONDITION}

The well-being of a city and the well-being of its population are interdependent. In the case of small town Sault Ste. Marie, parallel conditions are found between a deteriorating urban core and the considerable number of substance users residing within the area. Drug addiction has become extremely present within the streets of the city, which has left the community disoriented. Both the fabric and the human condition have become marginalized from the rest of the city because of the condemnation associated with the disease. The isolation has caused stresses within the city physically, mentally and emotionally to a point where both the population and urban environment have become unsound. ${ }^{9}$

Although drug addiction within Sault Ste. Marie is scattered throughout the city, it is most noticeable within the city's core. Over recent years numerous local businesses that built a foundation within the downtown have been driven out to avoid the presence of drug addiction. Methadone and Suboxone clinics have been inserted into a number of these vacant buildings although they are incapable of properly accommodating the resources needed. People are forced to wait outside for prescription refills and consultation because of the inadequate space provided for waiting areas. This itself has only made the downtown building occupancy issue worse. The lack of activity and a stable population has led to safety issues that continue to worsen.

Even with the advantages of being downtown and in close proximity to the waterfront, the streets remain completely disconnected and disengaged from the rest of the city. ${ }^{10}$ The attempt to aesthetically beautify the streets without addressing the drug related problems head-on, suggests denial. This passive aggressive attitude has not only wasted time and resources but also speaks to the city's lack of interest in addressing the underlying causes of the problems. The human dimension has been overlooked.

9 Glory Wang. Rehabilitation Strategies: The Case of Vancouver Downtown Eastside. Master's Thesis. Carleton University, 2004 Rehabilitation Strategies: The Case of Vancouver Downtown Eastside by Glory Wang examines models of treatment in drug addiction and tests the appropriateness of forming an analogy between a person who suffers from drug addiction and an existing deteriorating urban fabric." The connections that are made between addict and fabric have influenced the development of a number 10 lbid.

of concepts, methodologies and terminology described within this thesis. 


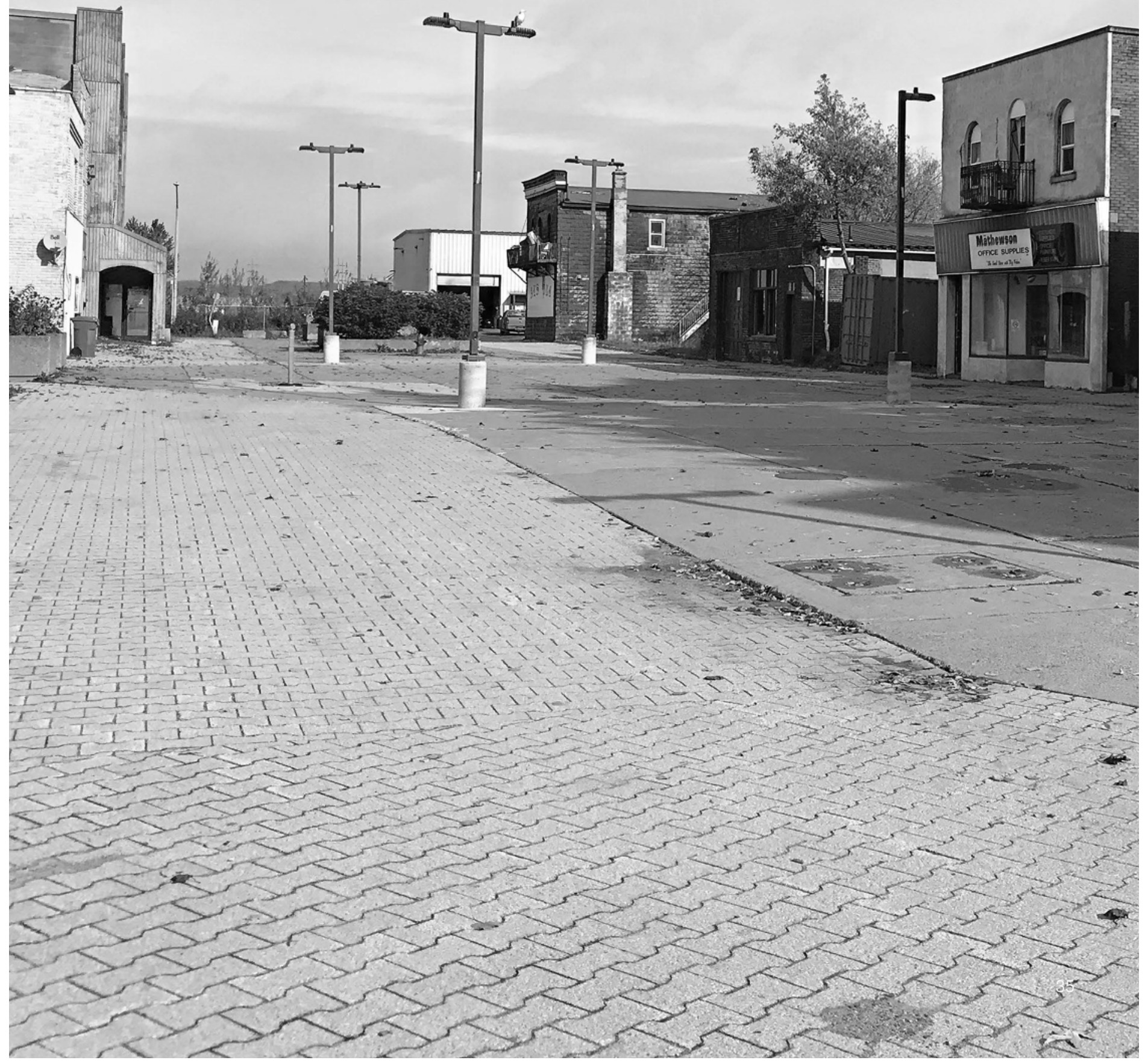


Research supported by case study exploration has been completed in order to endorse the effectiveness of drug rehabilitation treatments in the city of Sault Ste. Marie. Rehabilitation is a holistic method aimed to help addicted people get into recovery. ${ }^{11}$ Rinaldi et al. in the Delphi Survey of 1988 presented rehabilitation as an "application of planned procedures to identify and change patterns of behaviour that are maladaptive, destructive, or health injuring; or to restore appropriate levels of physical, psychological, or social functioning."2 Through a series of stages, an individual struggling with addiction focuses on personal development in the hopes of obtaining a healthier lifestyle, physically and socially. ${ }^{13}$

Like the addict, the existing fabric of Sault Ste. Marie holds enormous potential for recovery. Rather than gentrification as plastic surgery, the intention is to implement rehabilitation strategies on the city without imposing a complete identity transformation. ${ }^{14}$ This thesis proposes a network of rehabilitation spaces as a new, necessary and positive institution in the city. Combining rehabilitation clinics with additional programs that help users to establish drug free lifestyles is an opportunity to reintegrate recovered users and forgotten buildings back into society.

As architects, how can we benefit from treating buildings and urban fabric with the same regard as the human body? Can we rehabilitate existing spaces the same way we rehabilitate a person in order to accommodate growth?

11 Glory Wang. Rehabilitation Strategies: The Case of Vancouver Downtown Eastside. Master's Thesis. Carleton University, 2004 12 Connors, Gerald J. Donovan, Dennis M. and Diclemente, Carlo C. Substance Abuse Treatment and the Stages of Change: Selecting and Planning Interventions. New York, Guilford, 2001. Page 4.

13 Glory Wang. Rehabilitation Strategies: The Case of Vancouver Downtown Eastside. Master's Thesis. Carleton University, 2004.

14 Ibid. 


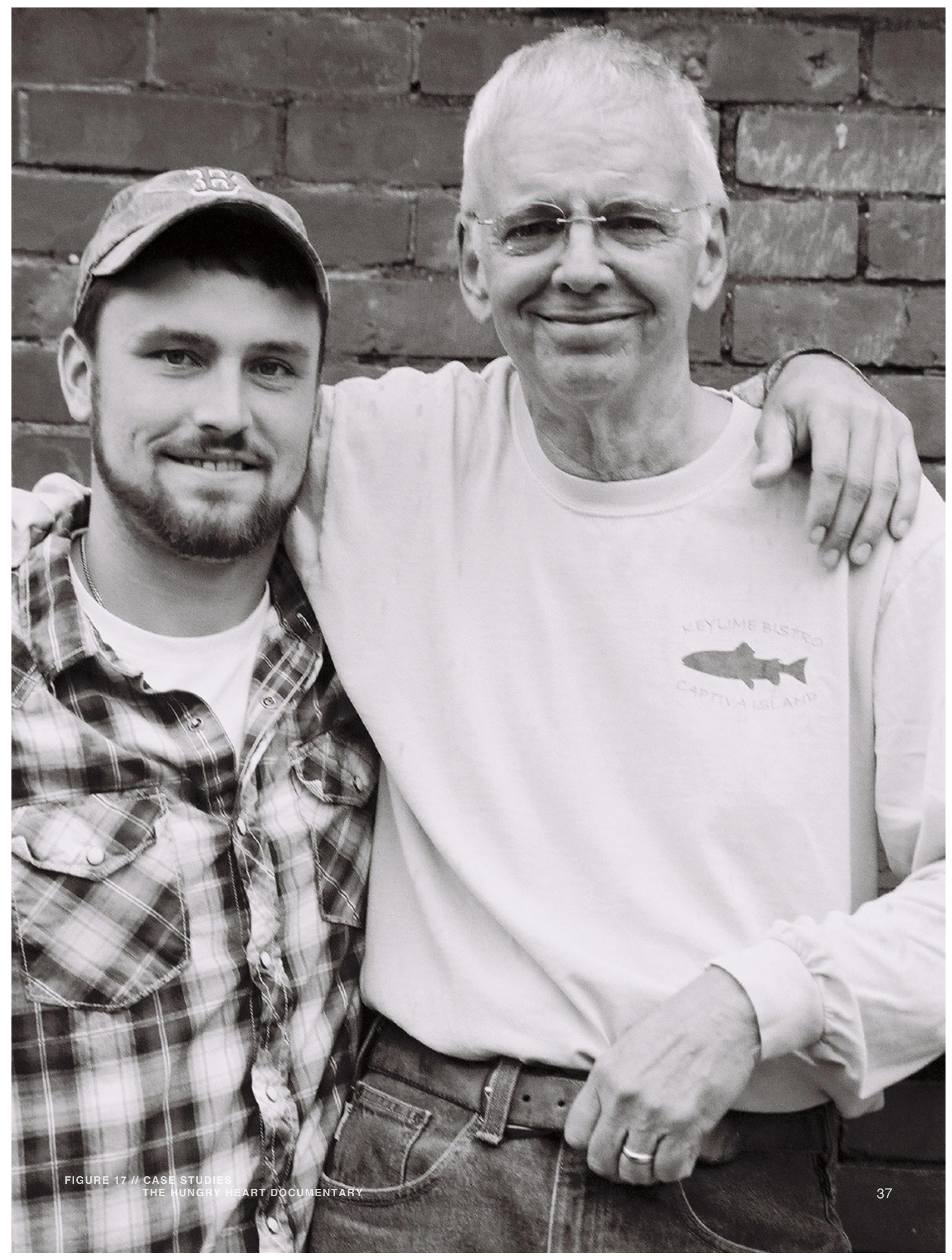




\section{CASE STUDIES}

The rehabilitation strategy proposed for Sault Ste. Marie is unique. In the preliminary phase of this thesis no direct case studies were found that actualize the ideas imagined for the city. Instead, I looked at documents (books and films) and related precedents to develop a broader context for the project.

\section{CASE STUDY $1 / /$ NARRATIVE \\ The Hungry Heart}

CASE STUDY 2 // SMALL CITY REINVENTION

Flint, Michigan

CASE STUDY 3 // BREAKING THE STIGMA

Psychiatric Centre 

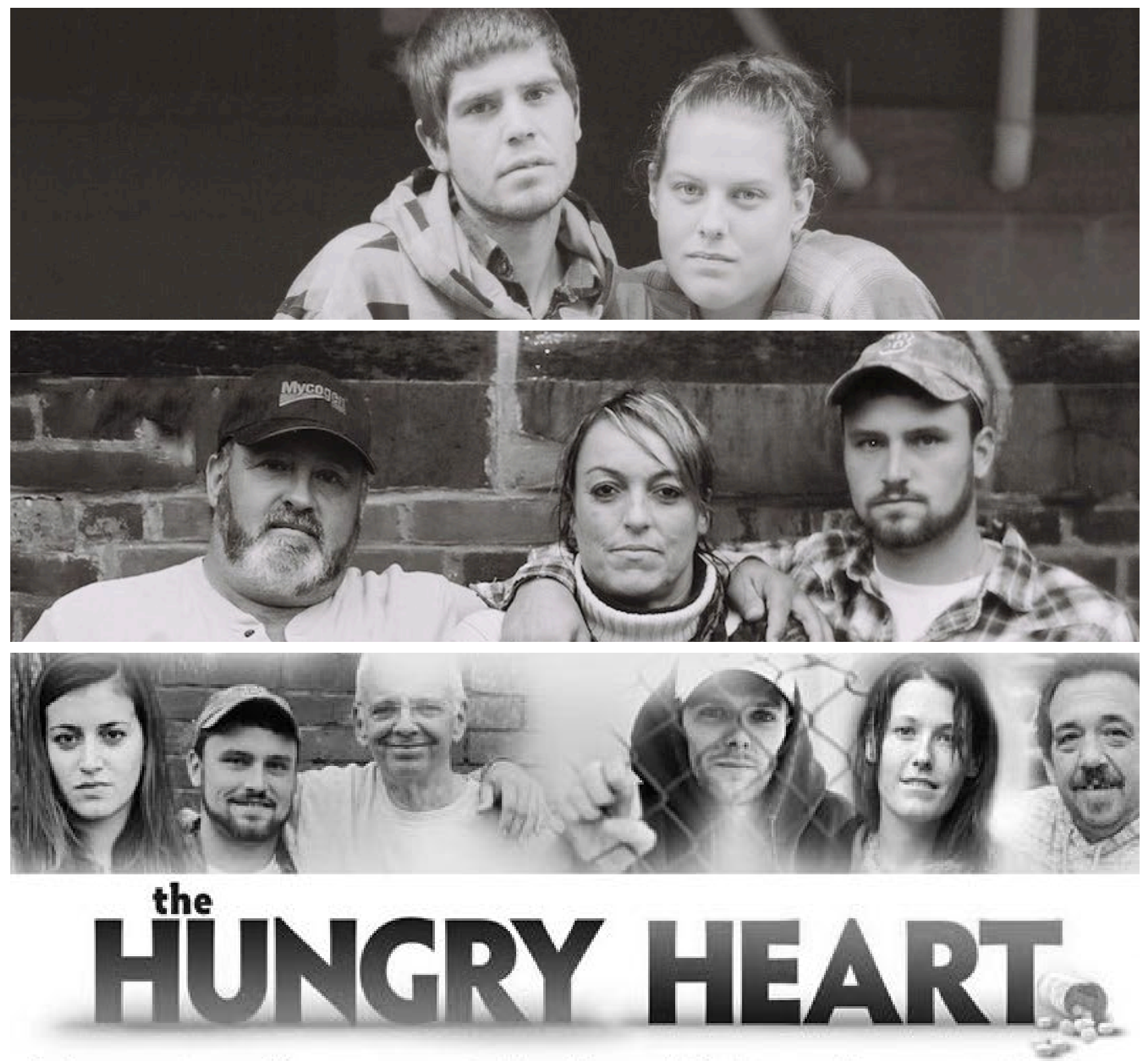

A documentary film on prescription drug addiction and recovery that has captured the hearts and minds of audiences across the country. 


\section{narrative}

The Hungry Heart is a documentary that addresses the issue of stigma and its association with drug addiction in a town of similar scale to Sault Ste. Marie. It provides an intimate look at the world of prescription drug addiction that is often hidden. The story is told through the lens of St. Albans Vermont Pediatrician, Fred Holmes. ${ }^{15}$

As a result of the drug addiction issues happening in the small town of St. Alban, Dr. Fred Holmes sought out a license that would allow him to prescribe suboxone to patients struggling with prescription drug addiction. Very similar to methadone, suboxone is provided to help addicts during their recovery process. ${ }^{16}$ The story of The Hungry Heart shows us many situations where young teenagers, middle-aged and older clients describe their experiences with using suboxone in the recovery process. We also see Dr. Holmes struggle with the challenge of placing suboxone into the hands of those who abuse it. ${ }^{17}$

The power of this specific documentary is its ability to showcase the diverse range of stories and the profound connection Dr. Holmes creates with all of his patients. It exhibits the healing power of conversation. Addicts yearn for a better life with hope on their side. ${ }^{18}$ The road to recovery is paved with success stories, struggle and defeat. As a result, we the viewers are able to relate and empathize with the people in the film. Acknowledging the problem and talking about it is the first step in the healing process. ${ }^{19}$

Like St. Albans Vermont, Sault Ste. Marie is just one example of this national crisis. These stories are happening everywhere and they are important. Throughout this thesis a list of characters similar to the ones represented in The Hungry Heart will epitomize a small cross section of the people living within Sault Ste. Marie who are struggling with drug addiction.

15 The Hungry Heart. Documentary. Bess O'Brian. Released September 21st 2013. DVD.
16 Ibid.
17 The Hungry Heart. Documentary. Bess O'Brian. Released September 21st 2013. DVD.
18 Ibid.
19 The Hungry Heart. Documentary. Bess O'Brian. Released September 21st 2013. DVD. 


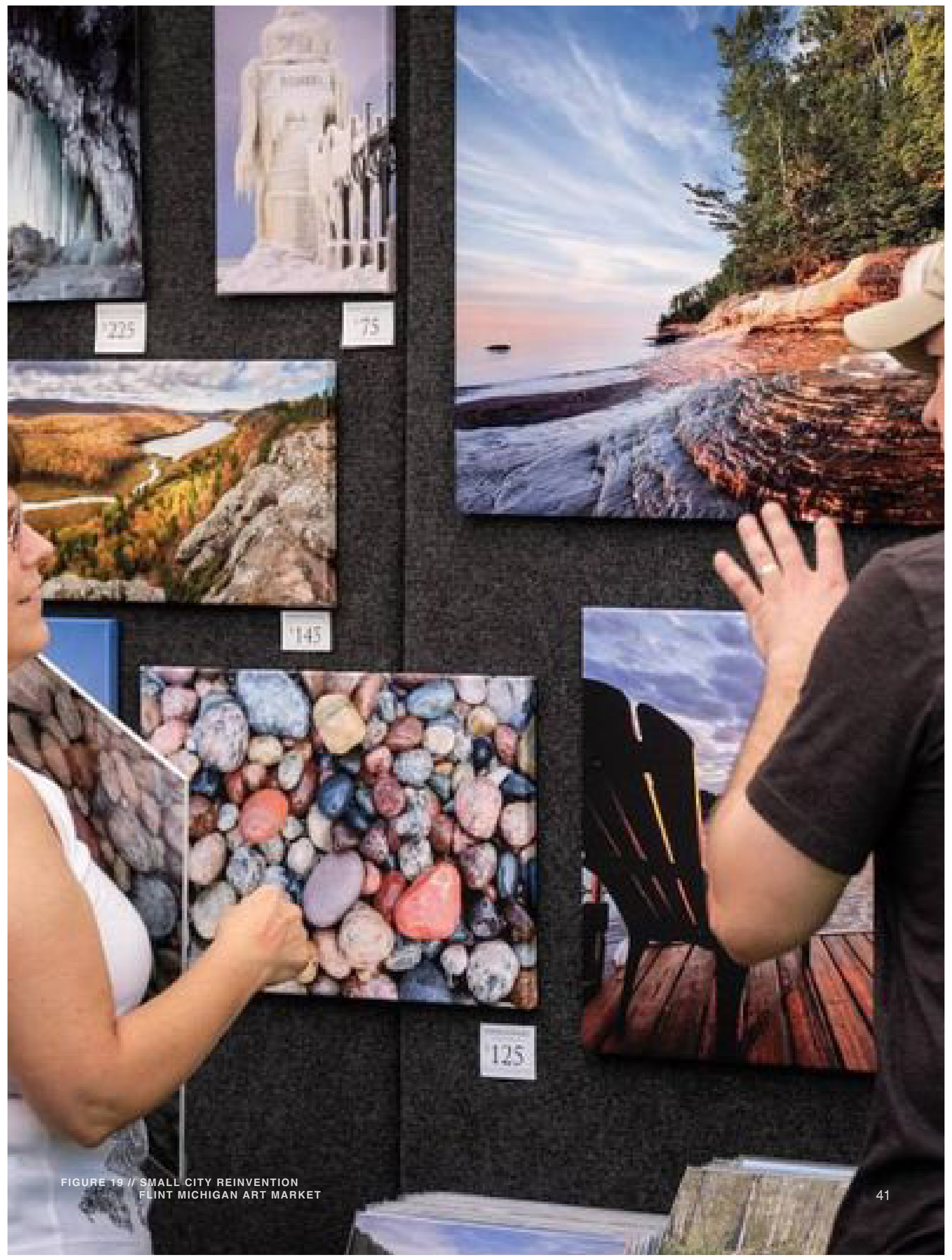




\section{small city reinvention}

"How can a city working to reinvent itself engage the arts at the center of their comprehensive planning efforts?" 20

Over the years, the city of Flint, Michigan has unfortunately turned into a city of major population loss and industrial decline. After the loss of its main auto-manufacturing industry the city has made conscious efforts to turn itself around. Just recently the city has begun to embark on city-wide comprehensive planning efforts. Arts representatives have sought out an opportunity to use arts and community collaboration to restore Flint. ${ }^{21}$

Being home to General Motors, Flint Michigan was at one point the second largest city in the state of Michigan. After the closing of many General Motors plants in the 1980's, the city scaled down to the seventh largest city. In 2011 the state of Michigan appointed an emergency manager to help prevent the city from economic collapse. ${ }^{22}$ The challenges associated with the city decline have become apparent within the fabric of the city. There has been residential abandonment, high rates of poverty and drug addiction, lack of commercial vitality and public safety concerns. ${ }^{23}$

The harsh economic conditions that the city is facing were prioritized according to citizen needs. The Mayor of Flint launched a new master planning process in 2011 in order to change the conversation about the city's outcome a encourage community engagement. This new process was aimed to promote equity, liveability, economic vitality, and sustainable development. ${ }^{24}$ With approximately 15,000 independent artists and 80 arts and cultural organizations in Flint, there was a vision for the city that involved social arts events and fundraisers. ${ }^{25}$ The local art leaders advocated that the creative community be involved in the city's efforts to revitalize itself, which sparked some community interest. The collaborative proposal planned for the city demonstrated how arts could be used as a platform to transform the city. ${ }^{26}$ As great as this was, other very important negative issues within the city were overlooked.

Fast forward to 2018 and Flint Michigan, much like Sault Ste. Marie, is still in flux.

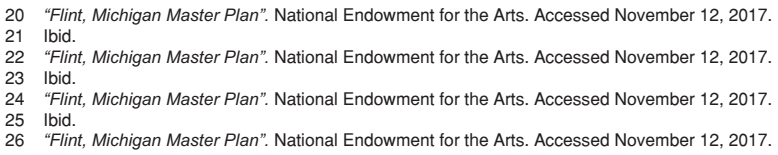




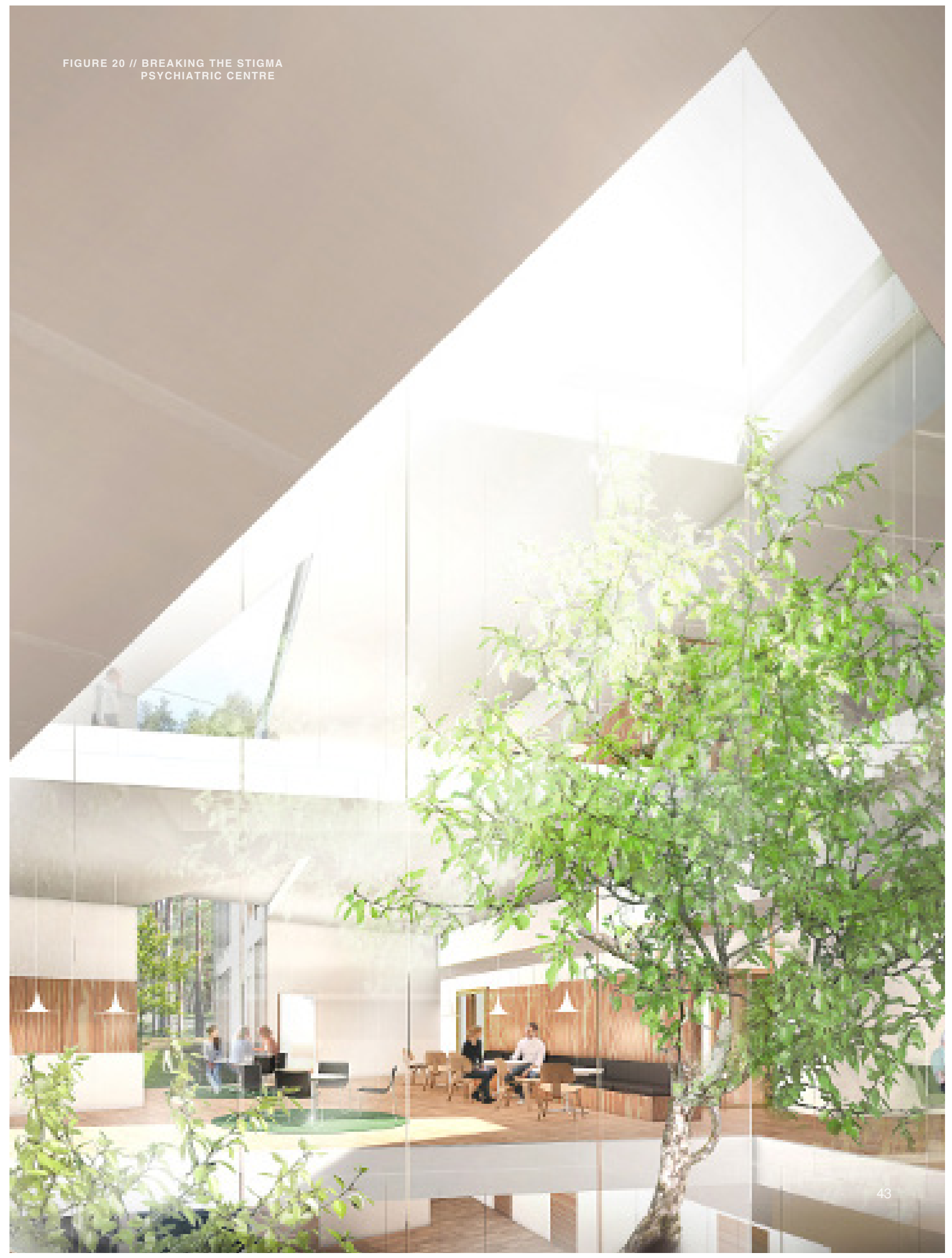




\section{breaking the stigma}

Stefan Lundberg of White Arkitekter Associates quoted "First impressions last. When you meet a person and shake their hand, that impression you have of them will colour your experience. It's the same with buildings - especially for people with mental health issues. You have to strengthen their own sense of dignity." 27

White Arkitekter has recently designed a treatment and rehabilitation facility that breaks the stigmatisation associated with psychiatric care. Based on the design of the Ostra Hospital Building for Psychiatry constructed in 2006, White has created a scheme that works with the 'architecture as medicine' model. This model is based on designing welcoming atmospheres for the occupant from the moment of arrival and throughout the rest of the building. ${ }^{28}$

A high number of cases involving violence have been reported in traditional psychiatric care facilities. With these numbers rising new design strategies are starting to be implemented. Researchers at Chalmers University of Technology and Gothenburg University have recently shown that properly designed non-traditional medical spaces can lessen levels of violence in psychiatric care by $44 \%$. By designing for the occupant's health, their aggressive behaviour is massively reduced. ${ }^{29}$

Instead of locked doors and closed wards, White believes that the most influential way architecture can support its occupants well-being is to emphasize continuity in everyday life. White addresses this by designing a core with centralized staff, connections to social situations to emphasise choice and normality, and access to outdoor spaces if available..$^{30}$ The design includes a two-storey high welcoming entrance. The main psychiatric facilities are organized together around a central corridor. Off of the main corridor is where you will find entrances to the treatment areas, offices and management. ${ }^{31}$ The care departments are designed in three different ways to create variation. A garden is designed for patients to come together for activities and social groups. While in the outdoor area no staff cards are required and patients have the flexibility to enter and exit the garden at their discretion. The overall design of the building is intended to gradually increase the patients' personal spheres, from their own room, to the garden, cafe and public areas. ${ }^{32}$

The architectural spaces are designed to suit the behaviours of its occupants.

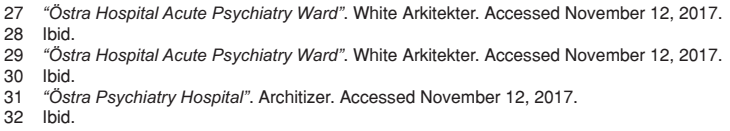




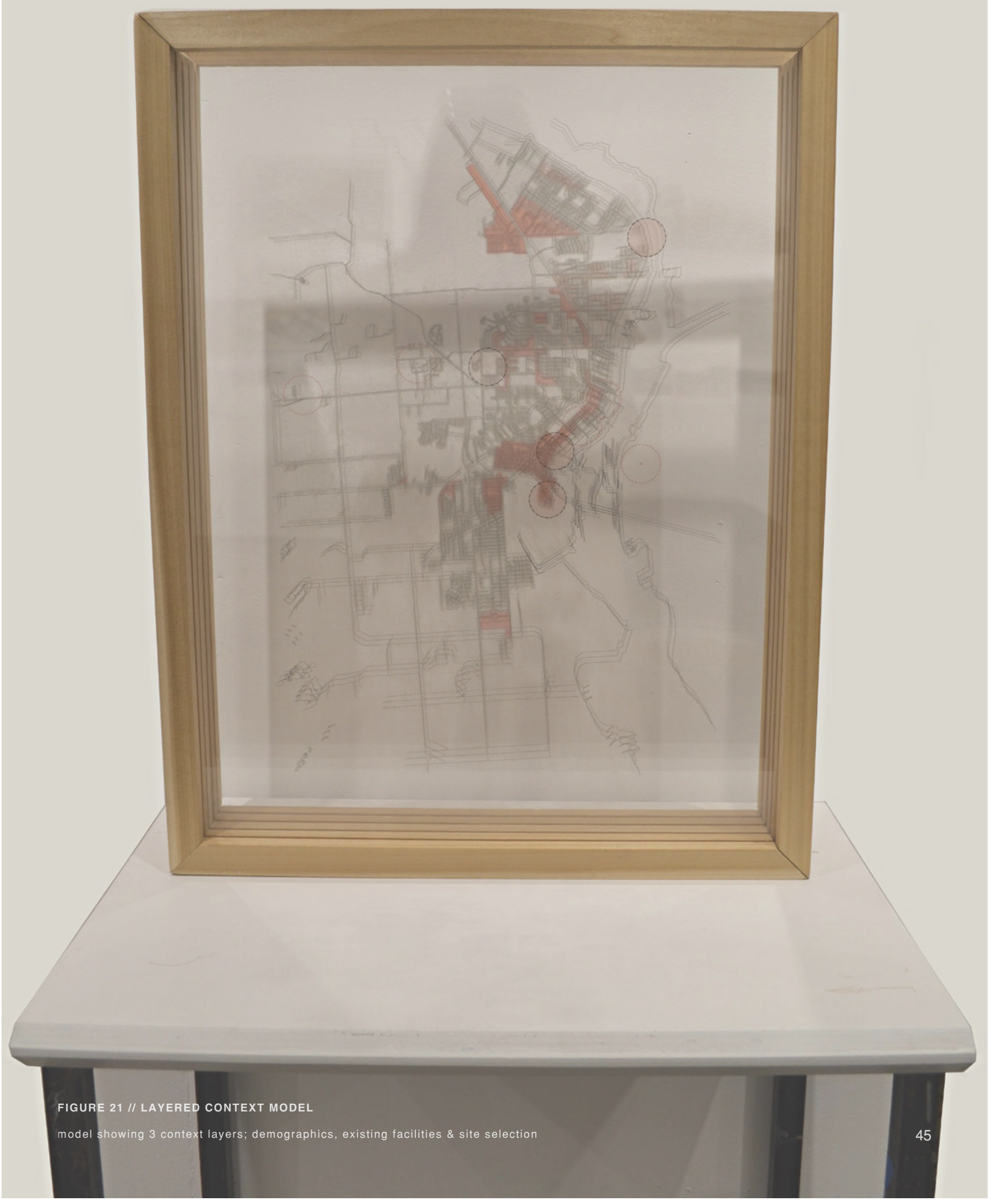




\section{CONTEXTUAL ANALYSIS}

Prior to design it was critical to understand how drug addiction and the current services provided for it work within the city of Sault Ste. Marie. This would determine the type of rehabilitation services required and where they would be located in the city. A series of mapping exercises was completed to grasp an understanding of the demographics of the city, the existing drug addiction facilities, and potential energy spots within the city fabric that could benefit from a new rehabilitation strategy. 


\section{demographics}

There is no standard type of a drug addict. Whether a 40-something year old homeless woman or upper middle class teenager, addiction is hardly ever a choice. Who were these people in the city struggling with drug addiction? How old were they? Where did they live? Were they homeless?

Although addiction seems to be more visually present in West End of the city, this does not exclude the fact that overdoses are occurring daily in the East end as well. Discussions with front-line workers provided an intimate look at the cross section of people within the city struggling with and recovering from addiction. The demographics range from financially supported high school students and their educators, to unsupported teenagers and homeless people.

Based on discussions, observations, and the stories portrayed in The Hungry Heart documentary, characters have been created in order to provide a better understanding of the people struggling with addiction and where they might live in the city. 


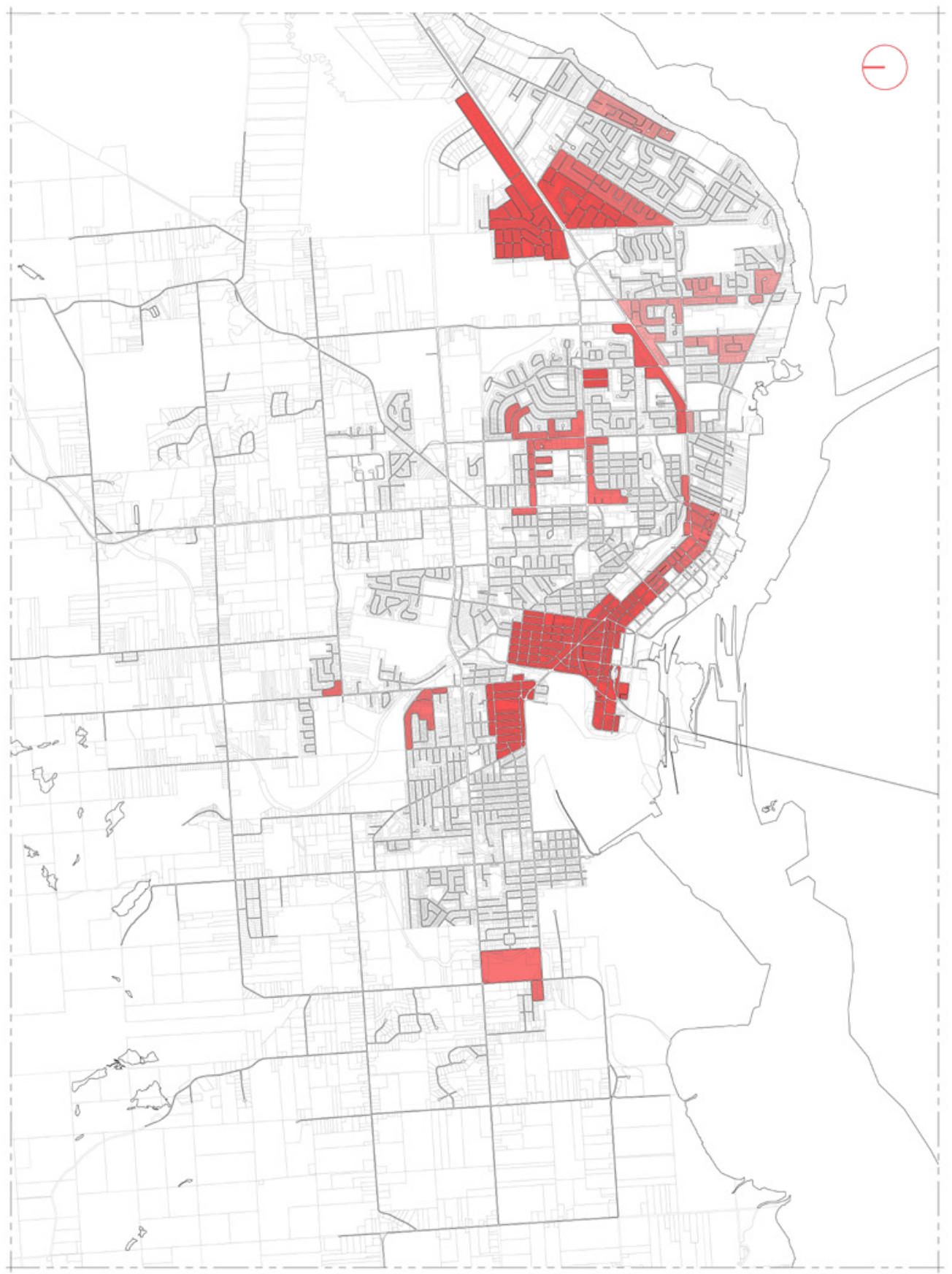




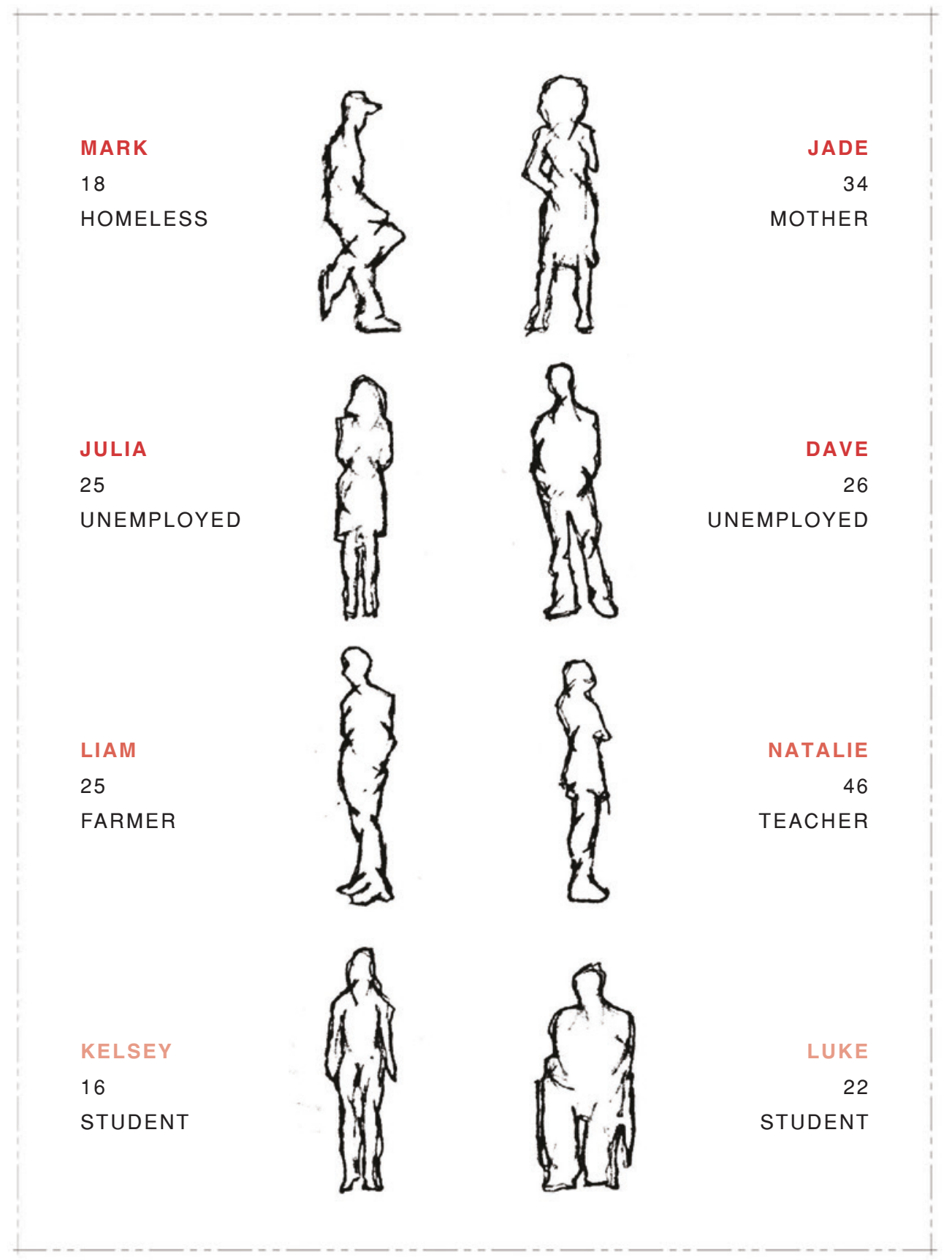




\section{existing facilities}

What are the resources available to addicts within the city of Sault Ste. Marie? What do they provide and to whom? Where are they located within the city? How does this impact the built environment? Are the current facilities capable of providing the necessary services?

Many users within the city have expressed that although help exists, it is extremely difficult to get. The system the city is currently operating is not working and this has much to do with the negative stigma. The inability to accommodate properly designed services has people overflowing onto the streets on a daily basis. Even following the recent CTV documentary aimed to create awareness and provoke conversation regarding these issues, no discussions of proper implementation have been had. 


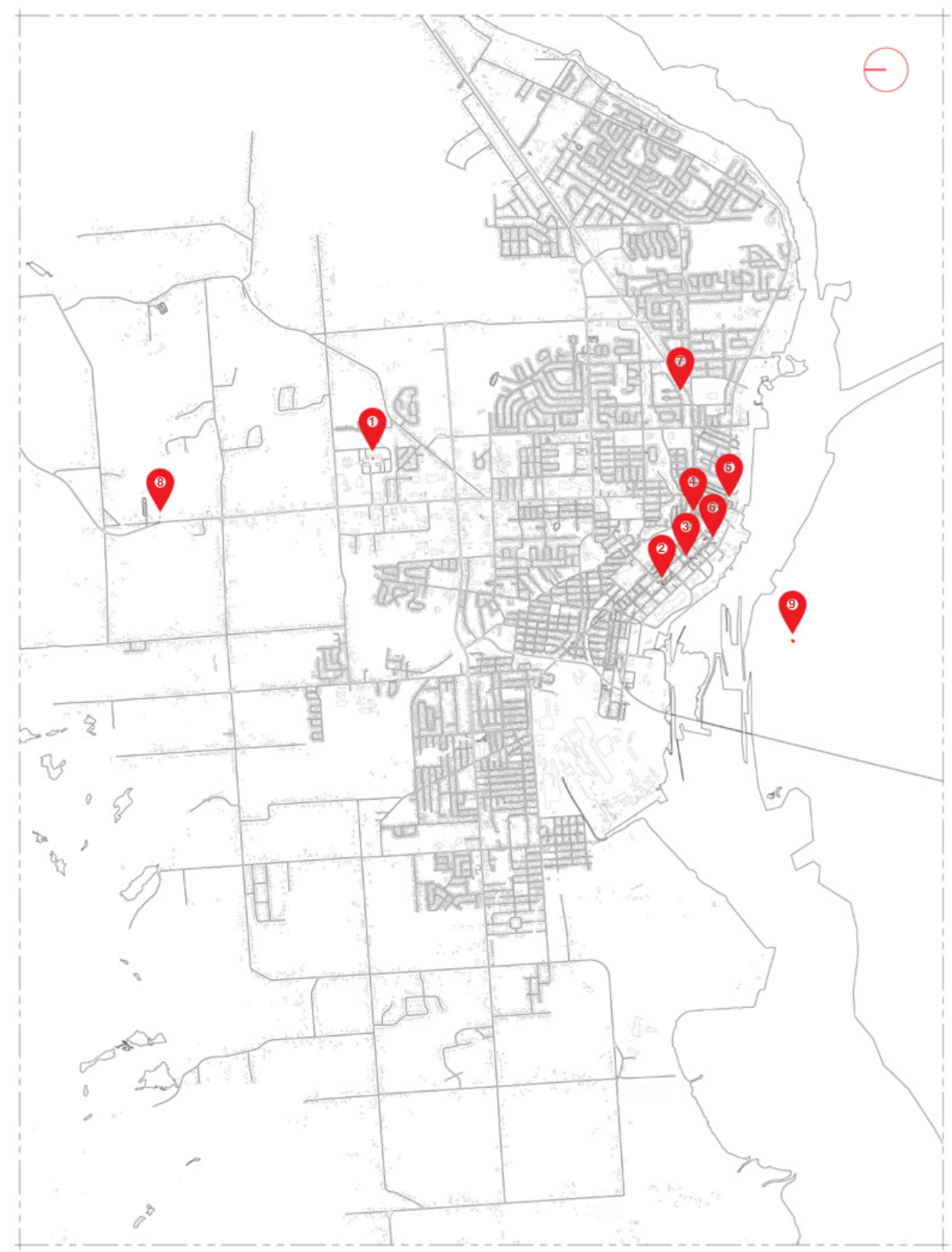




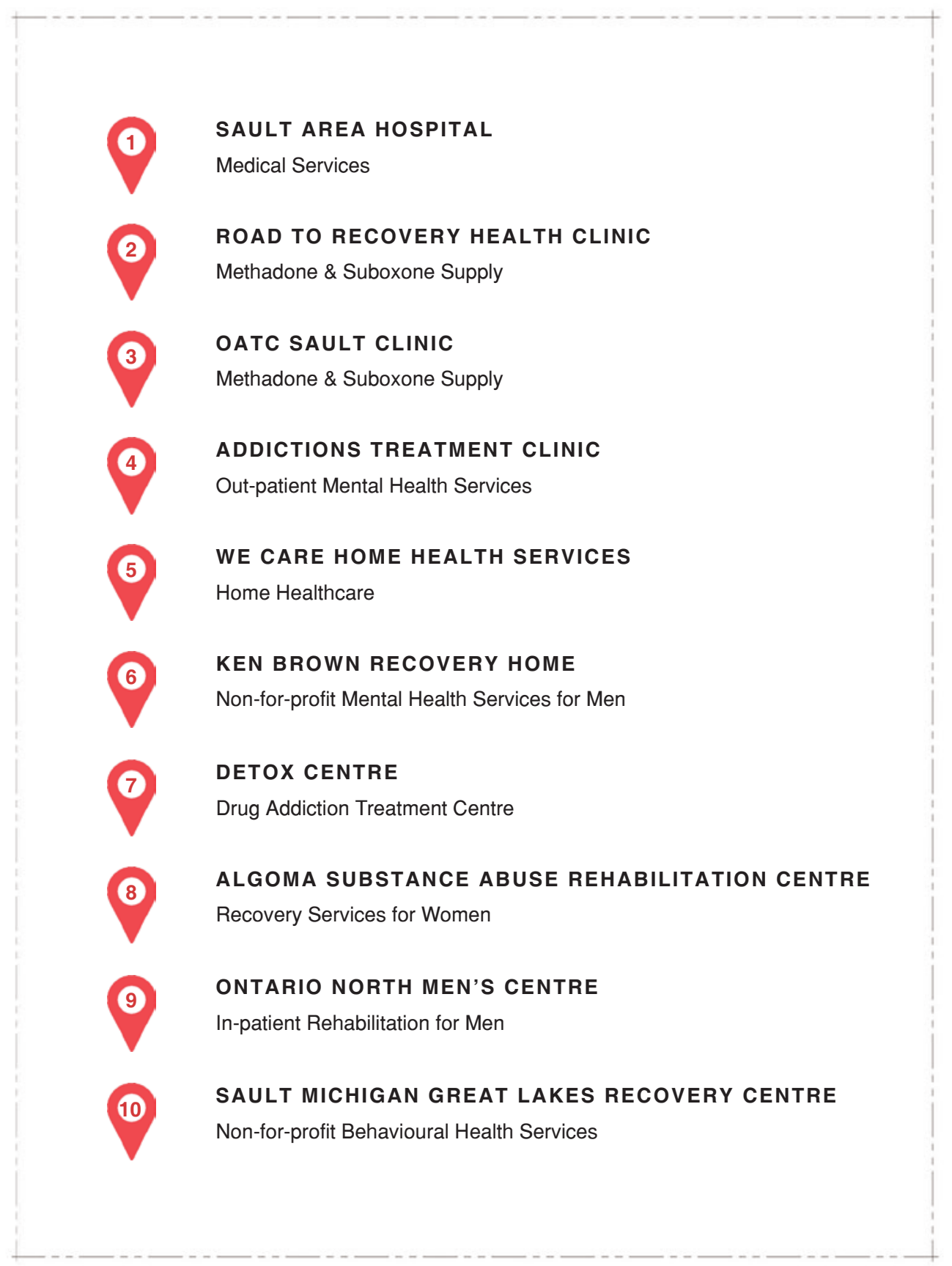




\section{site selection}

The exploration of demographics and current existing facilities within Sault Ste. Marie raised the question of whether the design approach should follow a centralized or decentralized program. After speaking with health professionals and drug addiction specialists, a decentralized program was the obvious route. Three existing buildings in three different neighbourhoods of Sault Ste. Marie will be adaptively reused to accommodate the clinic requirements and an additional job training and lifestyle program. The sites selected are identified as acupuncture spots within the city. ${ }^{33}$ They are meant to act as energy points that contribute to the overall healing process of the city. The interventions at each site are meant to be considered together. Each will satisfy the three recognized areas of treatment during rehabilitation; the individual, the socio-cultural and interpersonal/spiritual. ${ }^{34}$ In conclusion, the West End Community, Gore Street and Country Club were selected as appropriate sites for intervention.

Building selection was based on the vulnerability of existing space. Each one plays a very different role within the community but maintains a level of importance in the city's history, present and future life.

33 Glory Wang. Rehabilitation Strategies: The Case of Vancouver Downtown Eastside. Master's Thesis. Carleton University, 2004.

34 Ibid. 


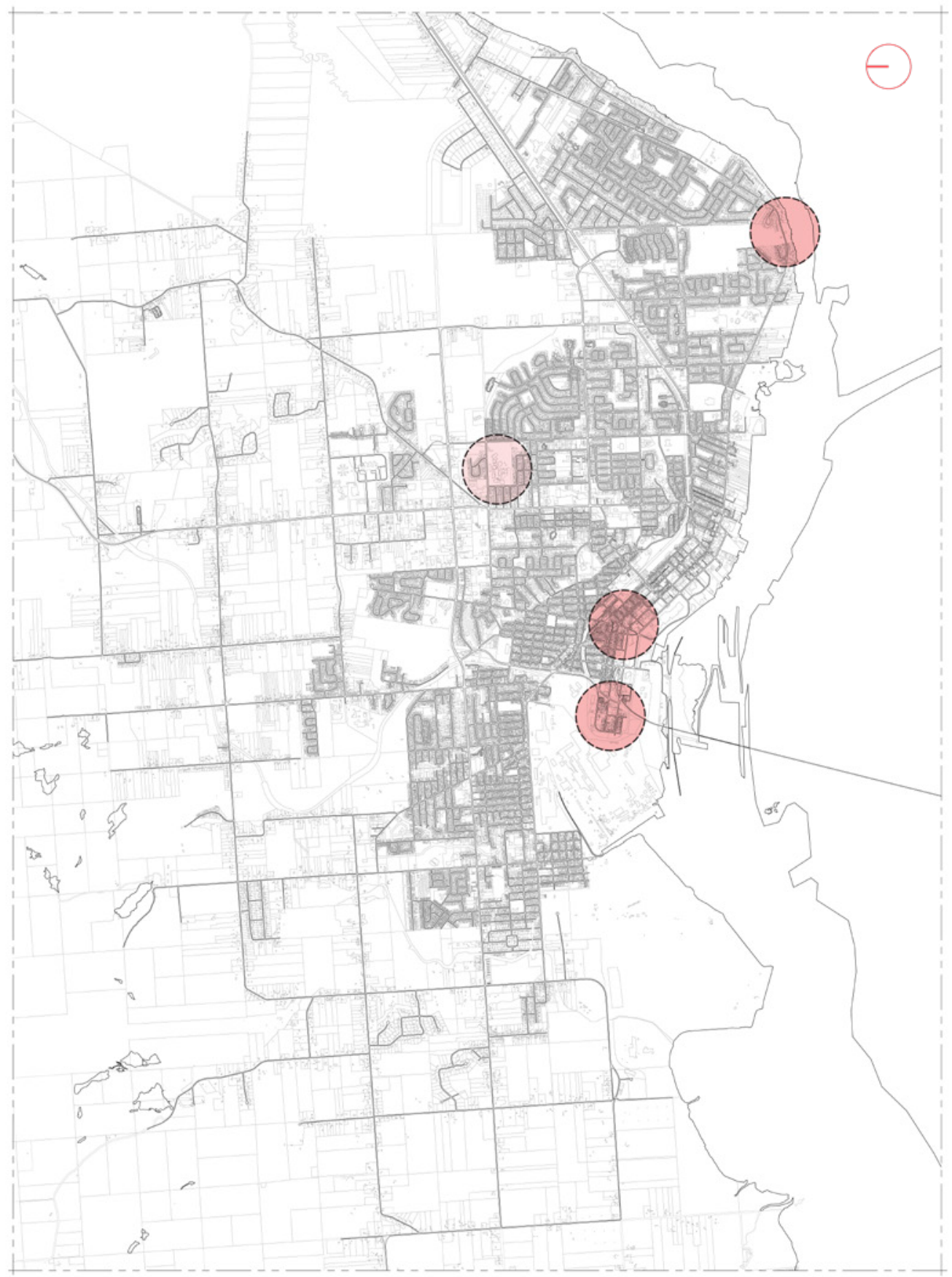




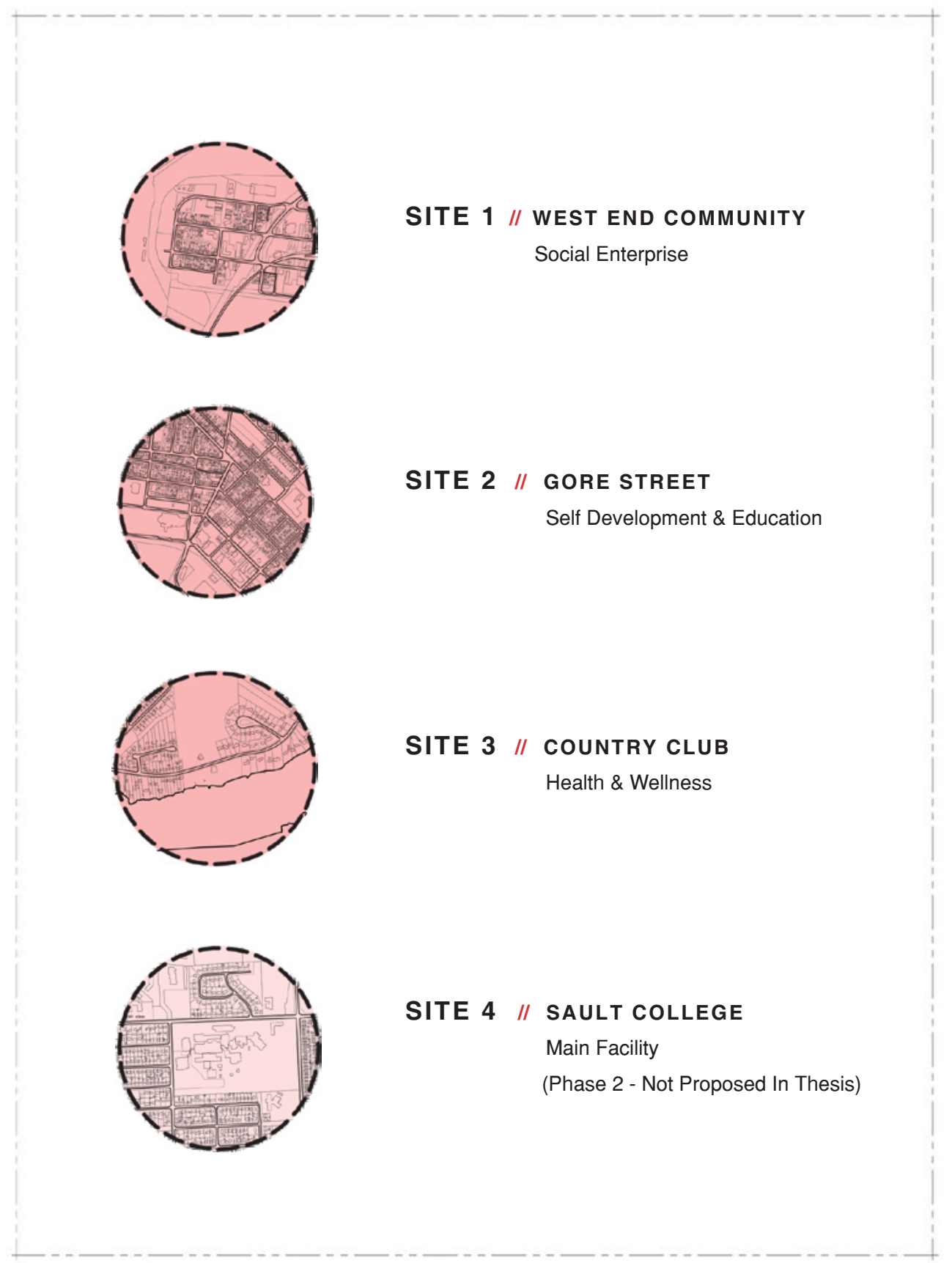




\section{rehabilitation}

$\begin{aligned} \text { admission assessment } & \text { dispensing machines } \\ \text { medical examination } & \text { offices } \\ \text { medical laboratory } & \text { individual counselling } \\ \text { urine collection + results } & \text { family counselling } \\ \text { safe injection } & \text { grief + domestic counselling } \\ \text { waiting rooms } & \text { therapy rooms } \\ \text { security } & \text { recreational rooms } \\ \text { pharmacy } & \text { social spaces } \\ \text { washrooms } & \text { team building spaces }\end{aligned}$

social enterprise west end community

$$
\begin{gathered}
\text { dining spaces } \\
\text { food program } \\
\text { kitchen } \\
\text { culinary arts education space } \\
\text { storage } \\
\text { washrooms }
\end{gathered}
$$

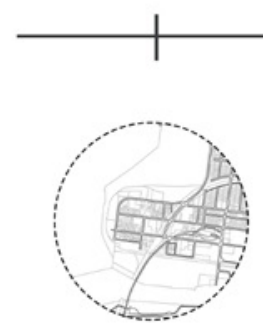

self development \& education

performing arts space

event space

wood workshop

tech workshop

incubator spaces

washrooms health \& wellness

country club

physical rehabilitation

mental rehabilitation

vocal rehabilitation

yoga \& meditation

sports \& leisure spaces

washrooms 


\section{PROGRAM}

The interventions proposed in this thesis are intended to act as catalysts of treatment for both the occupant and the building while also reinforcing a relationship between the two, and the community. The design must create stimulating environments that assist with the integration of the drug user back into society without relying on substance abuse. The program that is inserted into each building plays actively in the success of this intention.

After consulting with a Drug Addiction Psychiatrist, front-line workers, recovered addicts and stakeholders within the city, a list of programs were defined.

The services located at each site will combine medical treatment such as medical examination, methadone and suboxone supply, accessibility to Naloxone/Narcan overdose kits, safe injection spaces, psychological support, and social enhancement. Additional type programs will include social enterprise, self development and education, and health and wellness facilities.

The program in each building reflects its location in the city. Each intervention is designed differently and specific to the site and building. The organization and allocation of the program spaces has been defined by the needs of those using each facility. This was determined by careful consideration and planning efforts with the front-line workers, recovered addicts and stakeholders. 


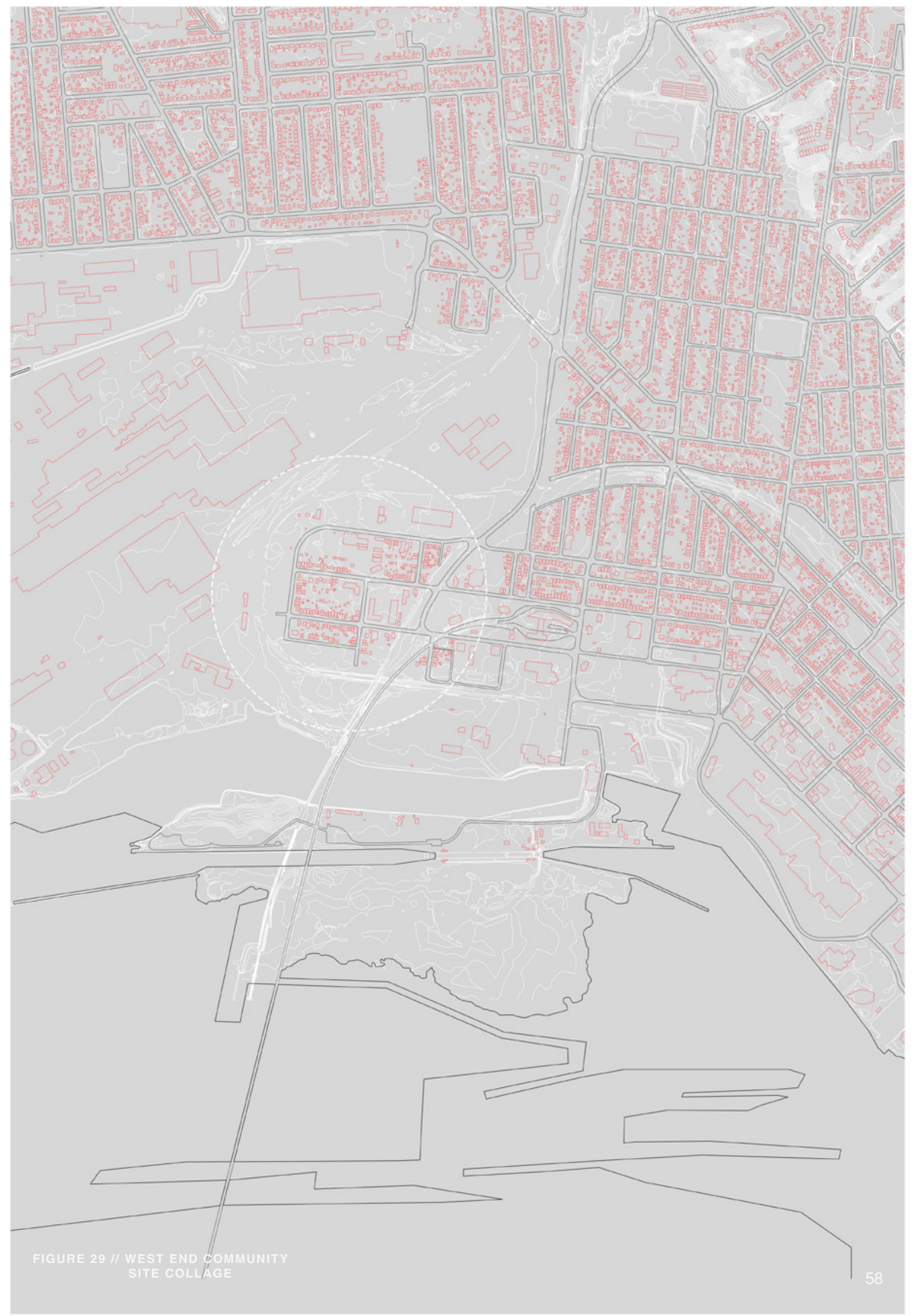




\section{west end community}

The West End Community is the first site that was selected. The site is comprised of a small plaza that is home

to the local soup kitchen, social housing, and a few local businesses in its core. The area neighbours the city's industrial Steel Plant. Over the years it has transitioned into an area of low activity and struggles to find a new identity.

The West End Community originally came into being in the 1900's as a result of the Algoma Steel Plant. Located adjacent to the industrial site was a growing thriving community identified as the city's 'Little Italy'. It was home to many of the immigrant families travelling from Italy to Sault Ste. Marie to work at the rapidly expanding steel plant. The streets were filled with family owned vendors as a reflection of the typical European lifestyle. ${ }^{35}$ The vendors eventually evolved into a community square that flourished with local businesses. The neighbourhood was a self contained community with schools, churches, parks and businesses that catered to the needs of the area. It was a collective village..$^{36}$

What happened to this thriving community? Failed urban renewal efforts, relocation to the suburbs and the decline of the steel plant has ultimately left the area almost abandoned. In more recent years it has become home to the Soup Kitchen Community Centre and a few other businesses but still remains visually unoccupied and definitely unsafe. A number of buildings in the area are rich with history and underutilized potential. They lay dormant with no future plans for redevelopment. 35 "Remember This? When James Street Was Bustling". Soo Today, December 06, 2015. Accessed March 18, 2018.
36 Ibid. 


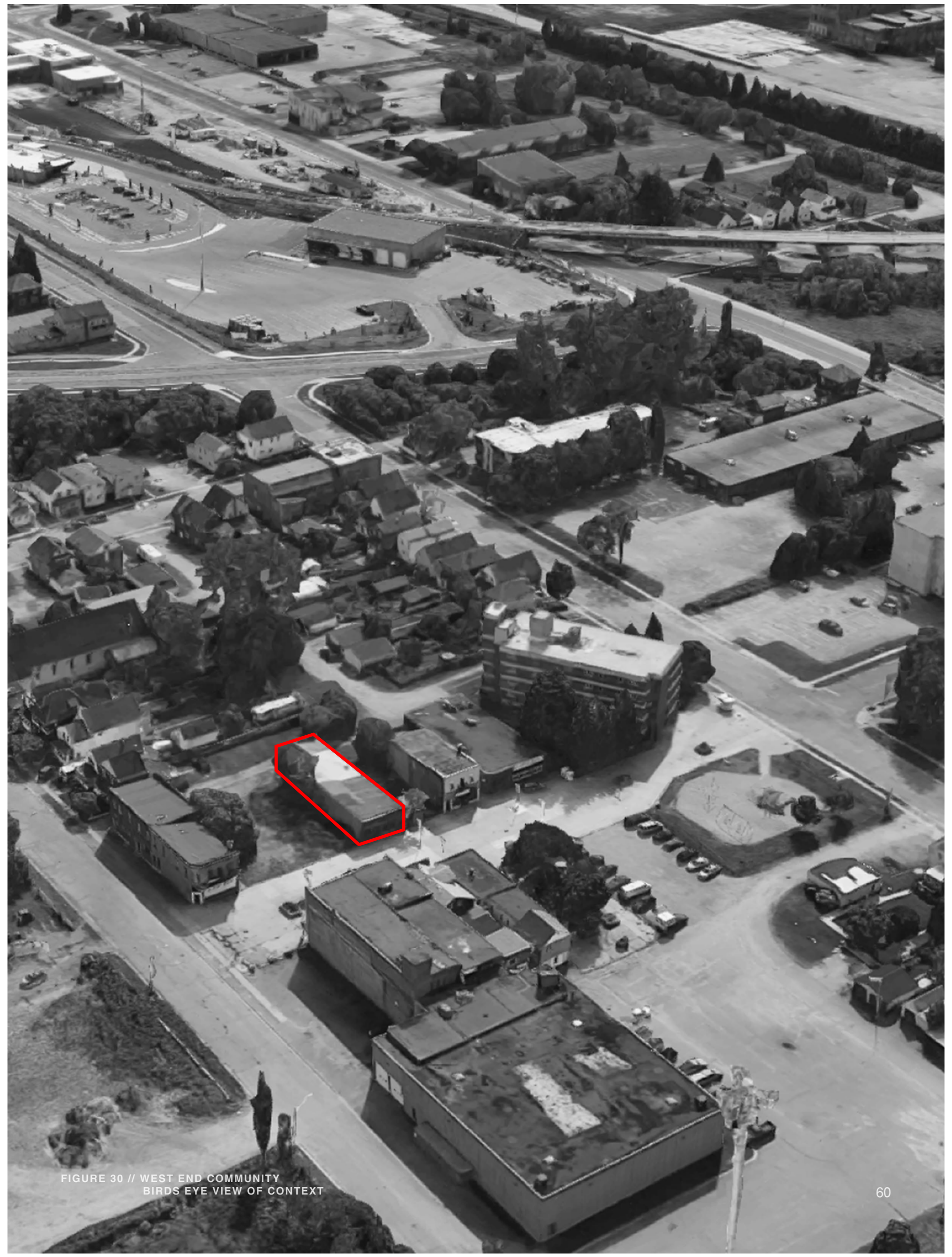



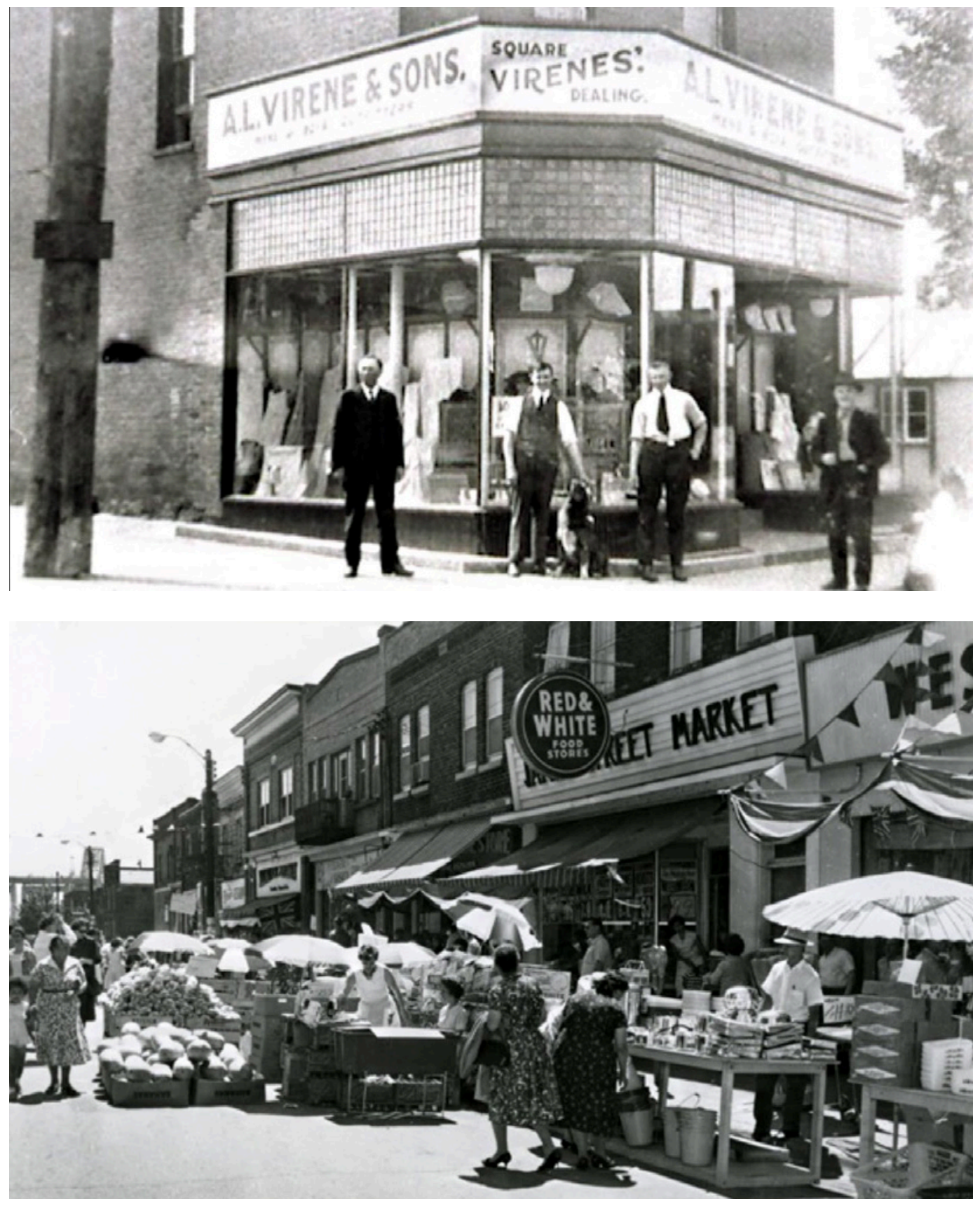

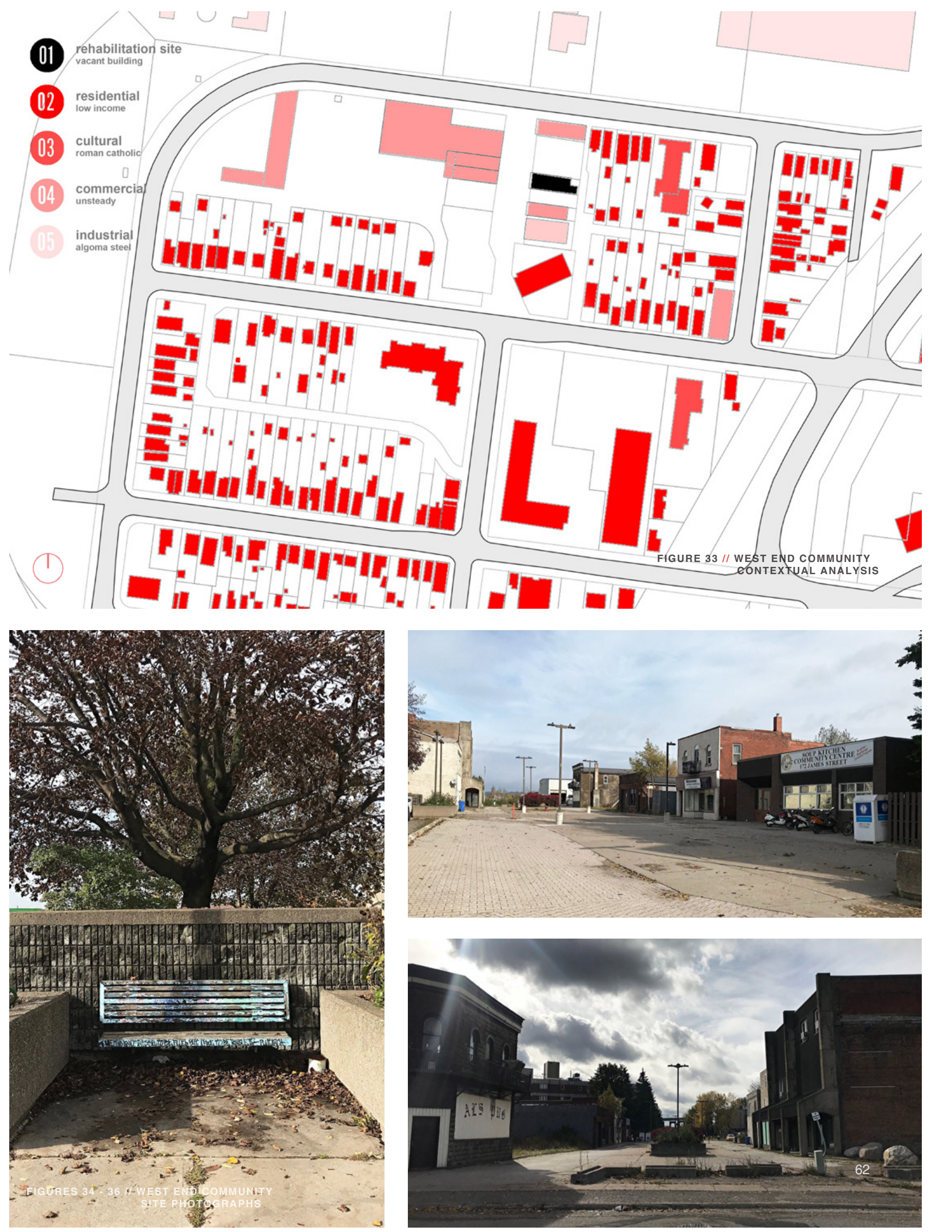
Next to the Soup Kitchen Community Centre is a former pharmacy that remains vacant. The 262 sm building is decorated with original brick and double height garage doors. It runs West to East with an entry facing the main plaza on the West side. The West facade hugs the pedestrian street forming a dialogue between the building and plaza. The garage door on the East facade opens up to a private road. The scale of the building makes it very approachable. The existing makeup of the building is quite simple. It is a rectangular wood frame building with exposed structure and no interior walls. It appears that no major changes have been made to the original building other than updating the windows and the removal of interior walls. This is the building proposed for rehabilitation.

The program proposed for this building includes the necessary medical program and an additional social enterprise program. Considering its adjacency to the soup kitchen, the building will be designed to house a community kitchen with multiple missions. It is meant to act as a culinary education space that will provide programs for recovering addicts to learn how to cook, feed themselves, and feed others within the community.

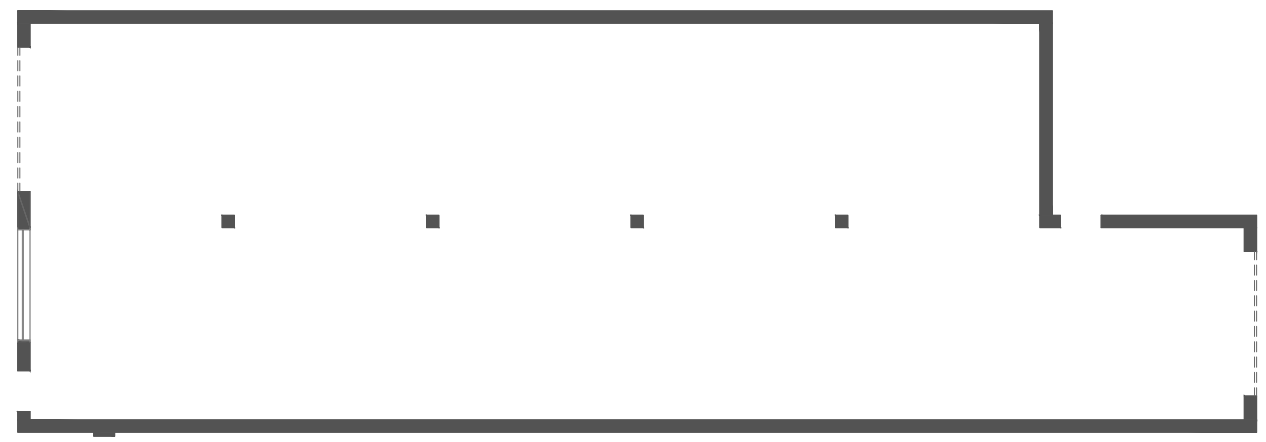

FIGURE 37 // WEST END COMMUNITY EXISTING FLOOR PLAN

prior to design the existing building was assessed and fully documented 


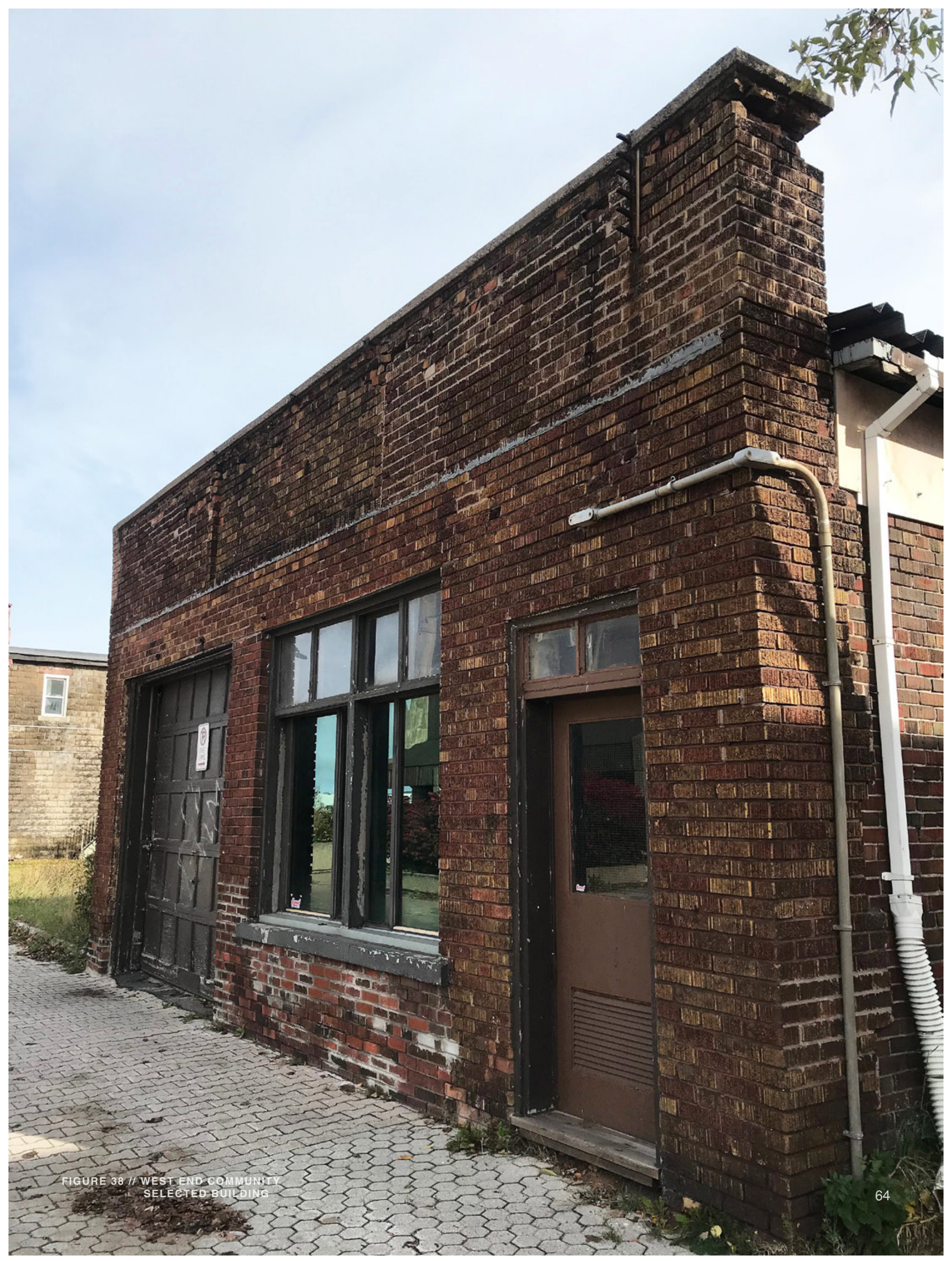



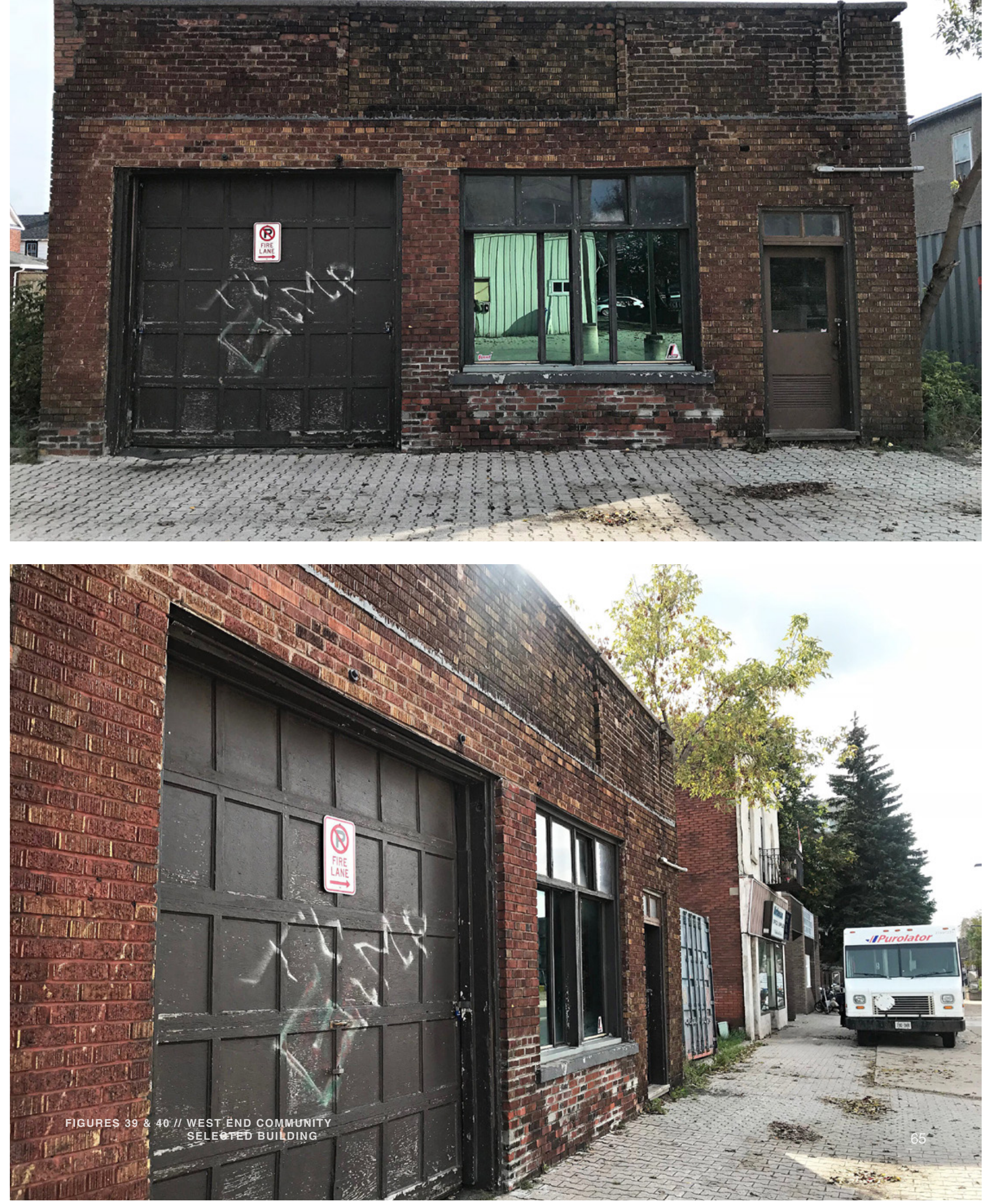


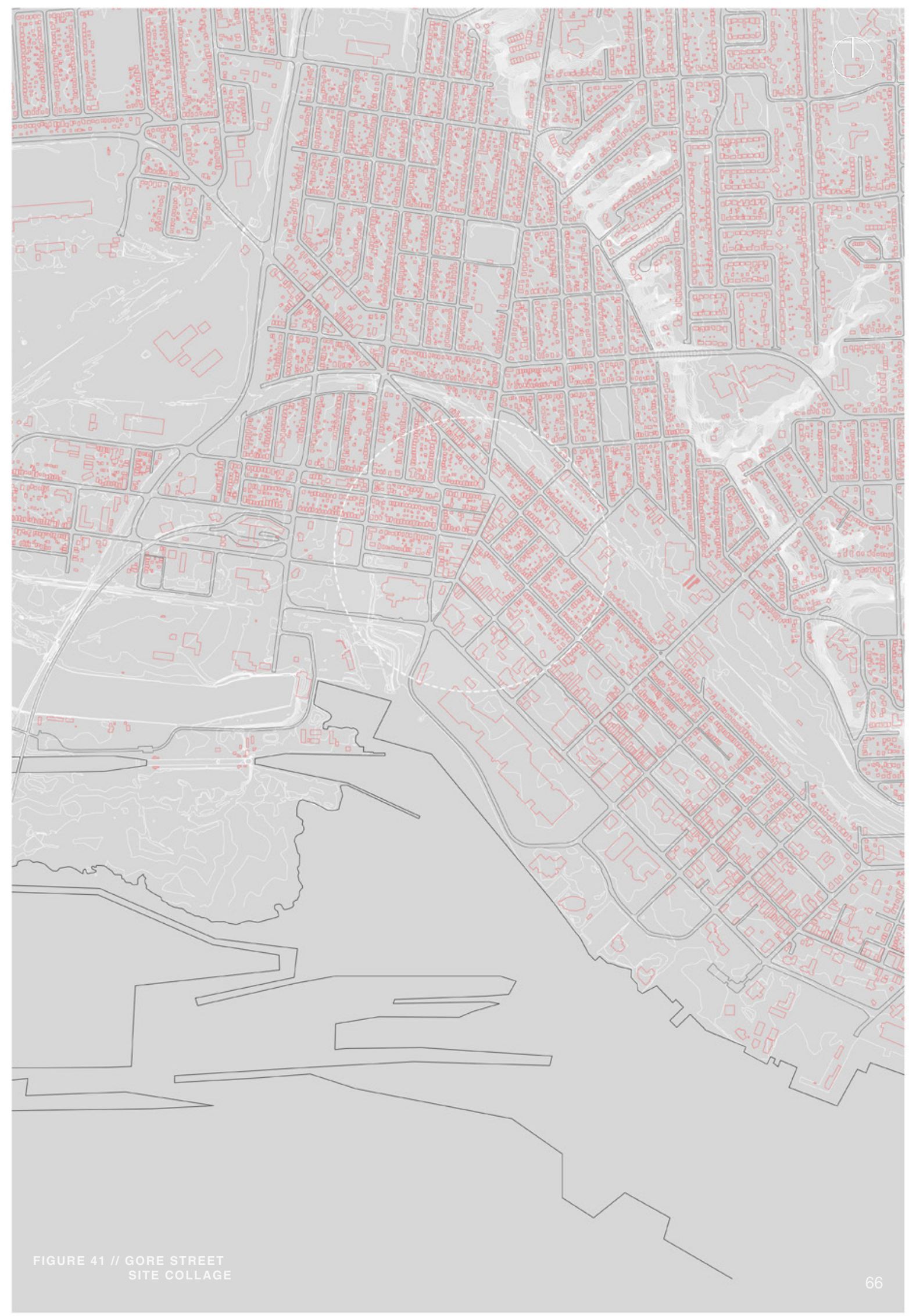




\section{gore street}

Gore Street is the second site that was selected. This street is located on the edge of the downtown core and is known for being a hub for drug use. Many consider it to be the 'cancer of the downtown core'. Over the past couple of years it has been the subject of a revitalization project that the city has yet to properly address. Money has been put into trying to improve the dynamic of the street by landscaping and adding public spaces but it still remains a centre of high drug activity.

Much like the West End Community, Gore Street has a rich history and meaning within the city. Being the connector to four major areas of the city, the west end, downtown, North side and the waterfront, it was a prime location to invest in. After the economic boom and development of these surrounding areas, Gore Street became the hub for the city's main arts and culture scene. For the city it represented ethnic heritage and community. Restaurants, theatres and locally owned businesses filled the street.

Fast forward to today and this representation is no more. Gore street is known as almost the exact opposite of what it once was. As the city began to decline so did the dynamic of the street. Theatres began to shut down because they could not financially sustain themselves, business owners began to relocate or close their doors, and safety issues began to arise. Arts and culture has unfortunately been substituted by drugs and prostitution. The decline sets the tone for the rest of the downtown core and the city has had no choice but to try and intervene. The Corporation of the City of Sault Ste. Marie has spent a lot of time and money trying to improve the dynamic of the street with landscaping, adding public spaces and improving the quality of a number of store-fronts. What the city has failed to improve is the drug problem. 


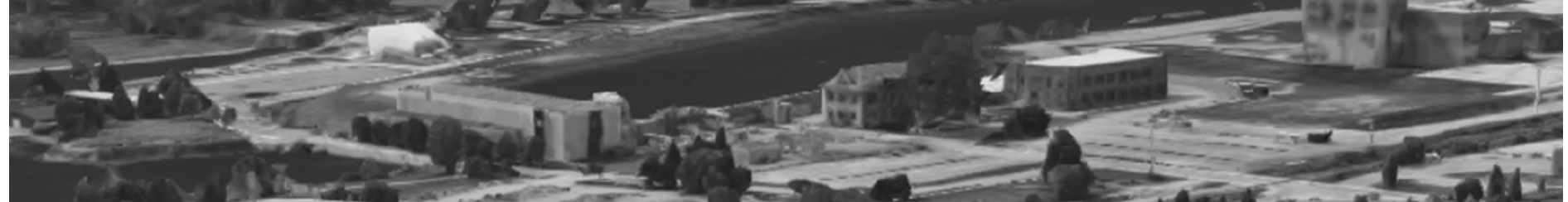

$$
525-2=12
$$

4

की $=0$

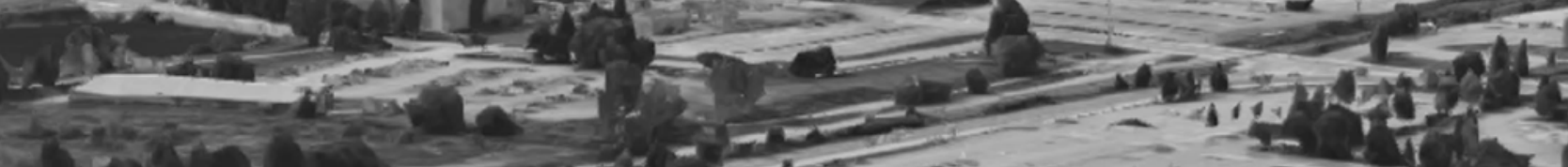

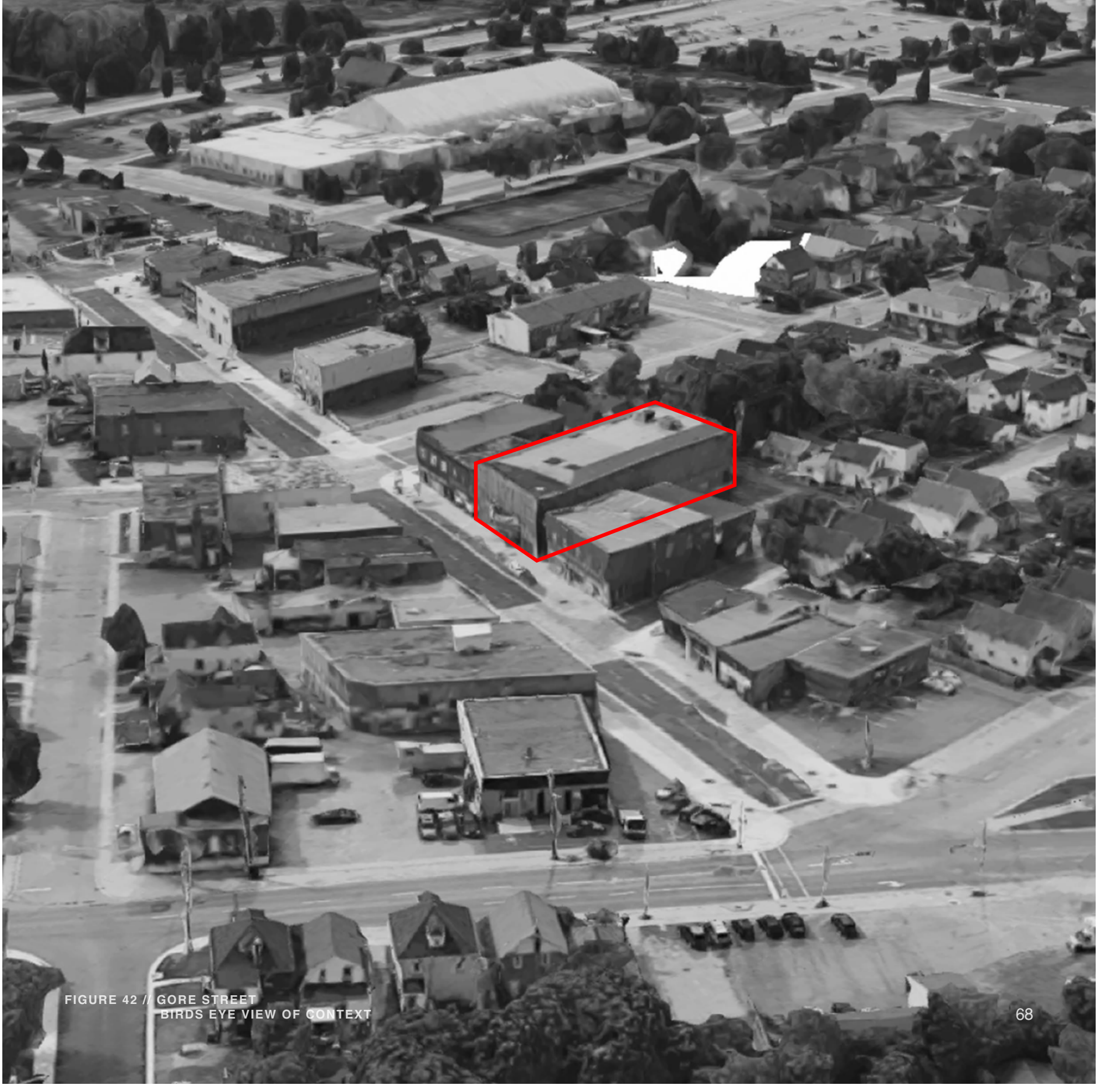



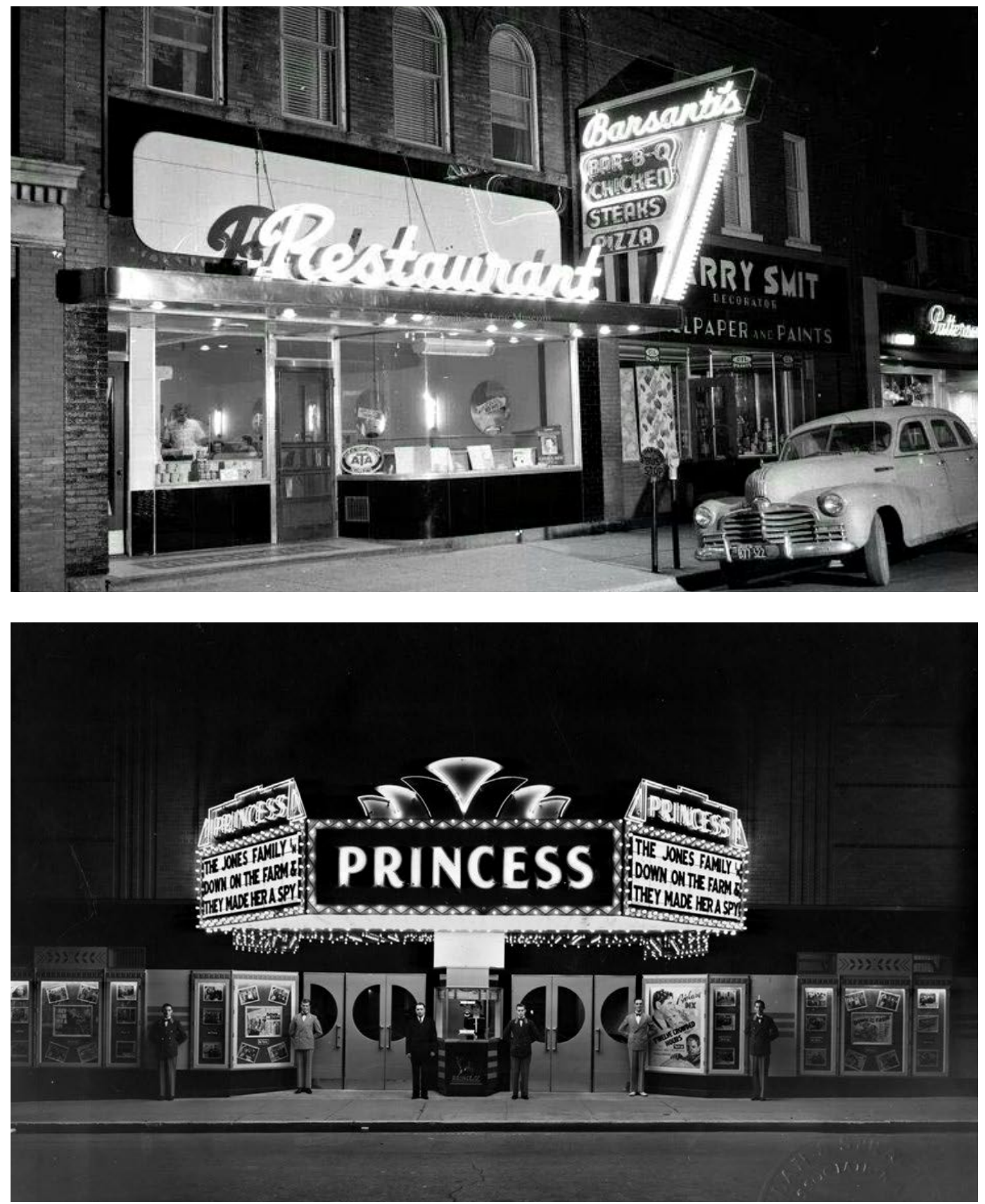

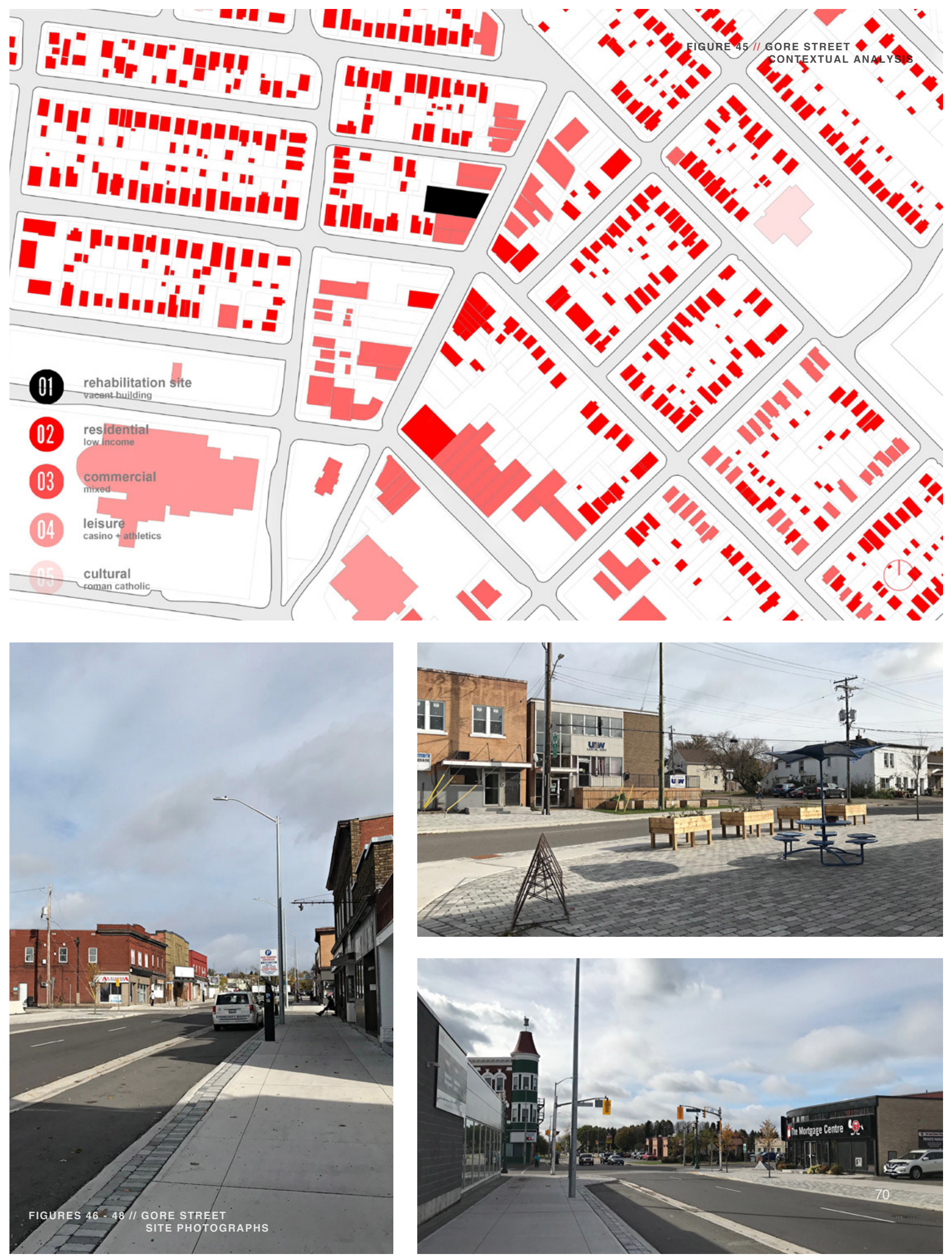
The former Princess Theatre is an iconic building in the evolution of Gore Street. Aside from the nostalgia associated with its history, the building's architecture and monumental size make it a city landmark. The 1,059 sm building displays original brick and detailing. Its street front is located on the East side of the building and hugs the sidewalk. It sits in between two vacant buildings. Structurally, the building appears to be intact. Other than the boarded up entrance doors the facade detailing is unharmed. It is a concrete structure with a layout similar to most theatres constructed in the 1900's. Upon entry there is a lobby, theatre space, and access to a lower level. The building has been vacant for almost 10 years and there are no plans for redevelopment. This is the second building proposed for rehabilitation.

The program proposed for this space includes the necessary medical program and an additional performing arts, self development and education program. The ultimate goal is to recover the sense of cultural identity that the area once had. The building will include a theatre space, workshop, incubator spaces, and classrooms.

FIGURE 49 // GORE STREET

EXISTING FLOOR PLANS

prior to design the existing building was assessed and fully documented
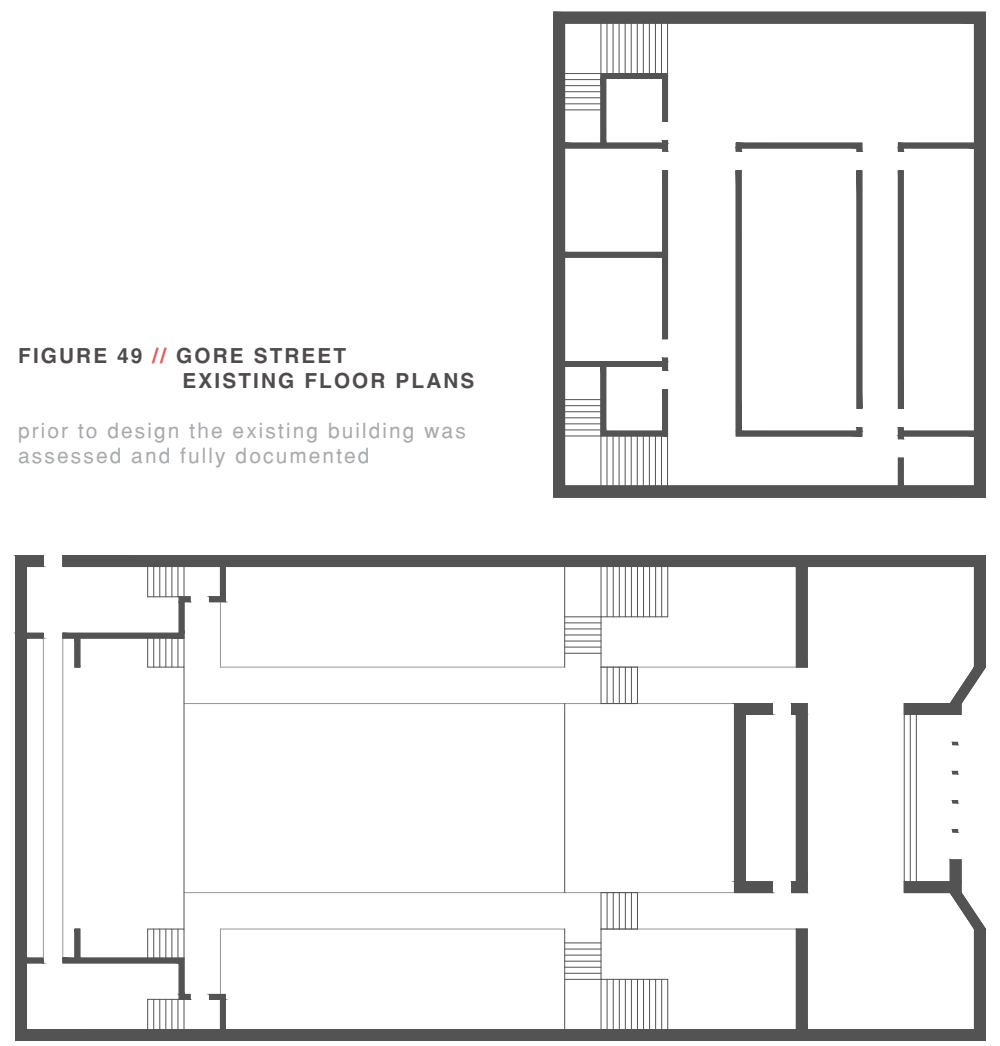


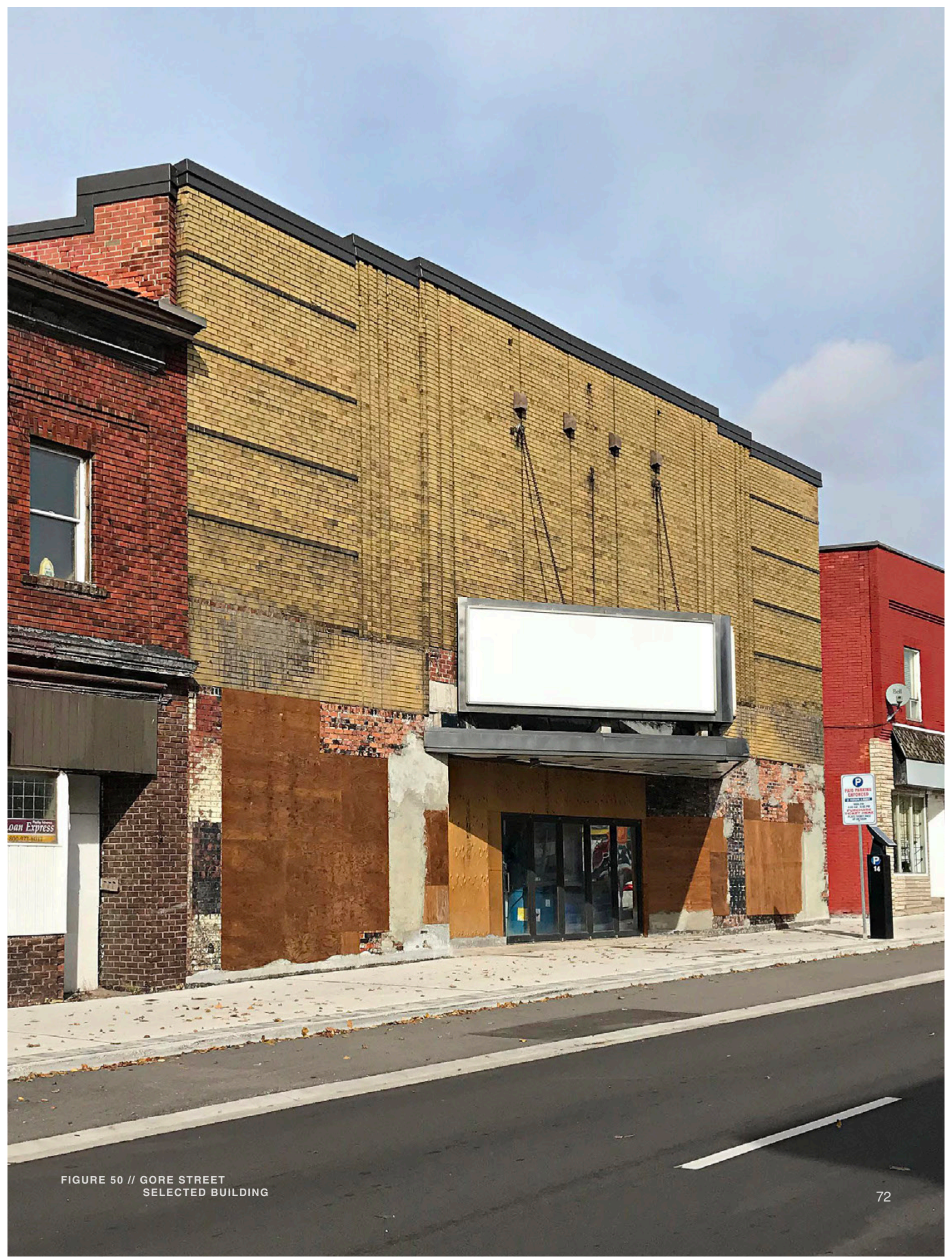




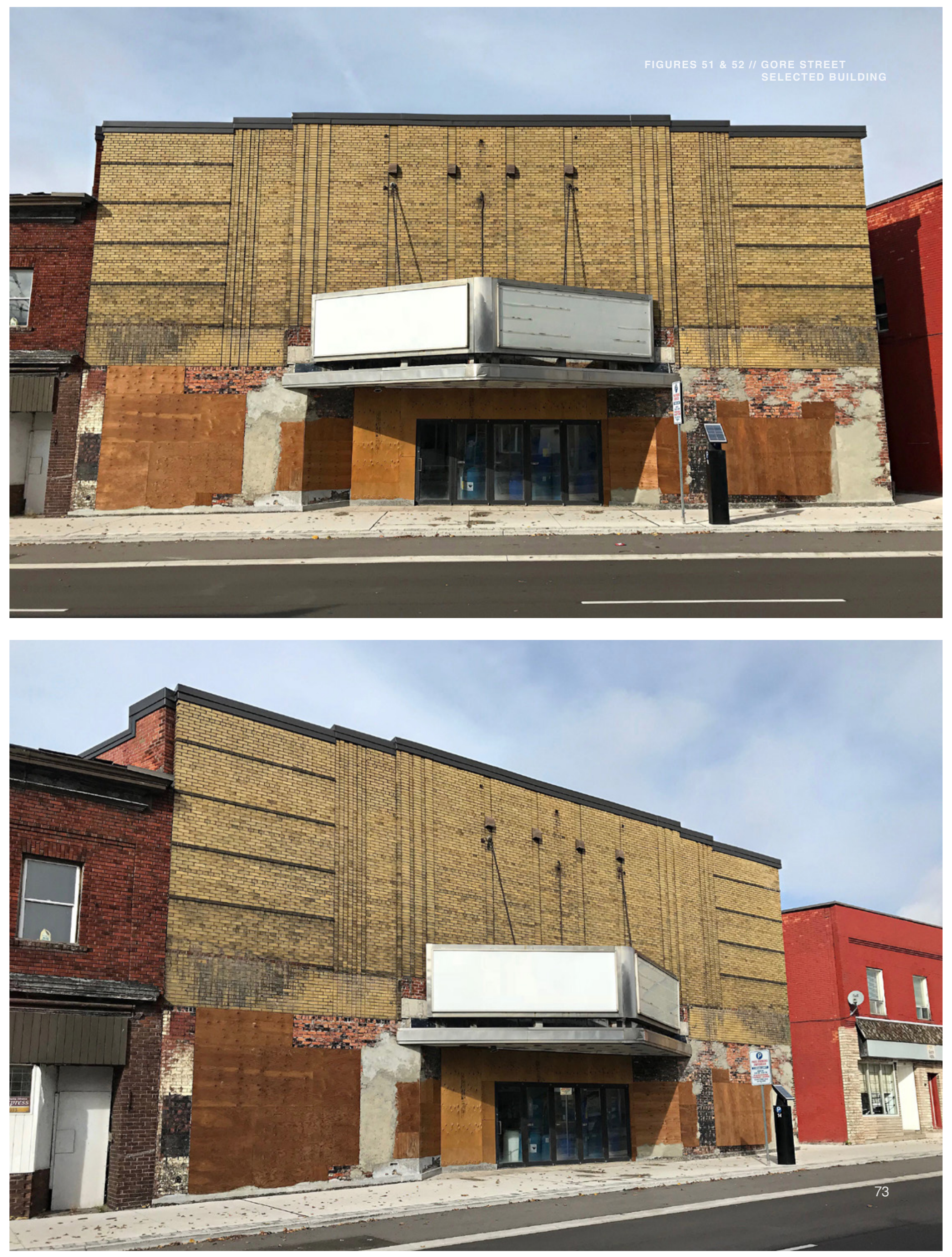




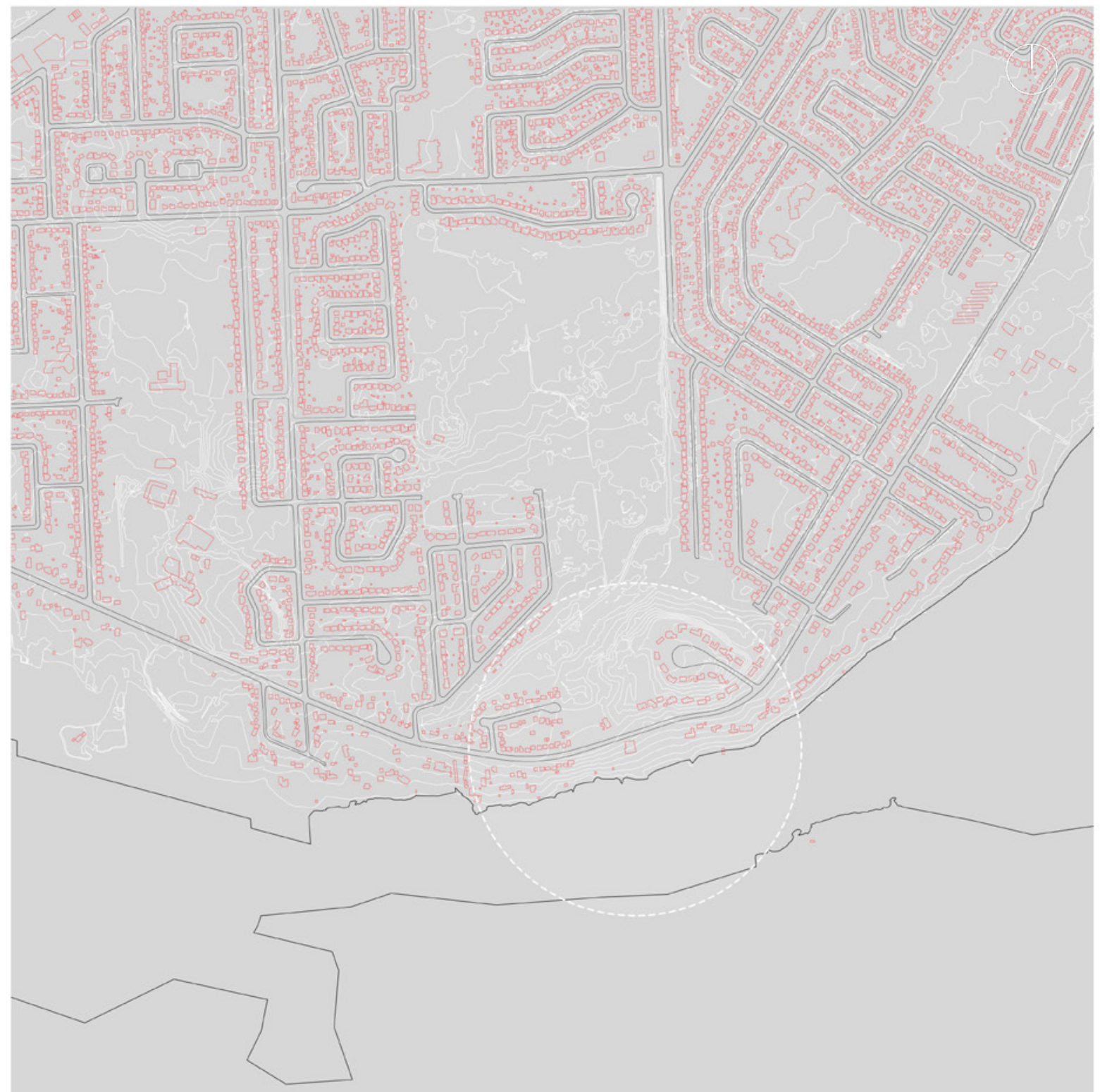




\section{country club}

The last selected site is the Country Club. This site is very different from the other two. It is located in the east end of the city and in an upper middle class area of town. It is a waterfront property owned by one of the local golf courses. The property and buildings located on site are currently up for sale. There is uncertainty as to how to redevelop the site. In hindsight, without proper planning its fate may not be much different than the other two sites.

The Country Club property was transformed to a public outdoor space in $1919 .{ }^{37}$ Considering most of the downtown waterfront property was utilized by the steel plant and paper mill at the time, it provided a beautiful retreat for people to spend time during the summer months. In time it became a commodity to those within the city because of its close proximity to the downtown core. This was the start to the residential development in the surrounding areas. The property was eventually transformed into a locally owned golf club that is still operating today.

The city has grown and a number of additional modern golf club facilities have been constructed within the city limits. The Country Club, by contrast appears outdated challenging its viability. It no longer thrives in the city like it once did and the community is concerned for its future.

37 "Sault Ste. Marie Golf Club Overview". Sault Ste. Marie Golf Club Course. Accessed March 23, 2018. 


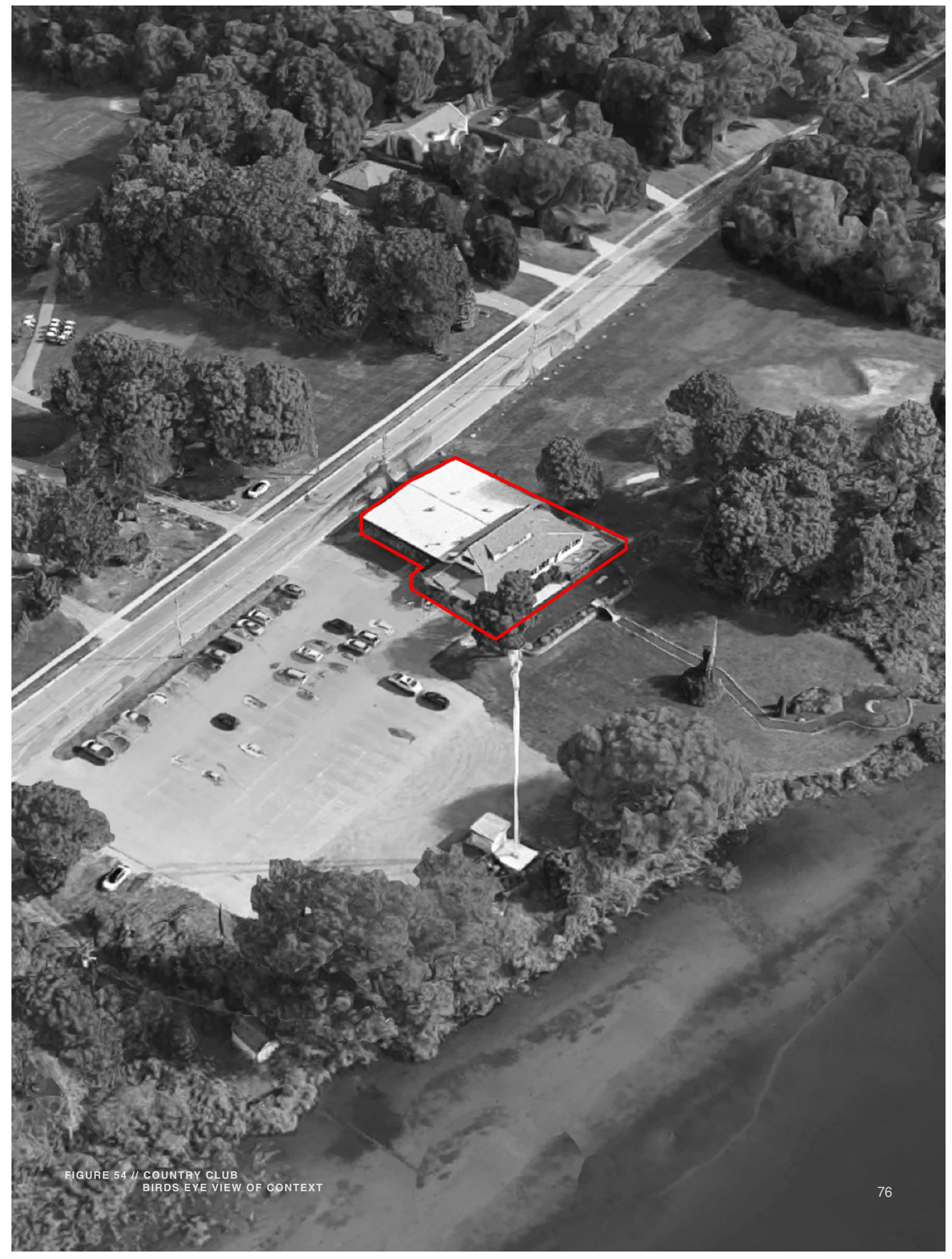



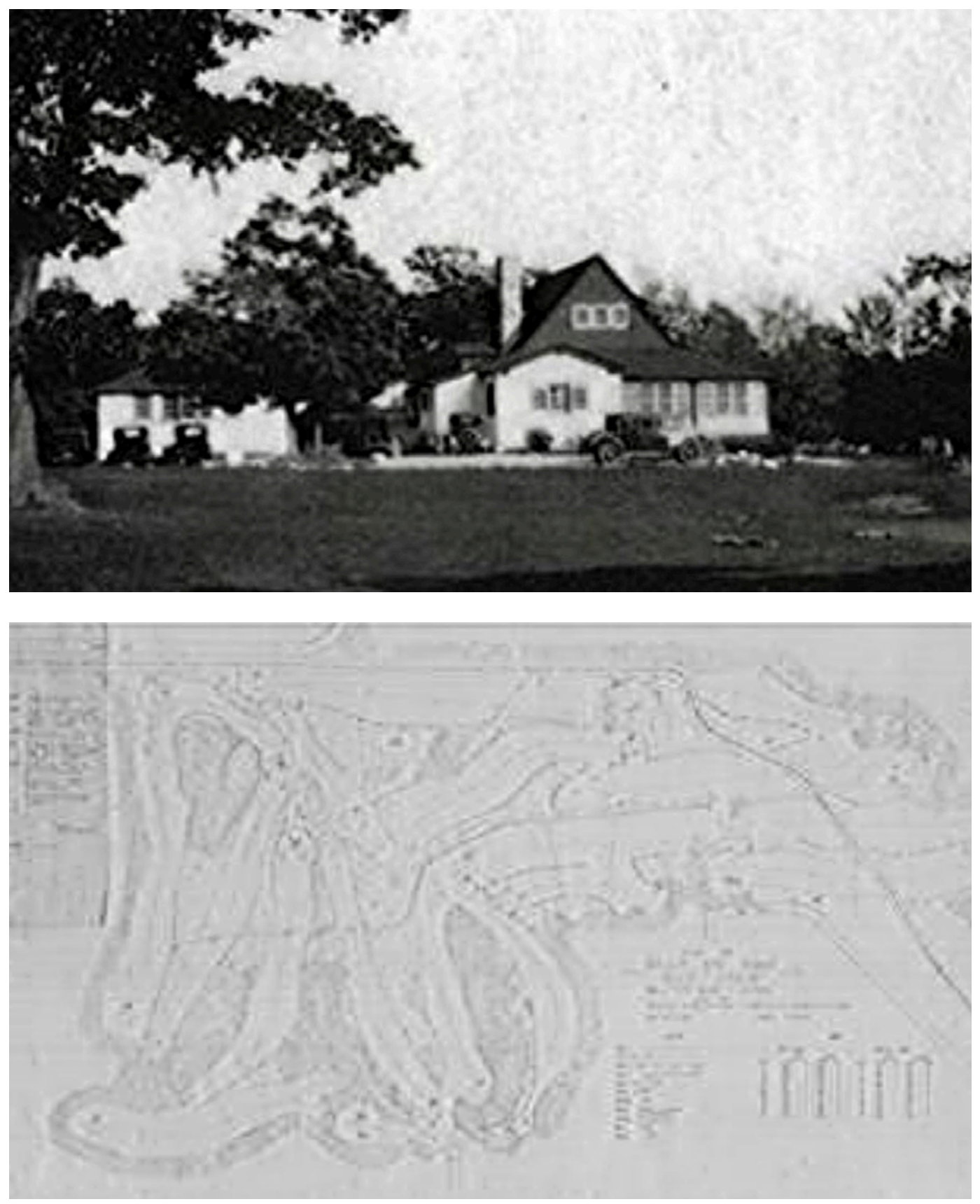

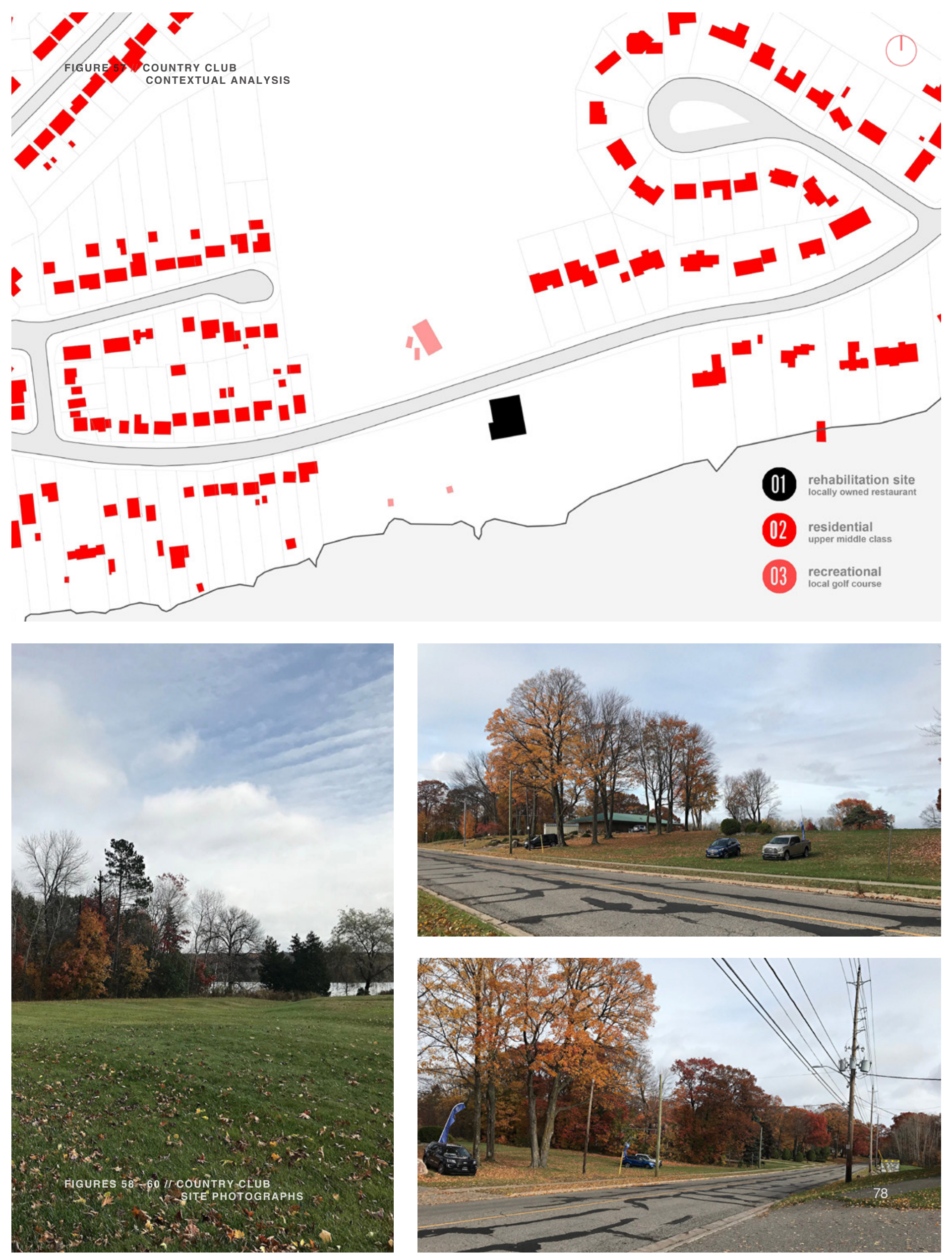
The Iron Club is a locally owned restaurant situated on the Country Club property that overlooks the St. Mary's River. With the recent financial decline of the golf course, the establishment has been struggling as well. Both have been put on the market for sale. The $842 \mathrm{sm}$ Victorian-Ranch style building sits adjacent to a large parcel of green space on the East and parking lot on the West. The North side of the building hugs one of the city's busiest main streets and the South side faces the waterfront. Due to recent renovations and an addition the buildings conditions are quite acceptable. It is a two storey wood framed structure with an interior layout that suits the building's original needs. Upon entry is an open concept hall that overlooks the waterfront, partitioned space for additional program and a stair that leads you to the upper level where there are offices. The open concept space opens up to an exterior deck that places you in the core of an already beautiful landscaped courtyard overlooking the water. This is the third building proposed for rehabilitation.

The program proposed for this space includes the necessary medical program and additional health and wellness spaces. The additional program is to provide space for physical, mental and vocational rehabilitation.

FIGURE $61 / /$ COUNTRY CLUB

EXISTING FLOOR PLANS

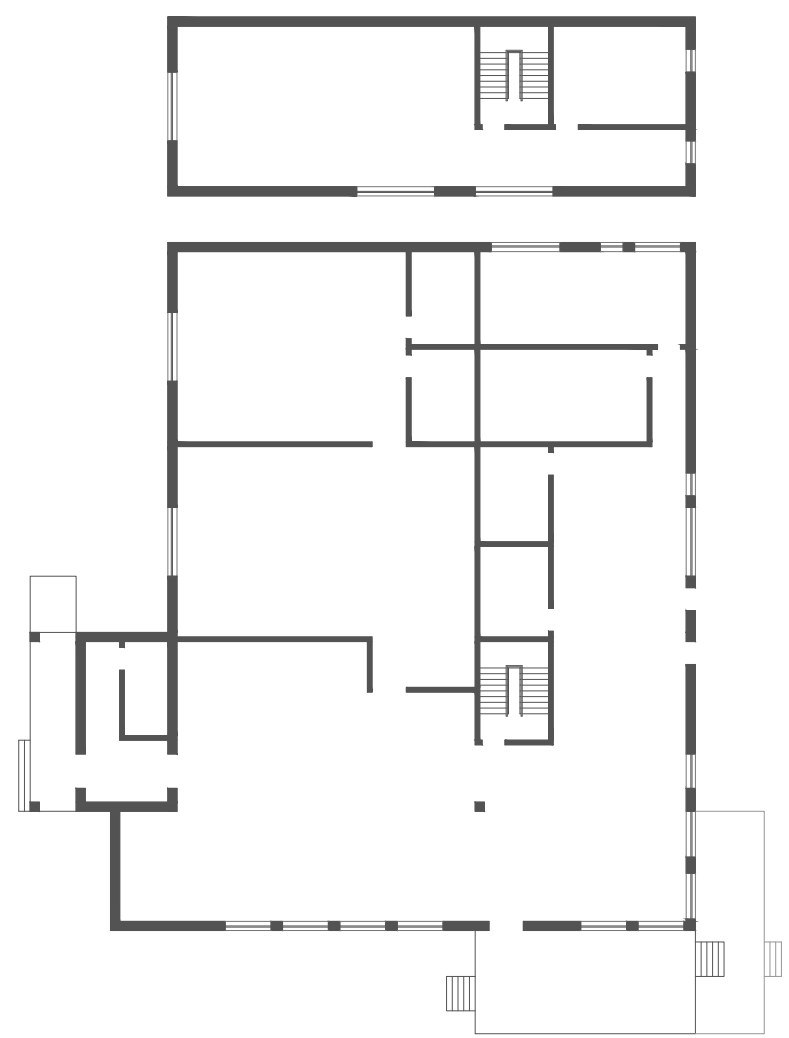




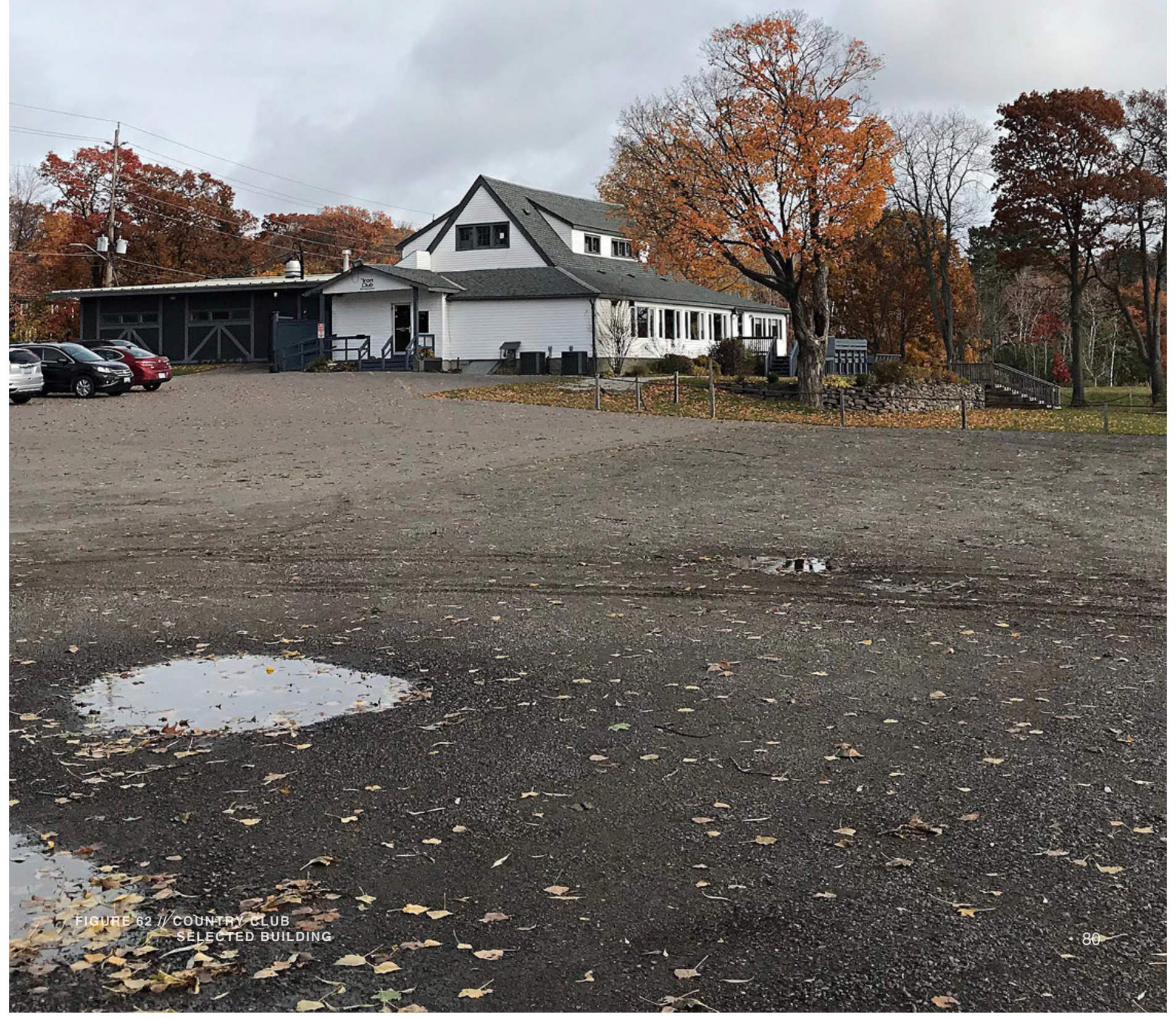



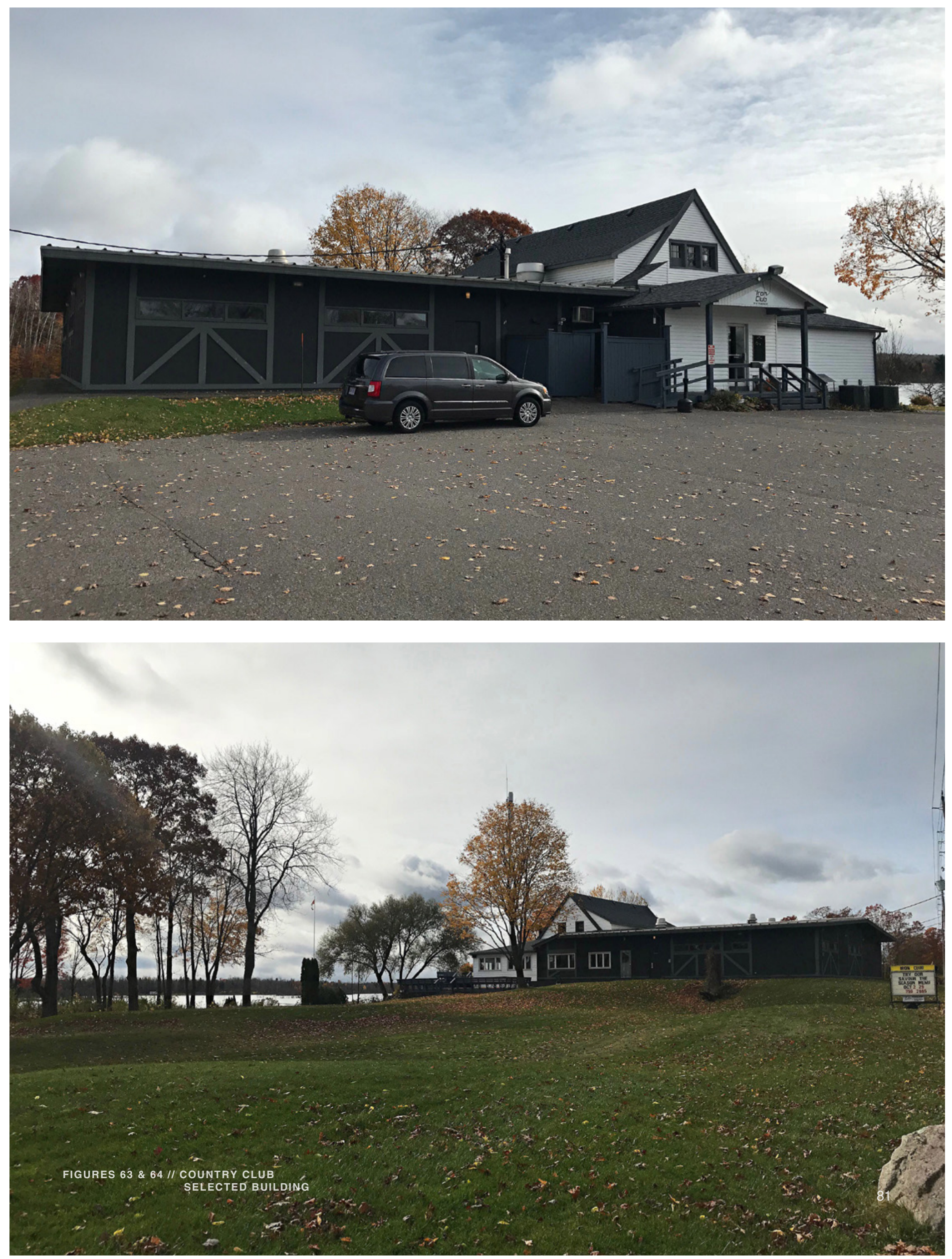


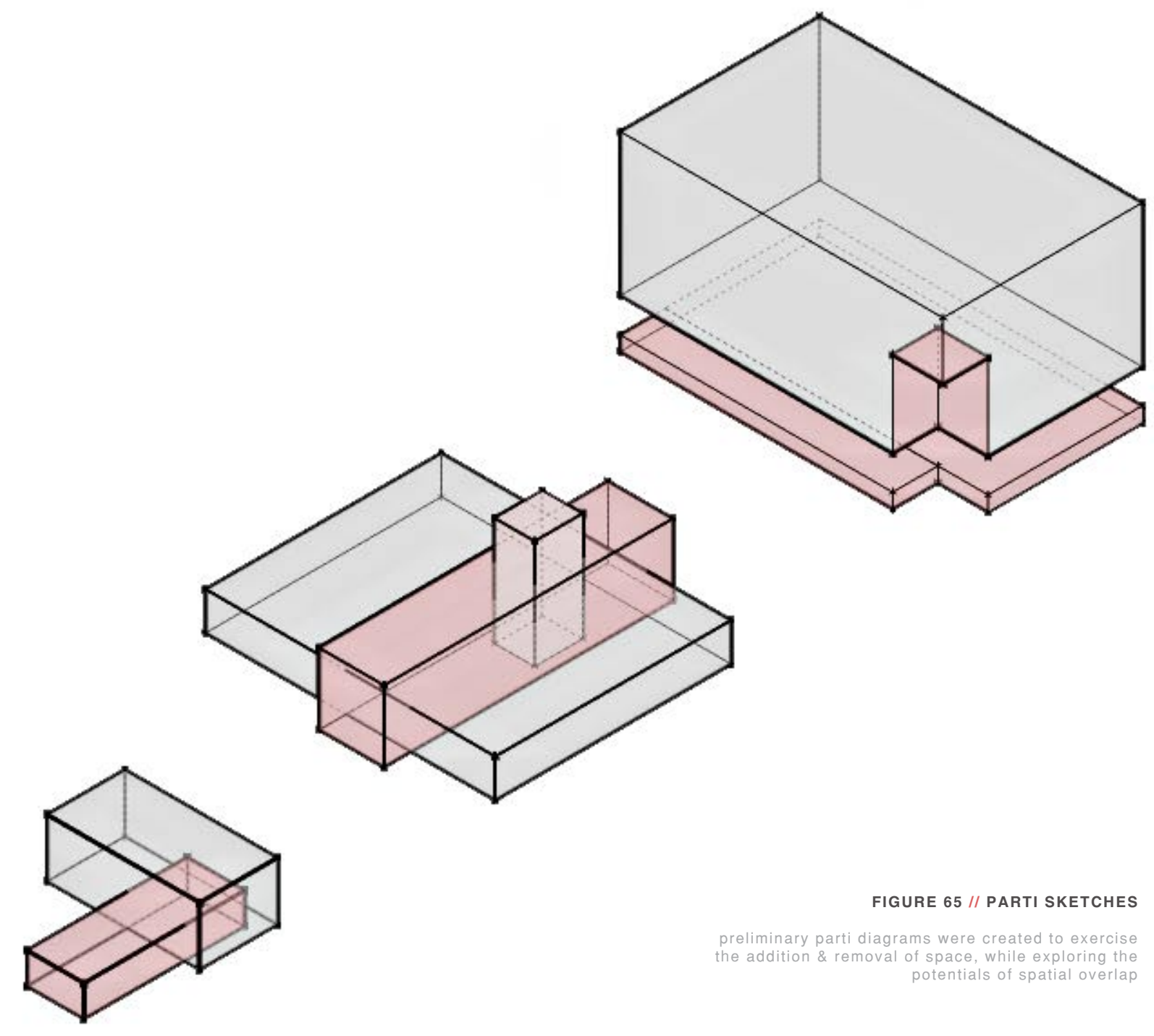




\section{DESIGN METHODOLOGY}

The four stages that are often associated with addiction recovery are assessment, detoxification, rehabilitation and aftercare. These terms could also be applied when speaking about the adaptive reuse of existing buildings. What do they mean? How can this terminology help define a methodology that acts as a tool to think about a design intervention in each space. Listed below is a general definition for each term and how it can be reinterpreted to establish a design methodology.

PHASE 1 // ASSESSMENT

"..the act or an instance of making a judgment about something." 38

When an addict seeks assistance during the first phases of recovery they are typically assessed by a front line worker to understand the conditions in order determine a course of action. This phase of recovery is important in gaining an understanding of what the problem is and what needs to be done to address it. The same process occurs when recovering an existing building. What components make up the structure of the building? What is the structure and skin of the building? Are these components in good condition? Is there anything that needs to be done to restore deteriorating elements? Can the existing space adapt to new conditions?

\section{PHASE 2 // DETOXIFICATION}

"...to remove a harmful substance : to free from an intoxicating or an addictive substance in the body." 39

As described in the definition detoxification typically involves removing harmful substances that contribute to the deterioration of a body or building. In the case of an addict it is to free the body from the addictive substance(s). In the case of a building it may involve literally removing elements and replacing them with new ones to restore function. This thesis proposes the detoxification process as a method of relieving the body and building of any conditions that impact either in a negative way or prevent it from growth. For the addict this is meant to address both the physical and mental. For the building it could involve removing or adding elements in order to prepare it for the rehabilitation phase.

38 "Assessment". Dictionary by Merriam-Webster. Accessed March 02, 2018. 9 "Detoxification". Dictionary by Merriam-Webster. Accessed March 02, 2018. 


\begin{tabular}{|c|c|c|c|}
\hline$\underset{\text { body }}{\text { assessment }}$ & detoxification & $\begin{array}{c}\text { rehabilitation } \\
\text { body }\end{array}$ & $\begin{array}{l}\text { afiercare } \\
\text { body }\end{array}$ \\
\hline $\begin{array}{l}\text { assessment of body conditions to } \\
\text { determine course of action } \\
\text { urine collection } \\
\text { physical examination }\end{array}$ & $\begin{array}{l}\text { methadone supply } \\
\text { suboxone suppy } \\
\text { safe injection }\end{array}$ & $\begin{array}{c}\text { individual + family counselling } \\
\text { grief + domestic counselling } \\
\text { personal therapy } \\
\text { team building }\end{array}$ & $\begin{array}{l}\text { recreational activity } \\
\text { social well being } \\
\text { social development pursuits }\end{array}$ \\
\hline 1 & 1 & 1 & 1 \\
\hline 1 & 1 & 1 & 1 \\
\hline $\begin{array}{l}\text { assessment } \\
\text { building }\end{array}$ & detoxification & $\begin{array}{l}\text { rehabilitation } \\
\text { building }\end{array}$ & $\begin{array}{l}\text { afiercare } \\
\text { building }\end{array}$ \\
\hline $\begin{array}{l}\text { assess building components } \\
\text { what is salvageable? } \\
\text { structure? skin? } \\
\text { increase or decrease spaces? }\end{array}$ & $\begin{array}{l}\text { detox building of unsalvageable components } \\
\text { make space healthy for improvements }\end{array}$ & $\begin{array}{l}\text { rehabilitate building components } \\
\text { rehabilitate interior spaces } \\
\text { add necessary design intervention }\end{array}$ & $\begin{array}{l}\text { occupants maintain spaces } \\
\text { aftercare by occupants }\end{array}$ \\
\hline 1 & 1 & 1 & 1 \\
\hline 1 & & & | \\
\hline $\begin{array}{l}\text { assessment } \\
\text { circulation }\end{array}$ & $\begin{array}{c}\text { detoxilication } \\
\text { circulation }\end{array}$ & $\begin{array}{c}\text { rehabilitation } \\
\text { circulation }\end{array}$ & $\begin{array}{l}\text { afitercare } \\
\text { circulation }\end{array}$ \\
\hline $\begin{array}{l}\text { admission assessment } \\
\text { urine collection } \\
\text { medical examination } \\
\text { medical lab } \\
\text { waiting room } \\
\text { reception }\end{array}$ & $\begin{array}{l}\text { methadone supply } \\
\text { suboxone suppy } \\
\text { pharmacy } \\
\text { safe injection } \\
\text { dispencing machines }\end{array}$ & $\begin{array}{l}\text { individual + family counselling } \\
\text { grief + domestic counselling } \\
\text { recreational rooms } \\
\text { social + team building spaces } \\
\text { therapy rooms } \\
\text { offices }\end{array}$ & additional program \\
\hline
\end{tabular}




\section{PHASE 3 // REHABILITATION}

“..the action, process or result of rehabilitating : an improved condition : restoring to a useful place in society." 40

Following the detoxification is the rehabilitation phase. This phase is very important for both the body and building because it sets up a framework for how both might be reintroduced into the community. For both the rehabilitation process can be the most difficult because it is where the most change occurs. An existing condition, physically or mentally, needs to adapt to a new life in order to sustain a healthy lifestyle. How can both find new positive meanings? How can an existing building be rehabilitated to suit a new function? This is where the intervention occurs.

\section{PHASE 4 // AFTERCARE}

“.. the care, treatment, help or supervision given to a person, place or thing." 41

The intent of the rehabilitation phase it to substitute the negative with new positive meanings for the body and building. Once rehabilitated how can one maintain a new way of life? For the addict this may involve attending physical and mental counselling, participating in new social activities, or engaging in new social development pursuits. For the building it is sustenance. How can the addict and building work together to care for another? This is the significance of the additional program.

40 "Rehabilitation". Dictionary by Merriam-Webster. Accessed March 02, 2018

41 "Aftercare". Dictionary by Merriam-Webster. Accessed March 02, 2018. 


\begin{tabular}{|c|c|c|c|}
\hline $\begin{array}{c}\text { assessment } \\
\text { body }\end{array}$ & $\begin{array}{l}\text { detoxification } \\
\text { body }\end{array}$ & $\begin{array}{c}\text { rehabilitation } \\
\text { body }\end{array}$ & $\begin{array}{l}\text { aftercare } \\
\text { body }\end{array}$ \\
\hline $\begin{array}{l}\text { assessment of body conditions to } \\
\text { determine course of action } \\
\text { urine collection } \\
\text { physical examination }\end{array}$ & $\begin{array}{l}\text { methadone supply } \\
\text { suboxone suppy } \\
\text { safe injection }\end{array}$ & $\begin{array}{l}\text { individual + family counselling } \\
\text { grief + domestic counselling } \\
\text { personal therapy } \\
\text { team building }\end{array}$ & $\begin{array}{l}\text { recreational activity } \\
\text { social well being } \\
\text { social development pursuits }\end{array}$ \\
\hline 1 & 1 & 1 & 1 \\
\hline $\begin{array}{l}\text { assessment } \\
\text { building }\end{array}$ & $\begin{array}{l}\text { detoxification } \\
\text { building }\end{array}$ & $\begin{array}{l}\text { rehabilitation } \\
\text { building }\end{array}$ & $\begin{array}{l}\text { aftercare } \\
\text { building }\end{array}$ \\
\hline $\begin{array}{l}\text { assess building components } \\
\text { what is salvageable? } \\
\text { structure? skin? } \\
\text { increase or decrease spaces? }\end{array}$ & $\begin{array}{l}\text { detox building of unsalvageable components } \\
\text { make space healthy for improvements }\end{array}$ & $\begin{array}{l}\text { rehabilitate building components } \\
\text { rehabilitate interior spaces } \\
\text { add necessary design intervention }\end{array}$ & $\begin{array}{l}\text { occupants maintain spaces } \\
\text { aftercare by occupants }\end{array}$ \\
\hline$\downarrow$ & 1 & 1 & 1 \\
\hline & & & 1 \\
\hline $\begin{array}{c}\text { assessment } \\
\text { circulation }\end{array}$ & $\begin{array}{c}\text { detoxification } \\
\text { circulation }\end{array}$ & $\begin{array}{c}\text { rehabilitation } \\
\text { circulation }\end{array}$ & $\begin{array}{l}\text { aftercare } \\
\text { circulation }\end{array}$ \\
\hline $\begin{array}{l}\text { admisssion assessment } \\
\text { urine colllection } \\
\text { medical examination } \\
\text { medical lab } \\
\text { waiting room } \\
\text { reception }\end{array}$ & $\begin{array}{l}\text { methadone supply } \\
\text { suboxone suppy } \\
\text { pharmacy } \\
\text { safe injection } \\
\text { dispencing machines }\end{array}$ & $\begin{array}{l}\text { individual + family counselling } \\
\text { grief + domestic counselling } \\
\text { recreational roooms } \\
\text { social + team building spaces } \\
\text { therapy rooms } \\
\text { offices }\end{array}$ & additional program \\
\hline
\end{tabular}



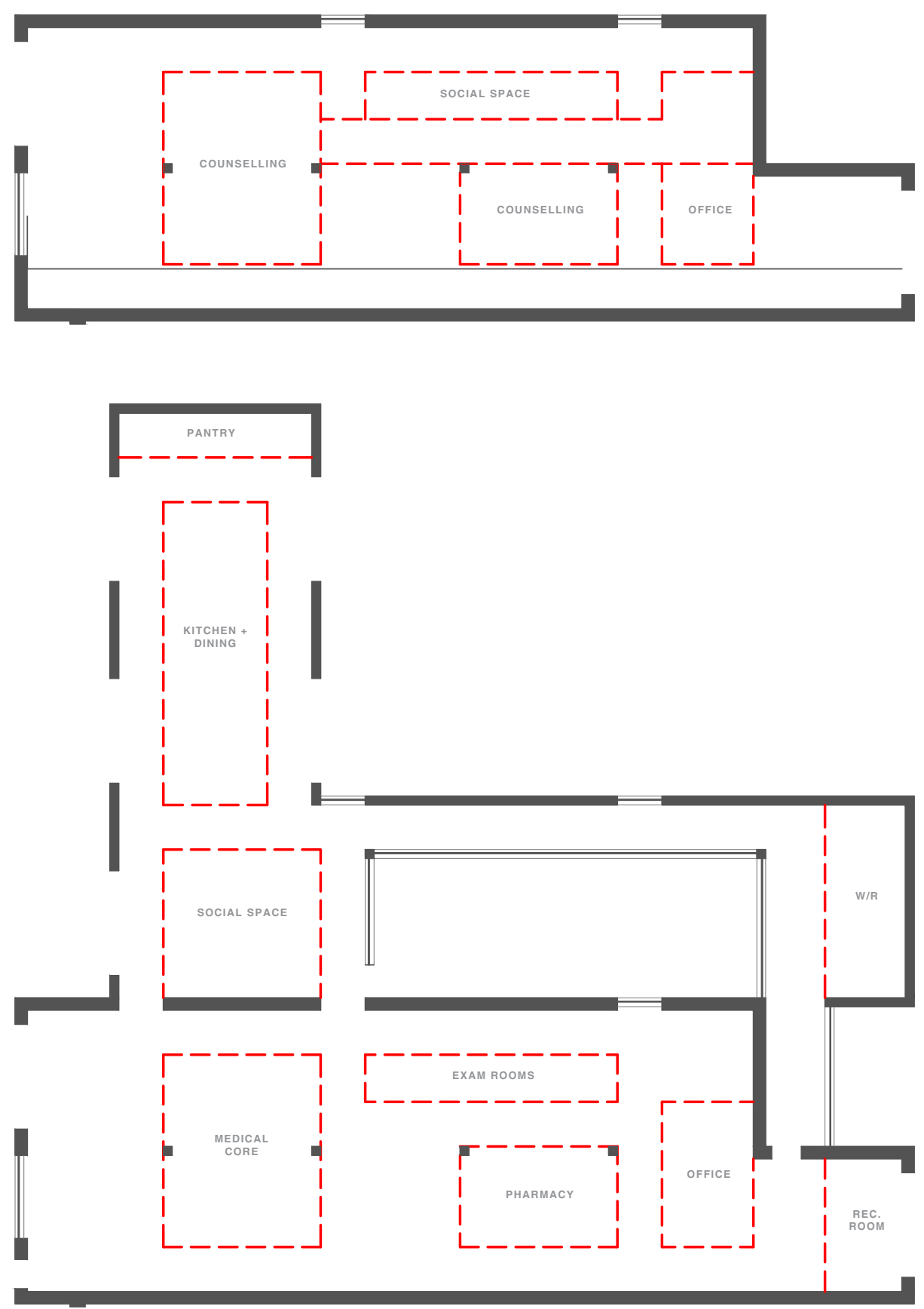

FIGURE 68 // DESIGN METHODOLOGY CIRCULATION WEST END COMMUNITY 

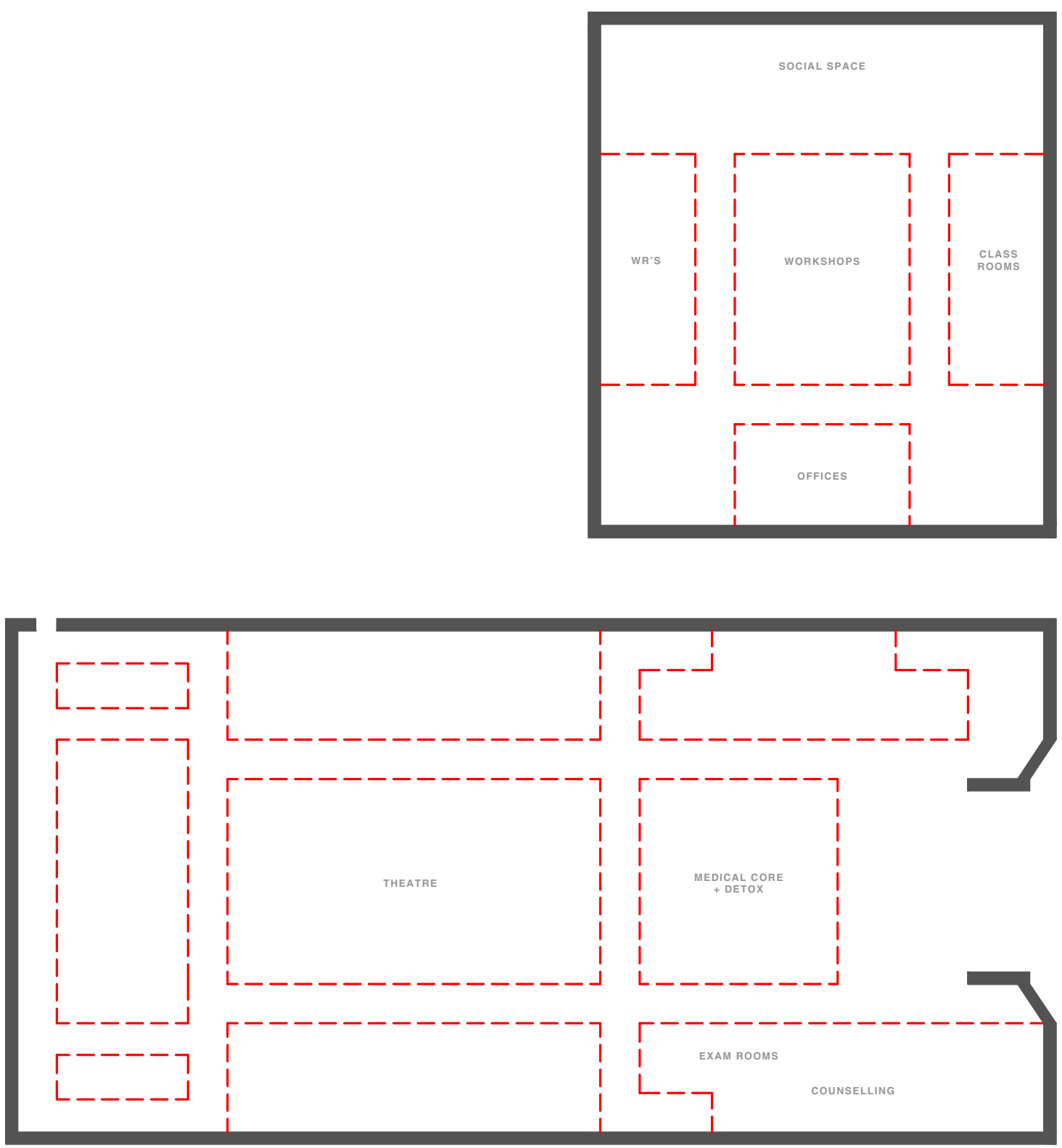

FIGURE 69 // DESIGN METHODOLOGY CIRCULATION GORE STREET 

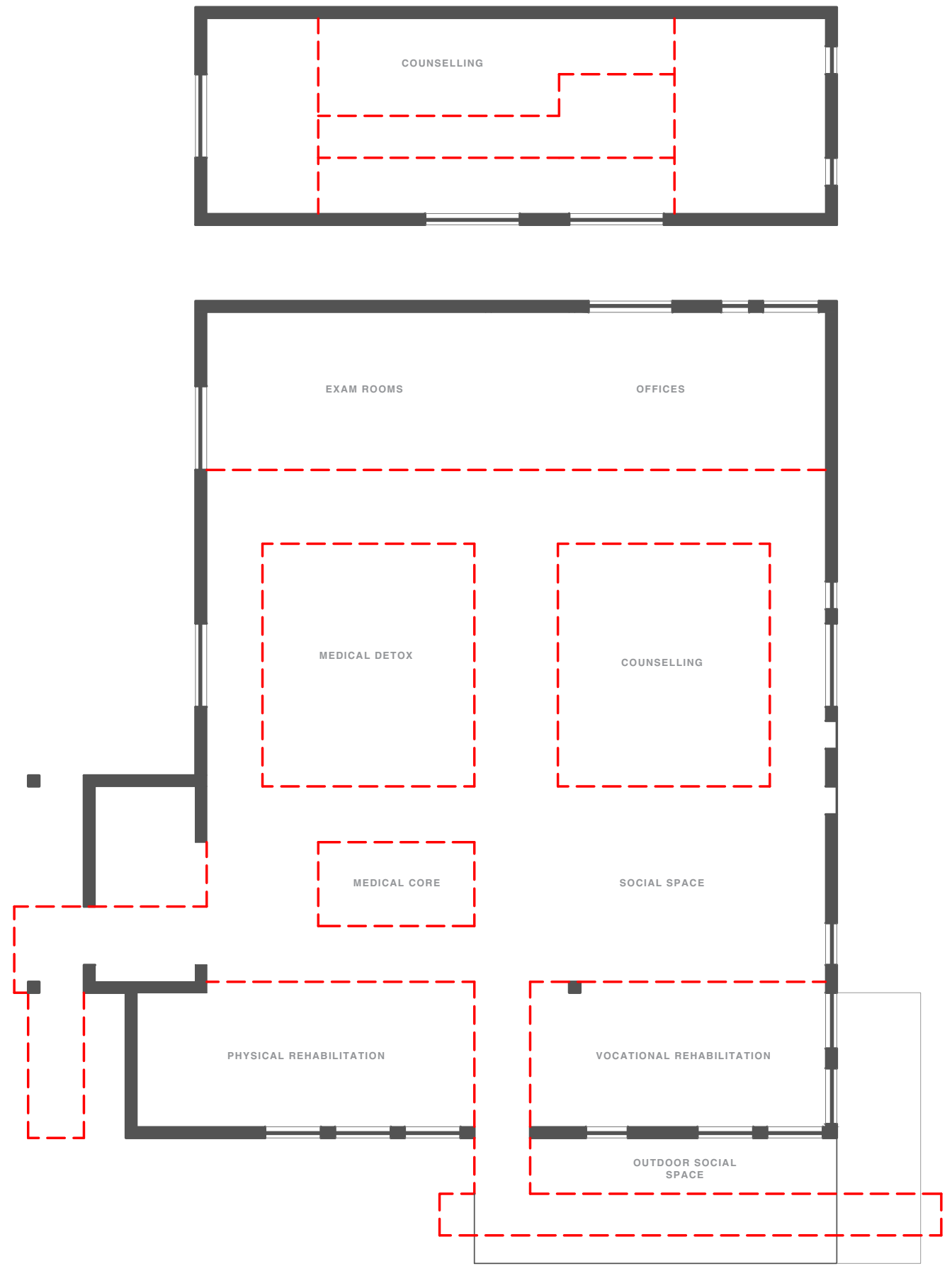

FIGURE 70 // DESIGN METHODOLOGY CIRCULATION COUNTRY CLUB 


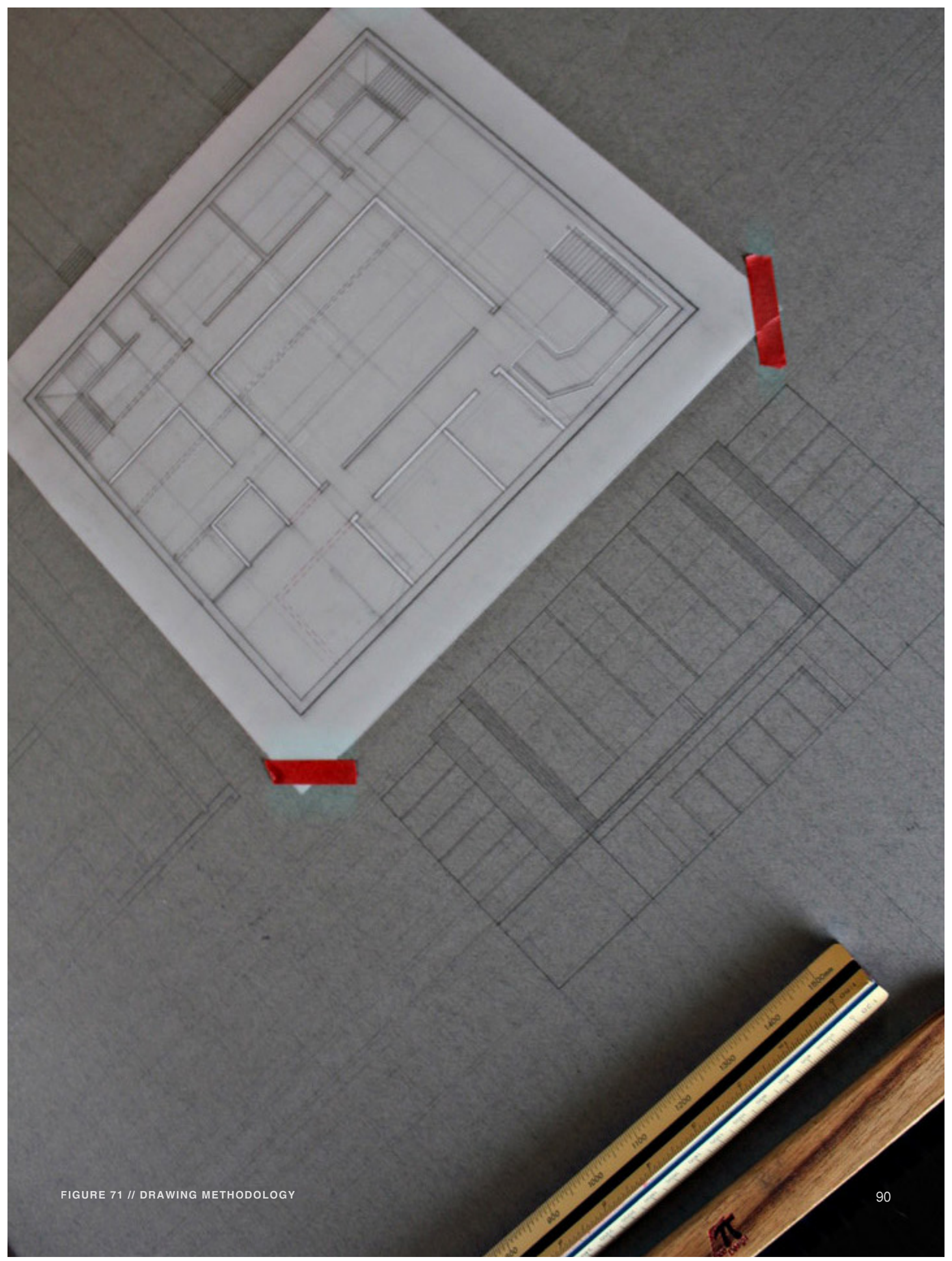




\section{DRAWING METHODOLOGY}

ASSESSMENT \& DETOXIFICATION

A similar methodology is being applied to the process of drawing. The intention is to treat the building the same way you would treat the body. The drawing becomes the anatomy of the building, a composition of skins and layers.

I have drawn each building by hand as a part of the assessment of existing conditions. Drawing by hand allowed me to personally and physically engage with each building. Drawing each existing building deepened my understanding of its conditions, characteristics, requirements and no longer relevant components. What was deteriorating? What was salvageable? What needed to change in order to accommodate an intervention? What should be illustrated in the drawings to best understand these relationships?

Subsequently elements were removed and added as part of the detoxification process. Layers of red tape were added to existing buildings if they required additional building skin. The removal of elements, such as exterior and interior walls, doors and windows, are indicated with red dotted lines.

A loose, freehand design intervention discovered through the application of these methodologies has then been proposed for each building. Layers have been added and removed using different methods and mediums. Each mark on each drawing is meant to demonstrate process, risk, hesitation, failure, adaptability, and rehabilitation, all conditions a recovering addict may experience during recovery. 


\begin{tabular}{|c|c|c|c|}
\hline $\begin{array}{c}\text { assessment } \\
\text { method }\end{array}$ & $\begin{array}{l}\text { detoxification } \\
\text { method }\end{array}$ & $\begin{array}{l}\text { rehabilitation } \\
\text { method }\end{array}$ & $\begin{array}{c}\text { aftercare } \\
\text { method }\end{array}$ \\
\hline $\begin{array}{l}\text { what are the building conditions? } \\
\text { whati is deteriofiting? } \\
\text { what is salvagable? } \\
\text { what needs to change? }\end{array}$ & $\begin{array}{l}\text { remove toxic conditions } \\
\text { maintain good conditions } \\
\text { add layers }\end{array}$ & $\begin{array}{l}\text { design existing spaces } \\
\text { addition or removel of space } \\
\text { accommodate program }\end{array}$ & $\begin{array}{l}\text { human activity } \\
\text { show life in buiding }\end{array}$ \\
\hline & + & + & + \\
\hline$\underset{\text { medium }}{\text { assessment }}$ & $\begin{array}{l}\text { detoxification } \\
\text { medium }\end{array}$ & $\begin{array}{l}\text { rehabilitation } \\
\text { medium }\end{array}$ & $\begin{array}{l}\text { aftercare } \\
\text { medium }\end{array}$ \\
\hline $\begin{array}{l}\text { building anatomy } \\
\text { draw existing conditions as is }\end{array}$ & $\begin{array}{l}\text { draw + add new building materials } \\
\text { remove parts of drawing if need be }\end{array}$ & $\begin{array}{l}\text { draw phases of intervention } \\
\text { layer design interventions } \\
\text { erase edits }\end{array}$ & $\begin{array}{l}\text { vignettes of spaces } \\
\text { hybrid perspectives } \\
\text { building details }\end{array}$ \\
\hline
\end{tabular}




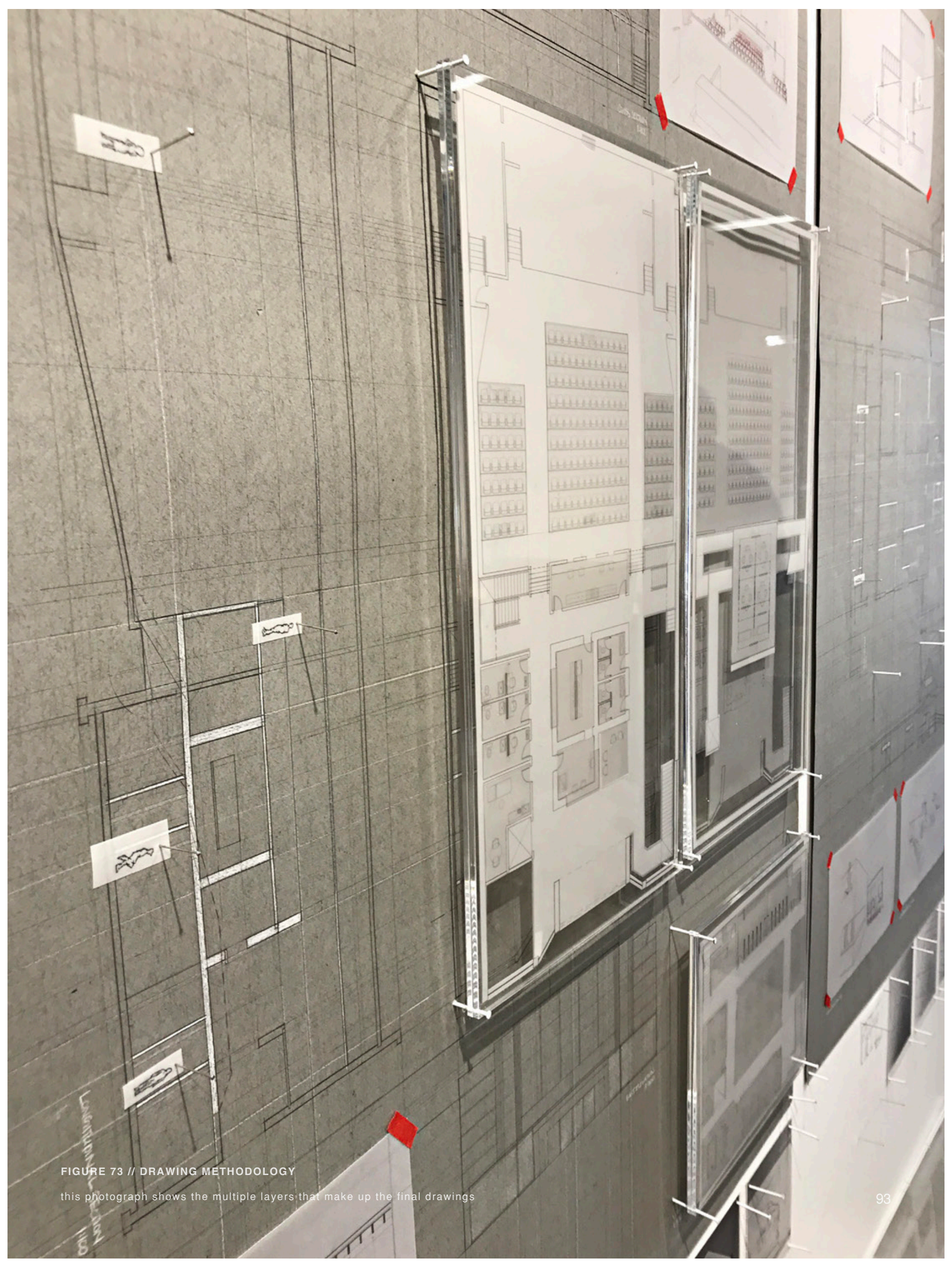




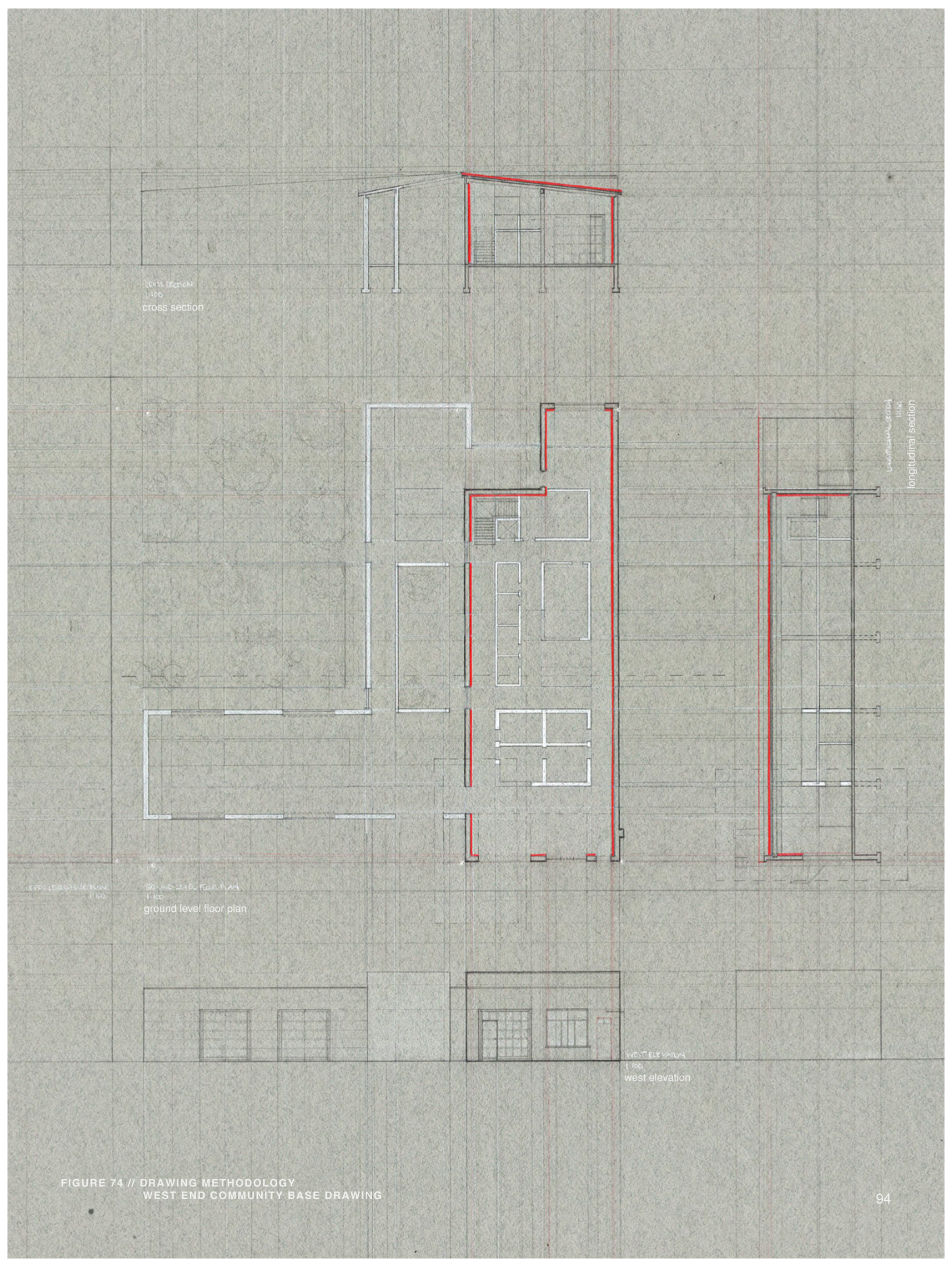



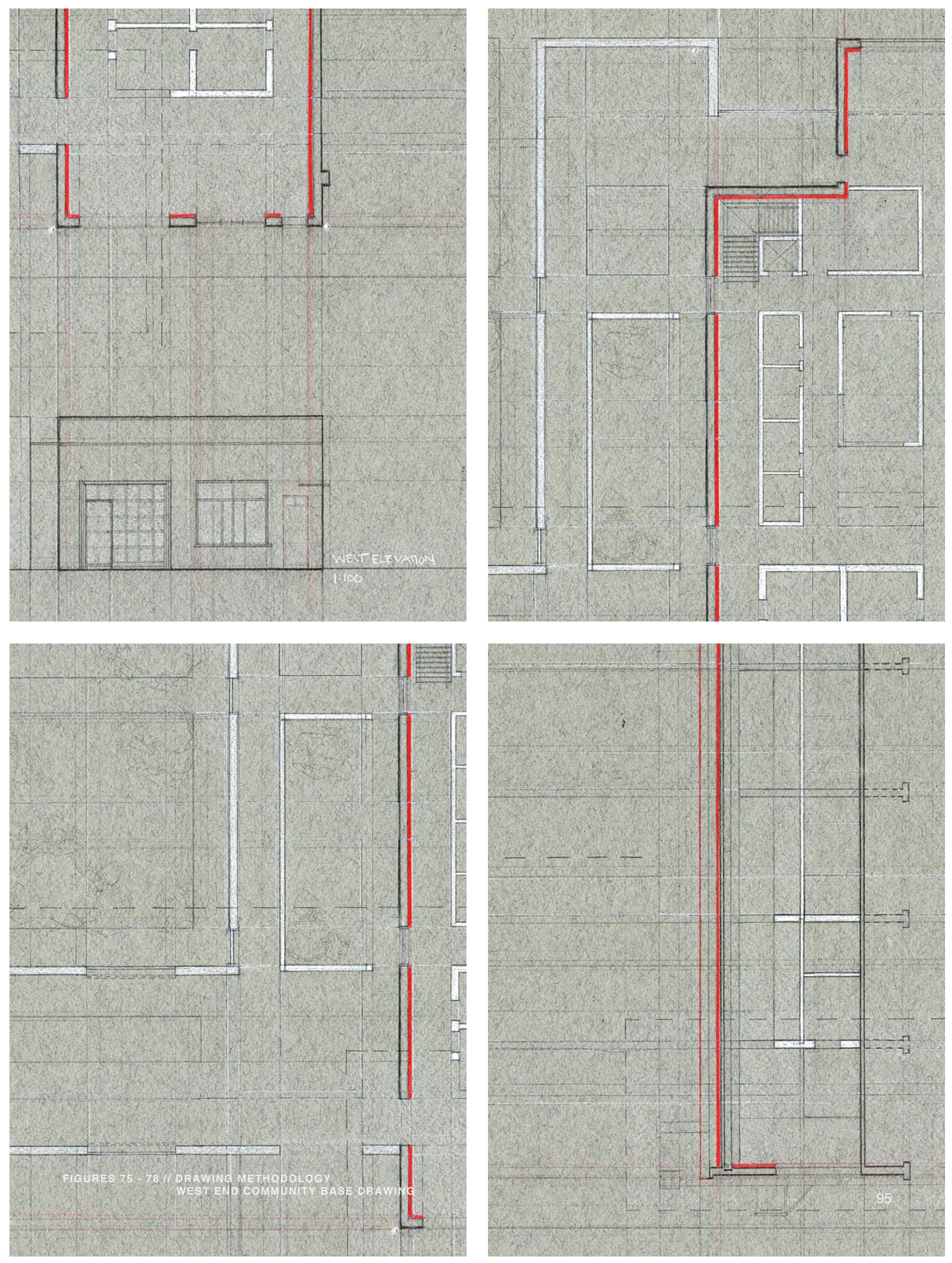

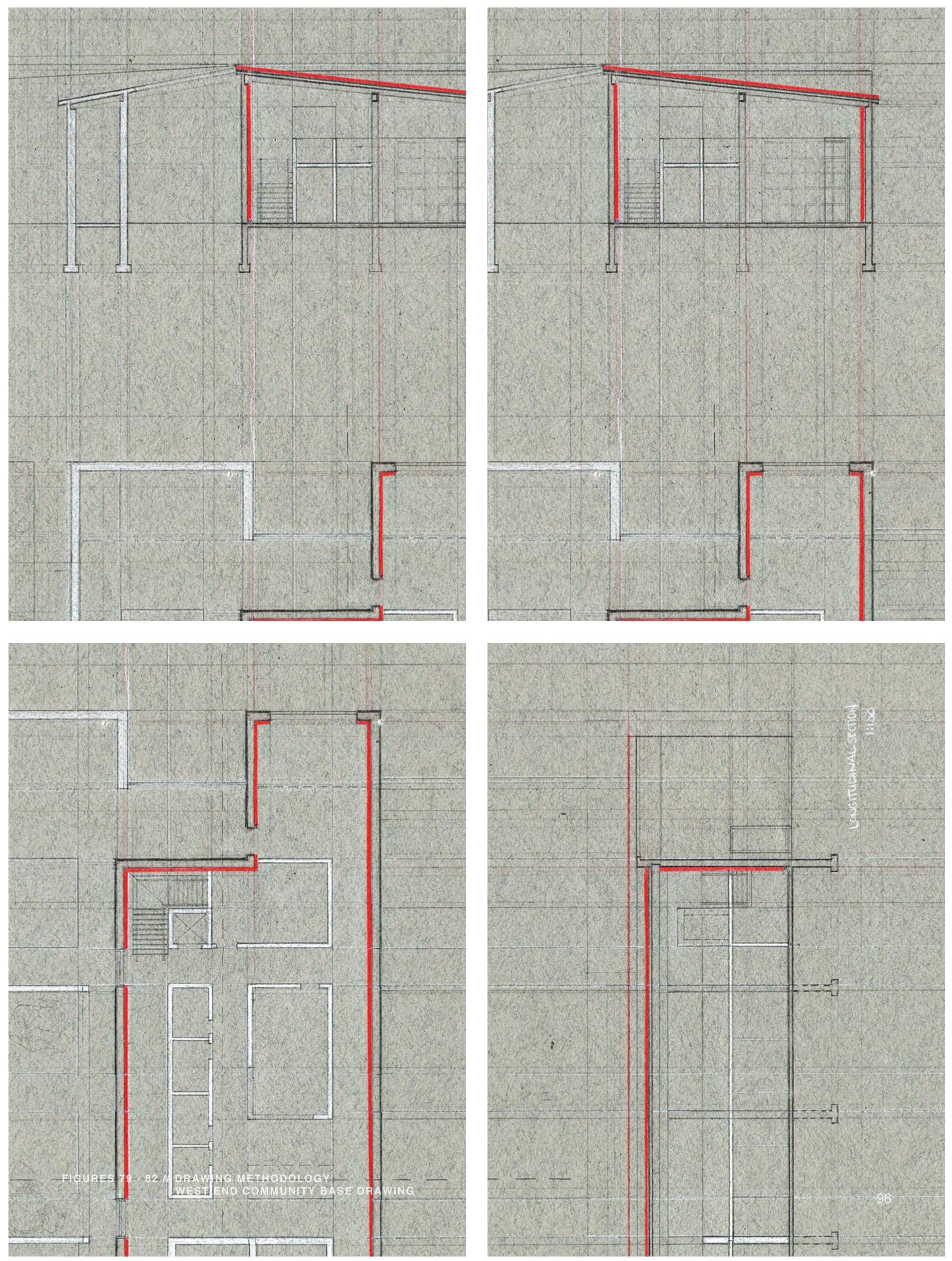

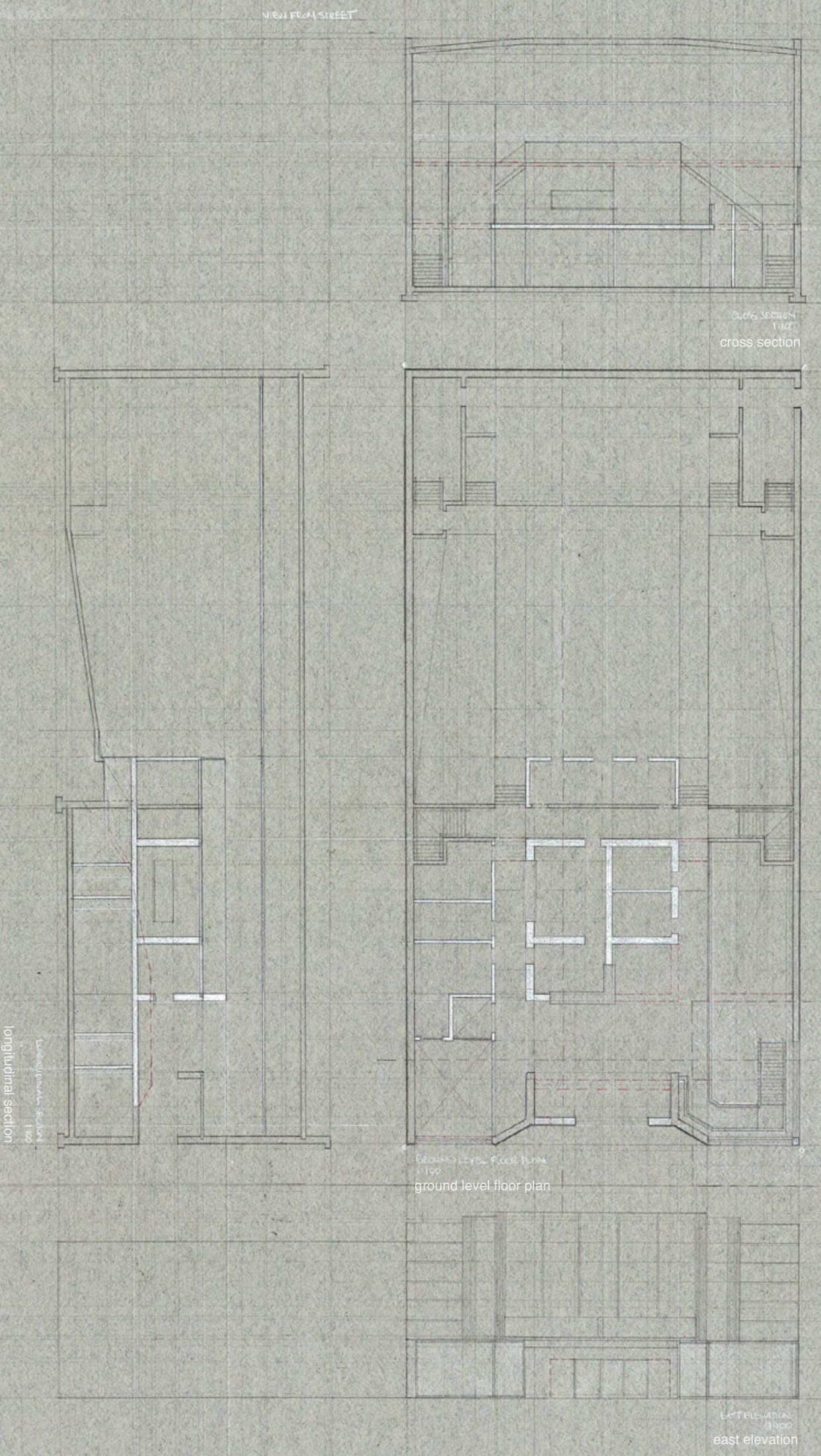

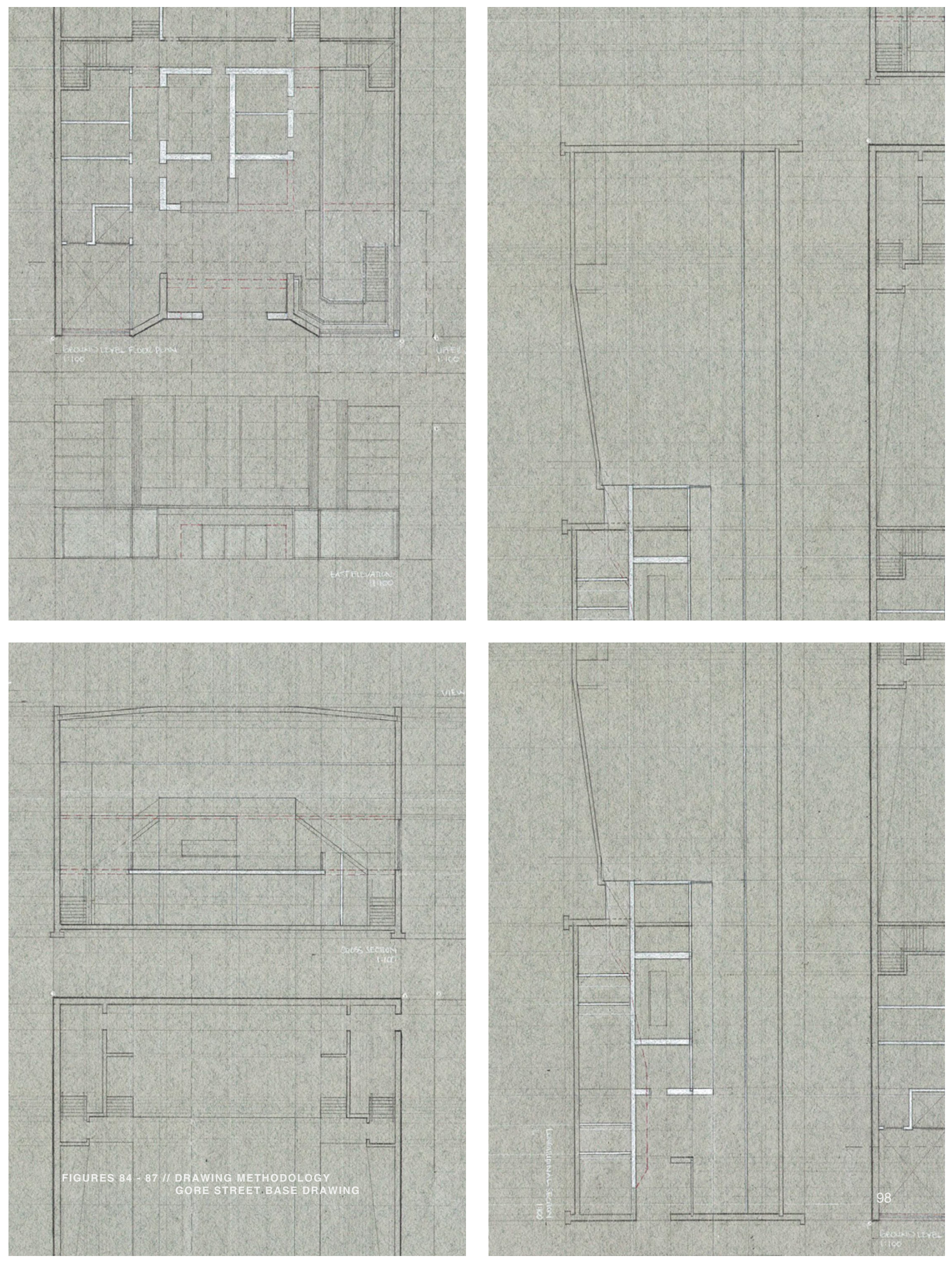

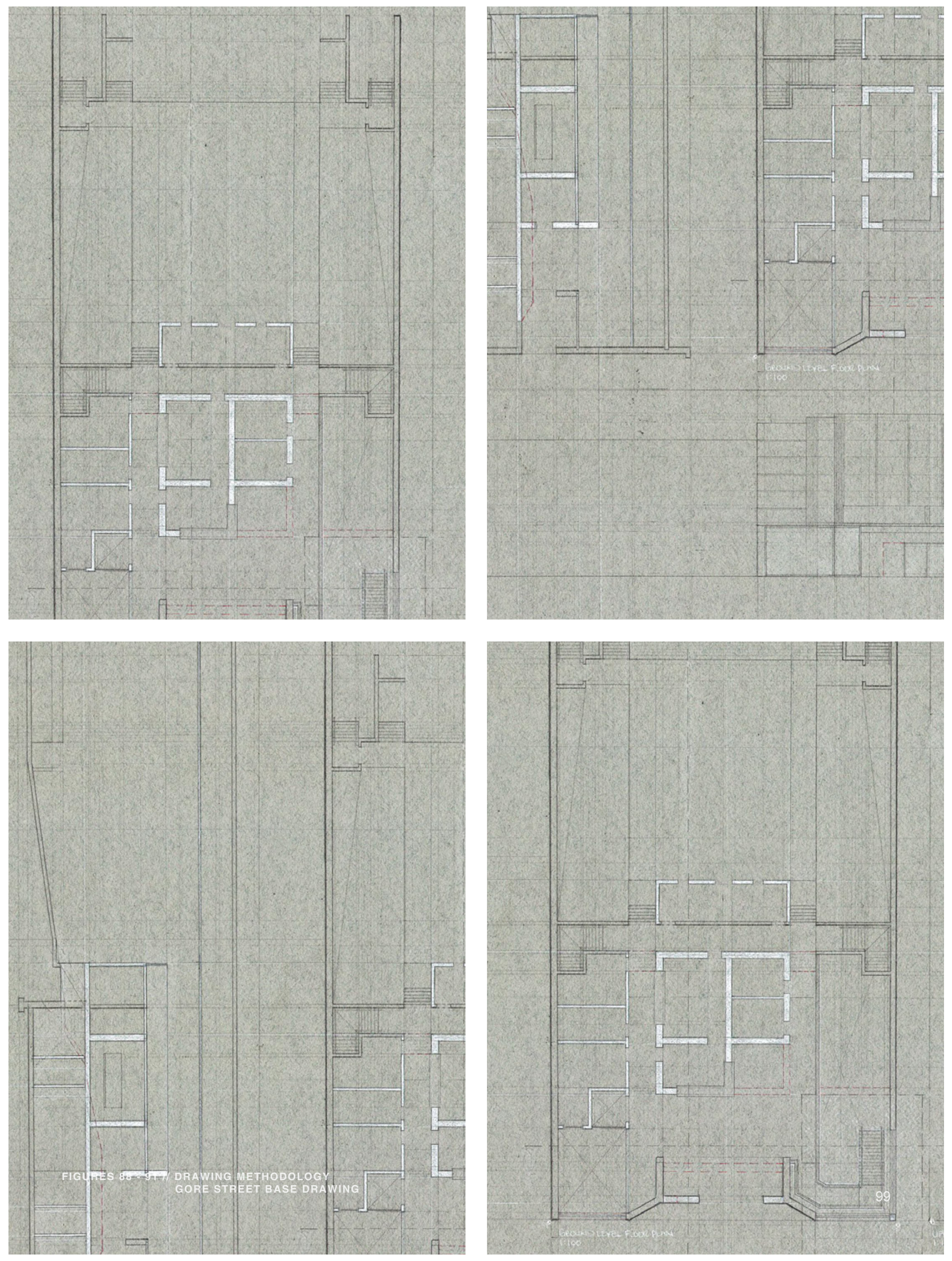


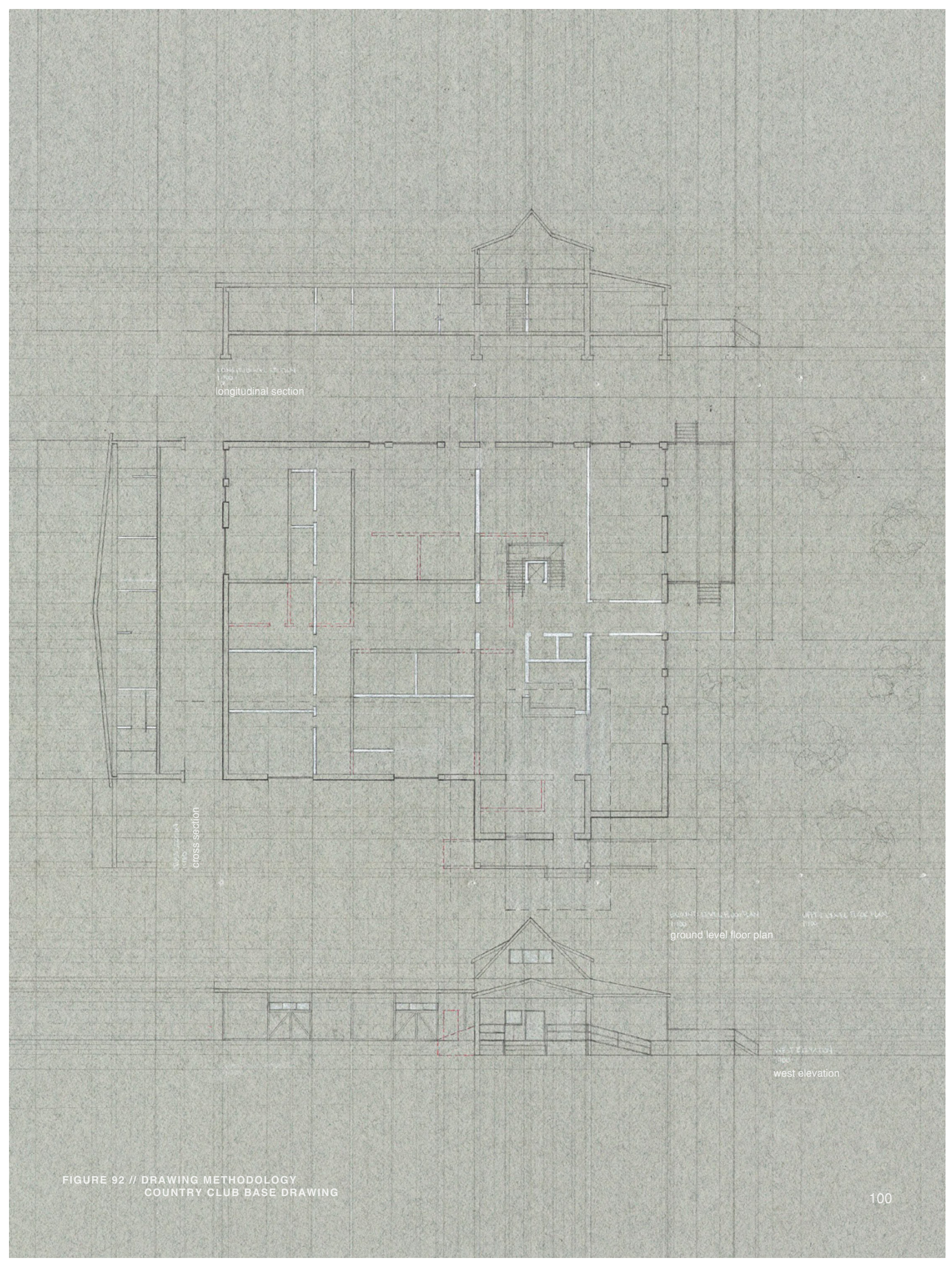



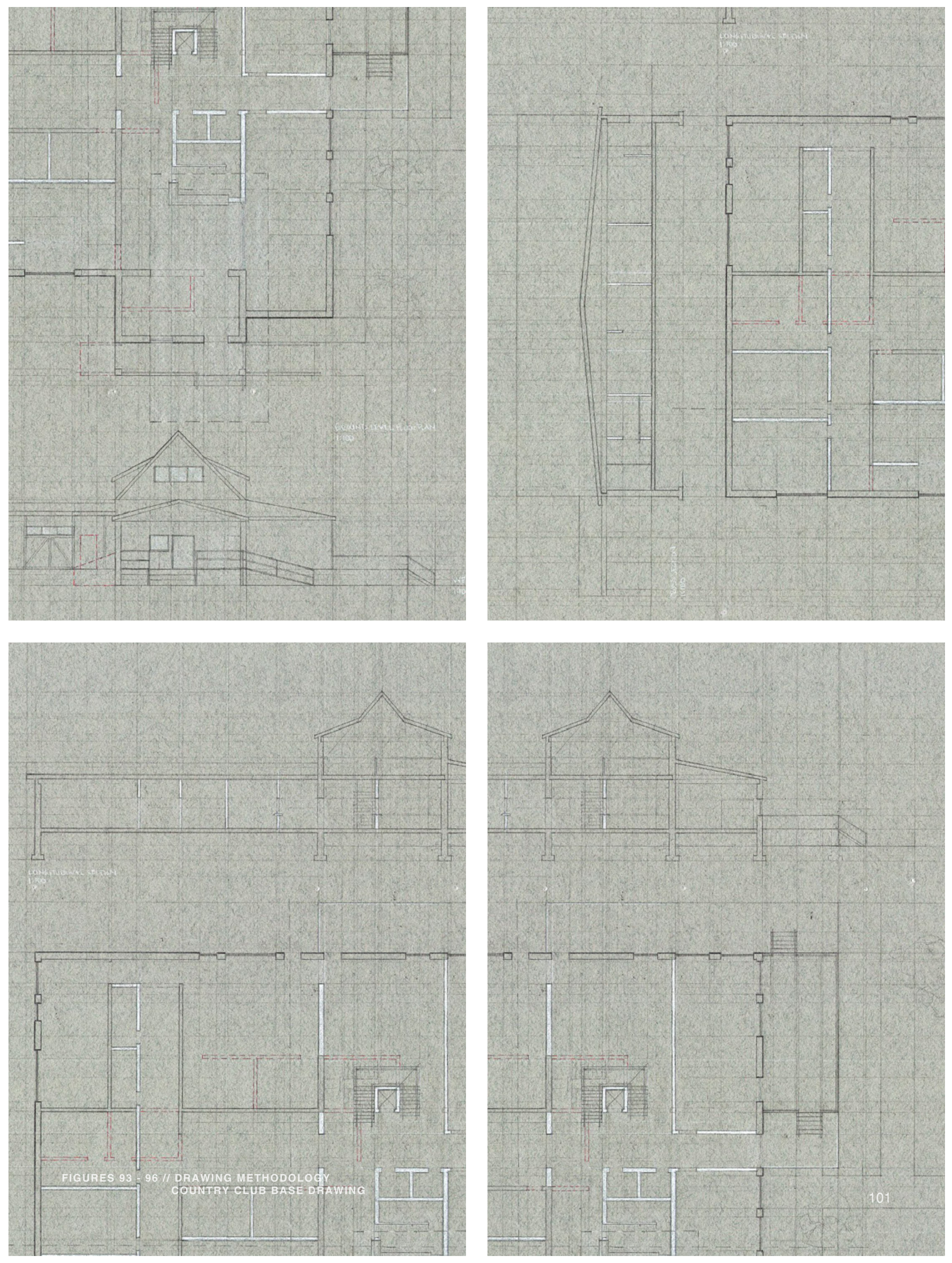

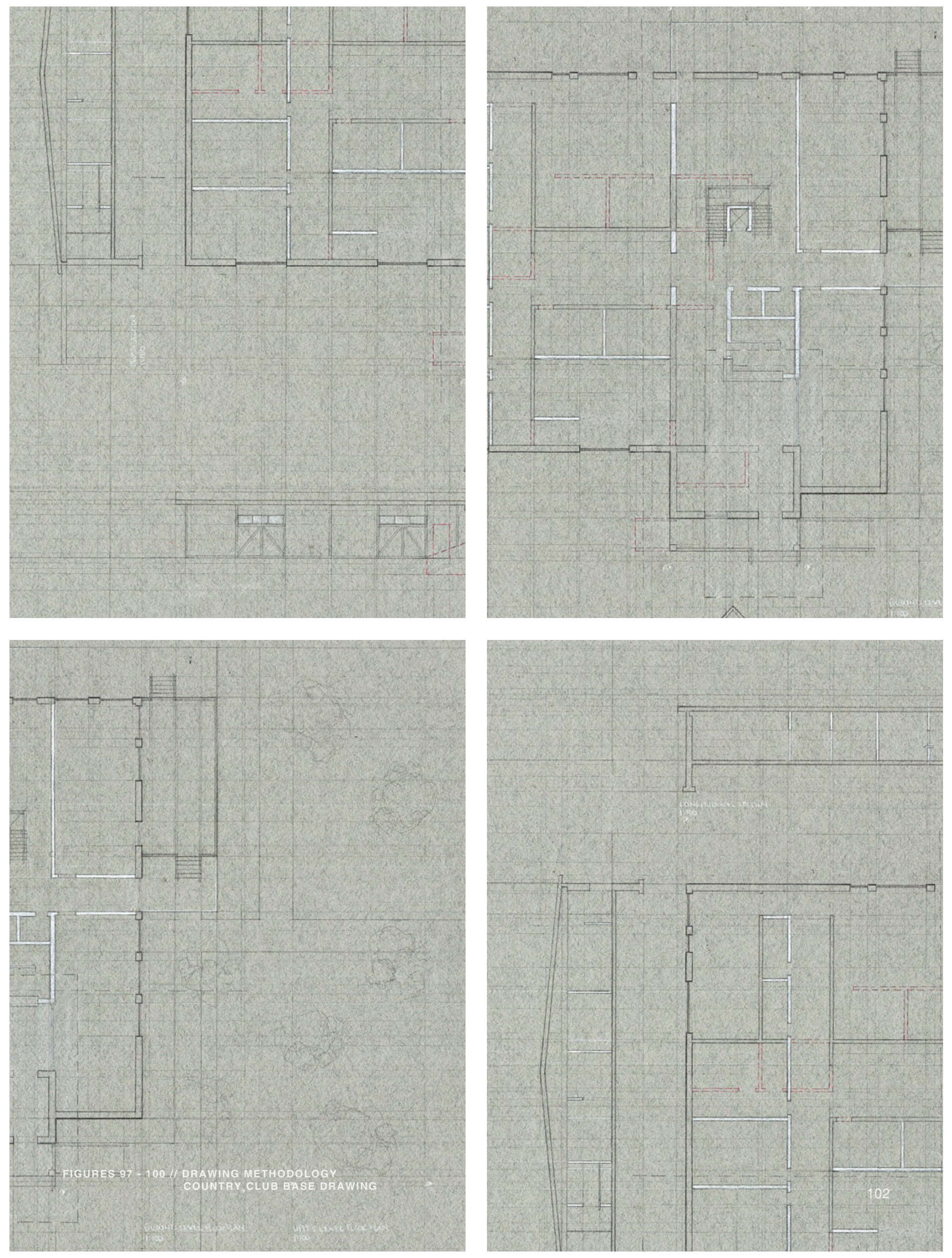


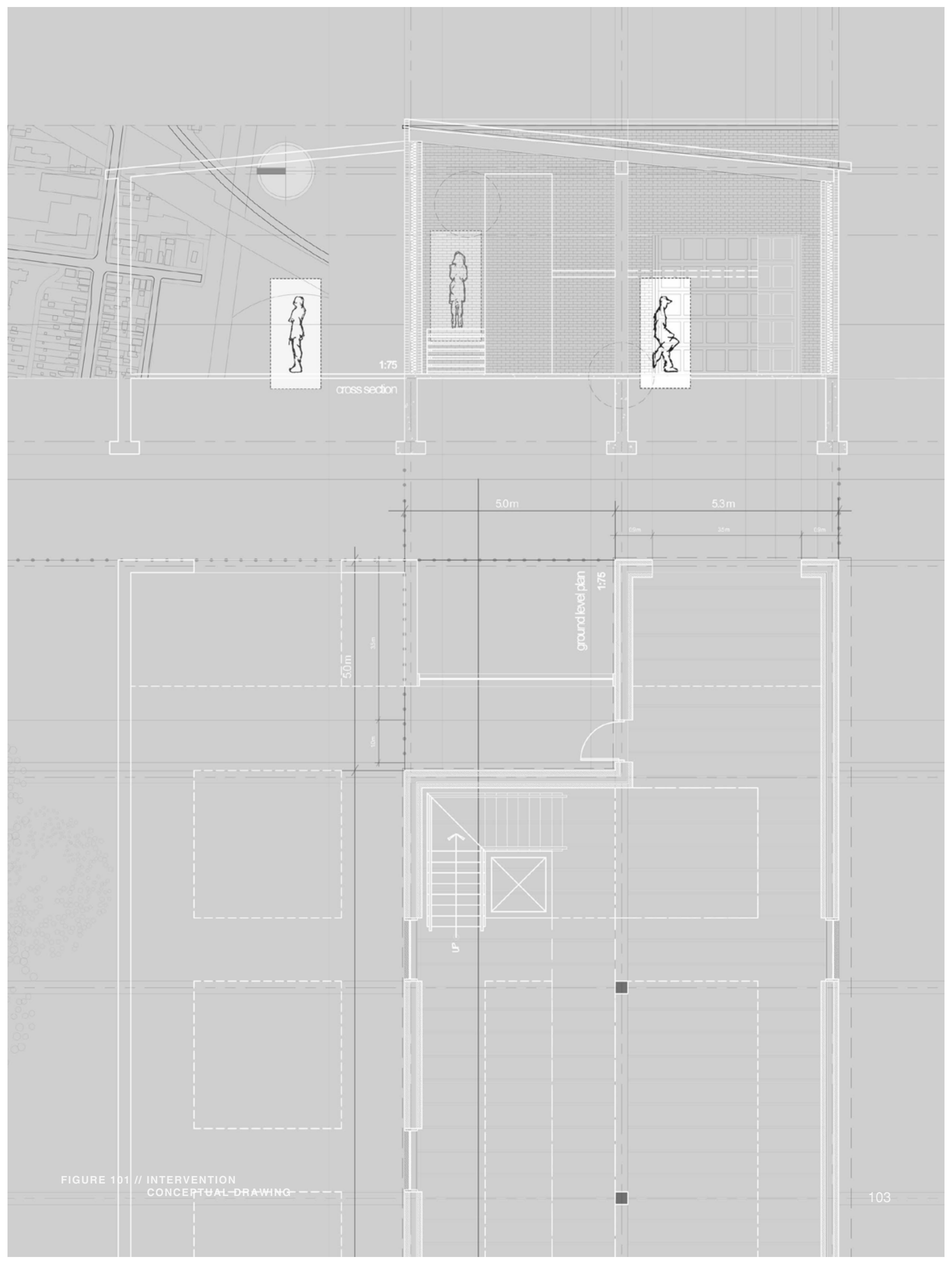




\section{INTERVENTION \\ REHABILITATION \& AFTERCARE}

What needs to be done to the existing buildings to allow them to function in their new capacities while acknowledging their histories and maintaining their essential characters?

All design interventions must be carefully thought out. How do you deal with the existing entrance in a way that acknowledges the original place of entry but is not intimidating to the visitor? How does the main door open? Is it solid or glass? What is it communicating? How does the interface between the clinic program and additional program work? How is this relationship inviting without being voyeuristic? What is the relationship between each part of the program and its surroundings? What kind of signage is there? Is there signage? What does the facade look like? How has it changed? What materials are being used?

Each intervention explores answers to these questions. Each entry should be made public but not too public. Visitors must know what they are entering without feeling intimidated. There should be a certain level of transparency through the entry doors that allows the people approaching to know what they are entering while also feeling welcome. The transparent entrance is meant to communicate "welcome in, we are open". There should be a certain level of layering of vertical space to create dialogue between programs. As a result of this, two storey spaces, catwalks and loft levels are created by removing existing floors. The core must be located at the entry of building as it represents a foundation and support to occupants. It is the building's backbone. There must be communication between public and front-line workers. The staff working within the core are the first people you see when entering to receive help. Upon entry there should be visual connections to vertical circulation cores making it clear that there is another level and that visitors are welcome. Moveable walls should be implemented that allow the user to create and shape space. Flexibility of space is important to those using it because conditions are always changing. It is important to create moments of pause. The relationship between the building and the occupant is about stillness as much as it is about movement. Whether it be physically, mental or emotional, moments of pause are important in the healing process.

Although designed with the same intentions, each building project is executed in a particular way that best suits the existing site, construction and location within the city. After careful assessment of each building through drawing, and planning following the rehabilitation design methodology, an architectural intervention has been proposed for each. There is a common architectural language that is carried through to each design, but the buildings remain unique. 


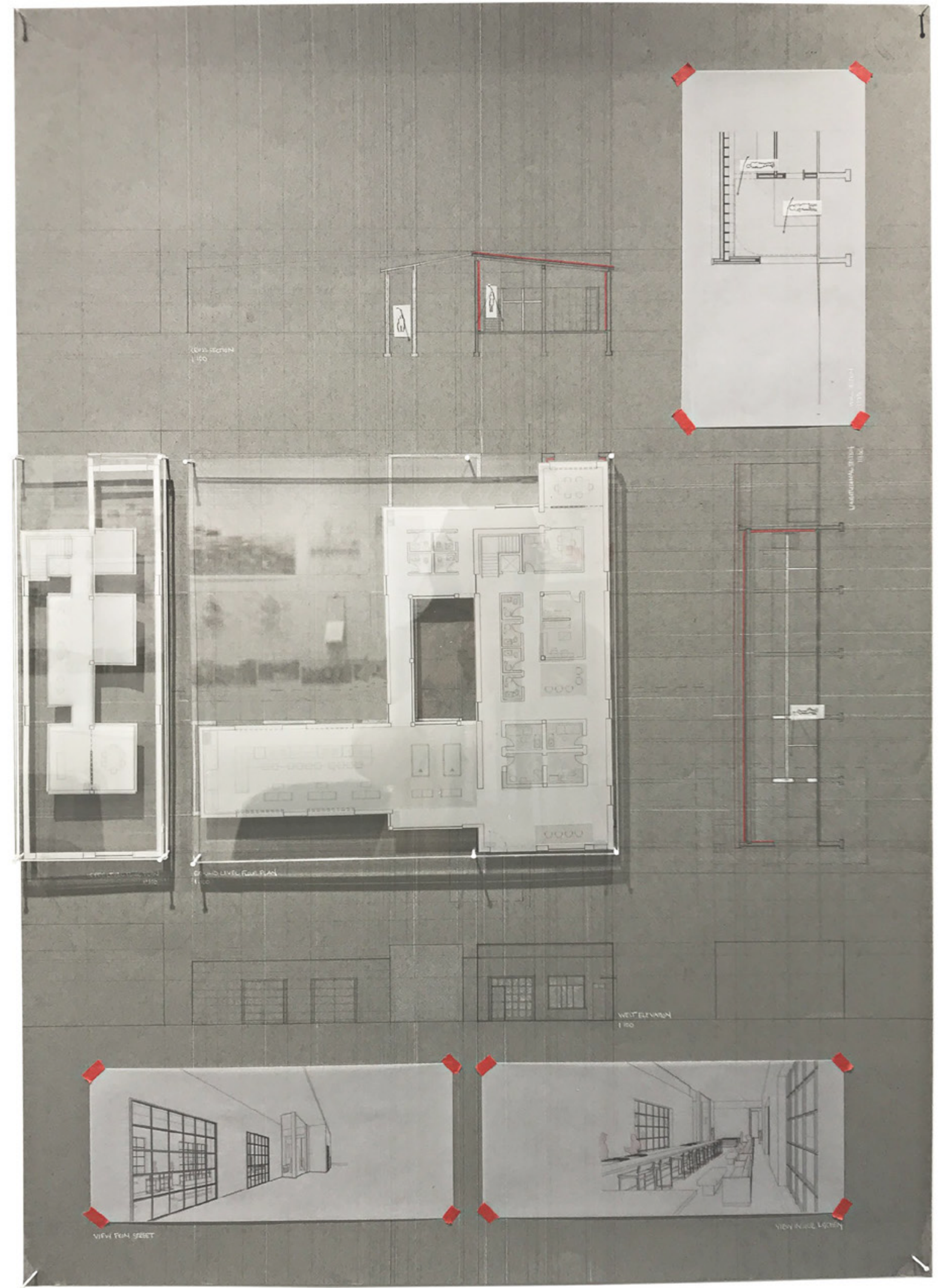




\section{west end community kitchen}

As you enter the West End Community plaza you are greeted by the building's new addition. The addition's facade is made of double height garage doors and finished in light cedar wood siding. The light cedar finish is meant to contrast the heaviness of the brick on the existing building, while also complementing its tones. The building's length hugs the street front and conceptually directs you to the main entry located at the existing building's garage door. When entering into the existing building you arrive in a two-storey space with views to the upper catwalk level, new addition and building core. The building core houses the medical admission. Upon entry you are given the choice to speak to a worker or enter into the new community kitchen. When greeted and admitted by the working staff you will enter into a corridor with views to the exterior covered courtyard and main stair leading up to the loft level. As you continue down the corridor you will be greeted by a common space that provides pharmacy resources, safe injection spaces and a sitting area. Just past that common space is a staff office. The staff office is designed for front-line workers to share and for recovering addicts to go to for help or questions. The loft level can be reached by stair or elevator. There you will experience the existing exposed structure of the building. The wood joists and natural light coming in from the existing garage doors and newly integrated double height windows provide warmth to the space. Upon entering you will be greeted by a sitting area that leads to a catwalk accessing the counselling spaces. There are two main counselling spaces with an additional seating area. Returning back to the main level you will find a social / team building space just past the office. Off of this space is a connection point into the new building addition.

An exterior courtyard has been created between the existing building and new addition. The courtyard is partially covered to allow protection but let in natural light. It sits between an existing wall and corridor leading you to the community kitchen. Walking down the corridor to the community kitchen you will have views to the exterior garden that has been created between the two wings of the building addition. The community kitchen is a shared space. Closest to the existing building is a social space that provides seating and recreational games for its occupants. The space next to that is an open concept kitchen and dining area aimed to encourage teaching and learning of the culinary arts. It is meant to strengthen communication and make the learning process inclusive to everyone utilizing the building. This space is decorated with new garage doors similar to the existing. These doors are intended to open up during the summer months and create visual connections between the street front, interior kitchen and garden. 
FIGURES 103 \& 104 // SPATIAL SKETCHES WEST END COMMUNITY KITCHEN
FIGURES $105 \& 106 / /$ SECTION SKETCHES WEST END COMMUNITY KITCHEN

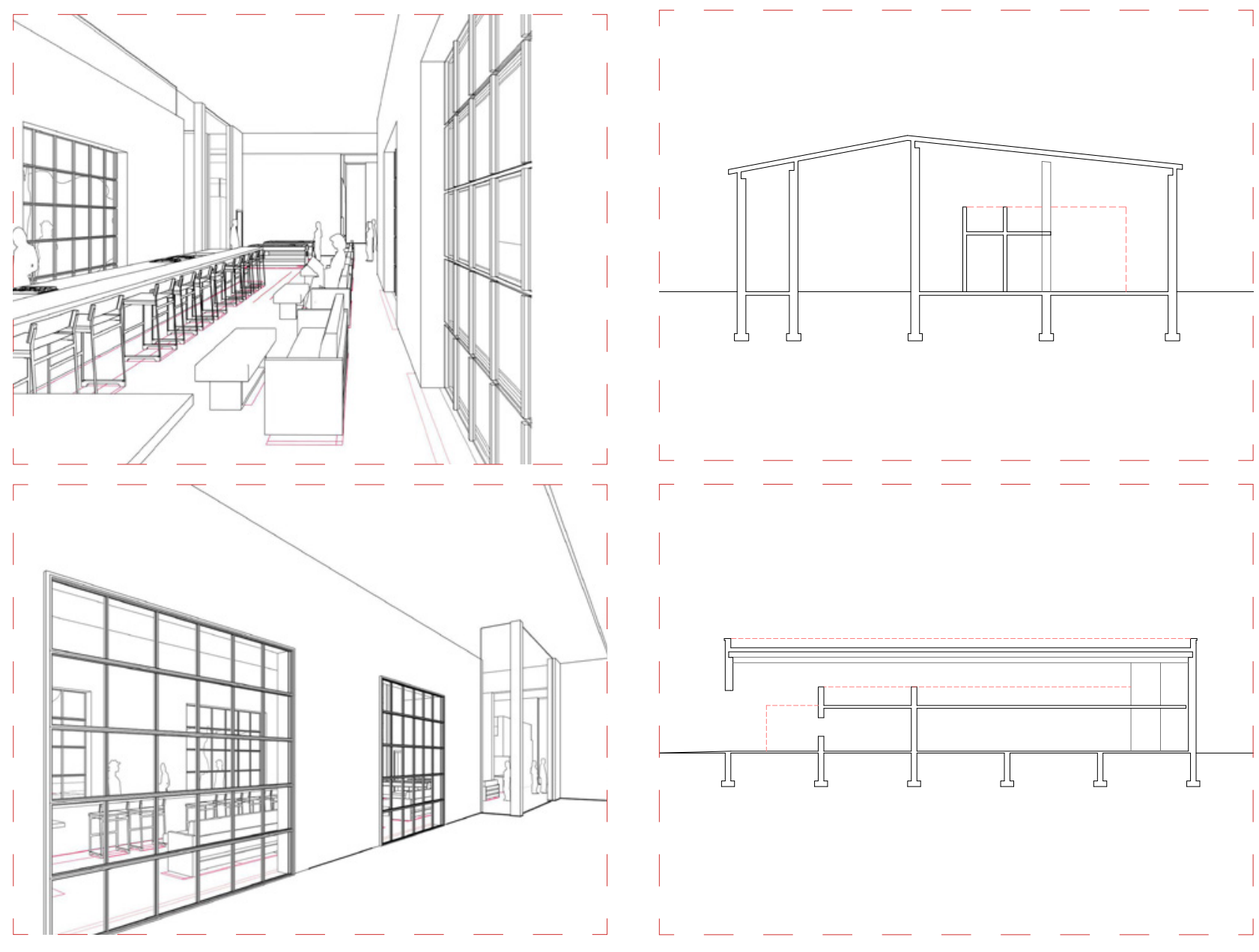

FIGURE 107 // WALL SECTION

WEST END COMMUNITY KITCHEN

The relationship between the community kitchen and adjacent plaza is very important within this design. It is important for those arriving to feel encouraged to approach and enter the facility. This is addressed by creating transparency at the entry.

An upper level has been designed to allow the users to experience the building in a variety of ways. This vertical overlap of space(s) creates both public and private experiences for the occupants.

Throughout the drawings, the users are strategically placed in spaces where they have the choice to be a part of social atmos pheres but also private and self contained.

The drawings exclude exterior doors to conceptually represent circulation between interior and exterior space.

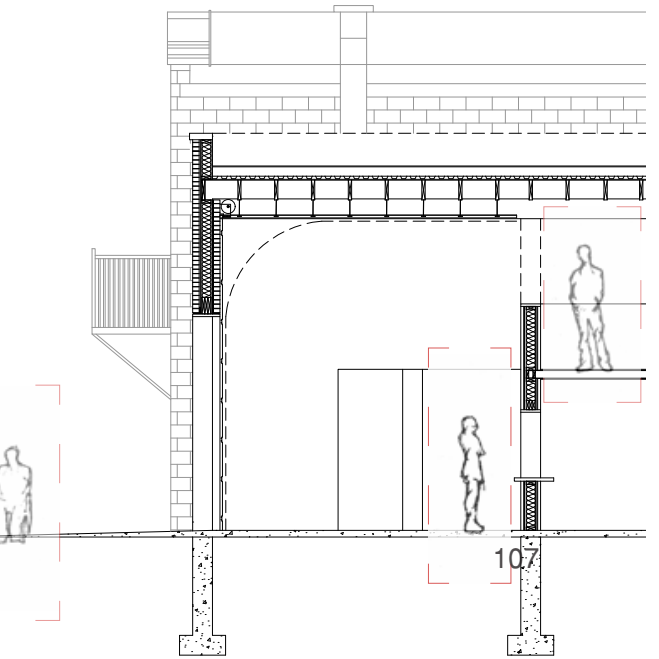




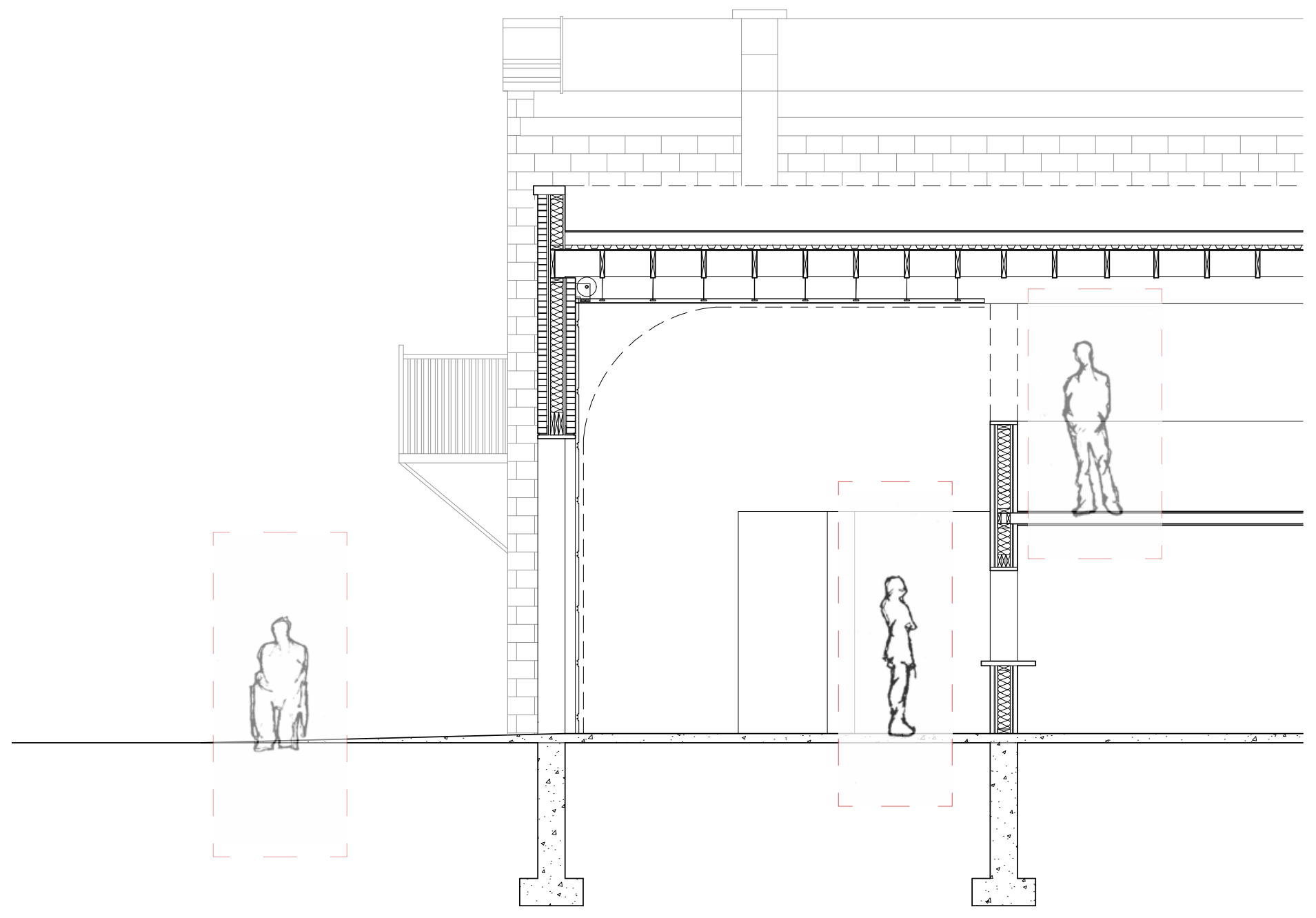




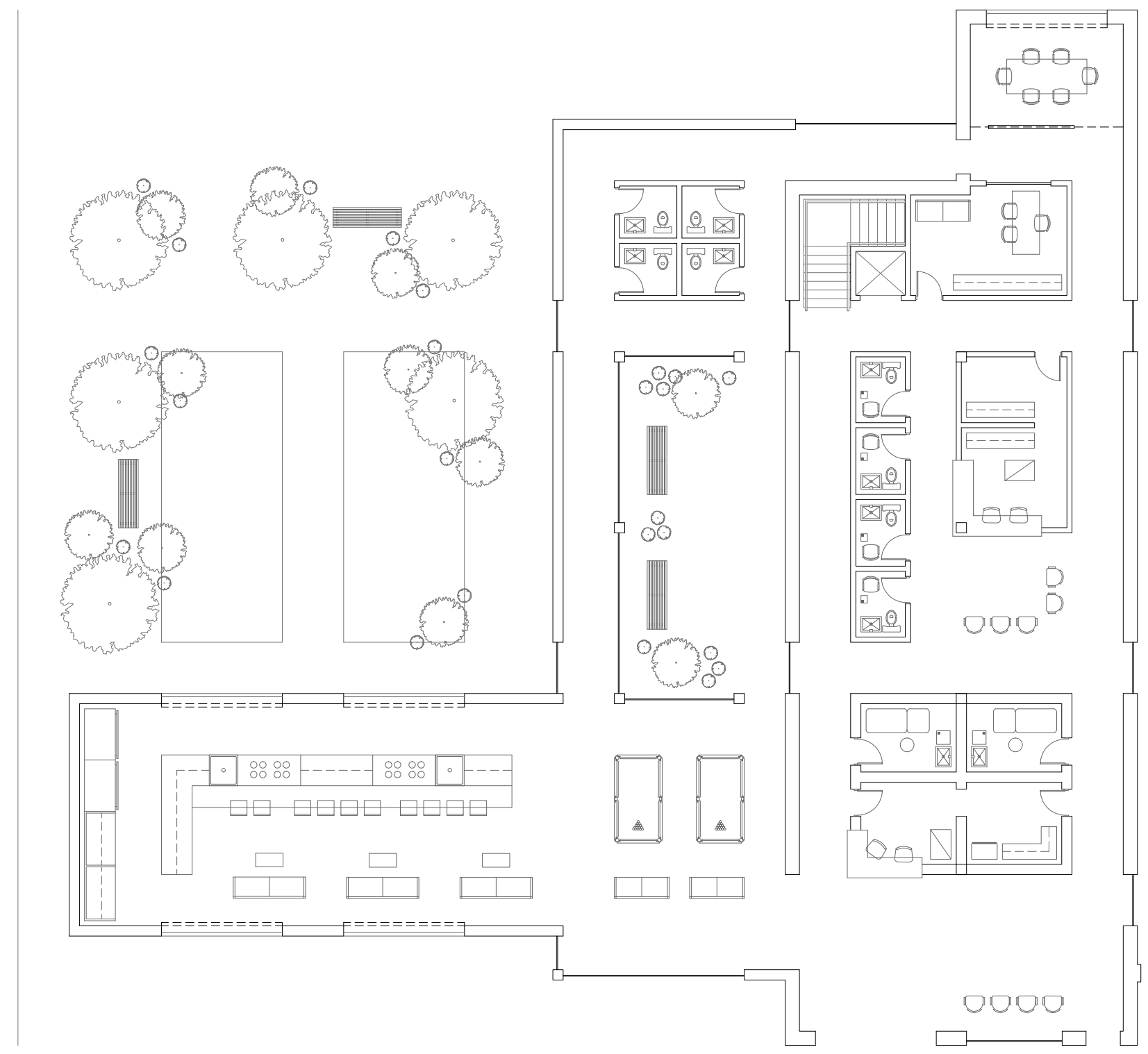




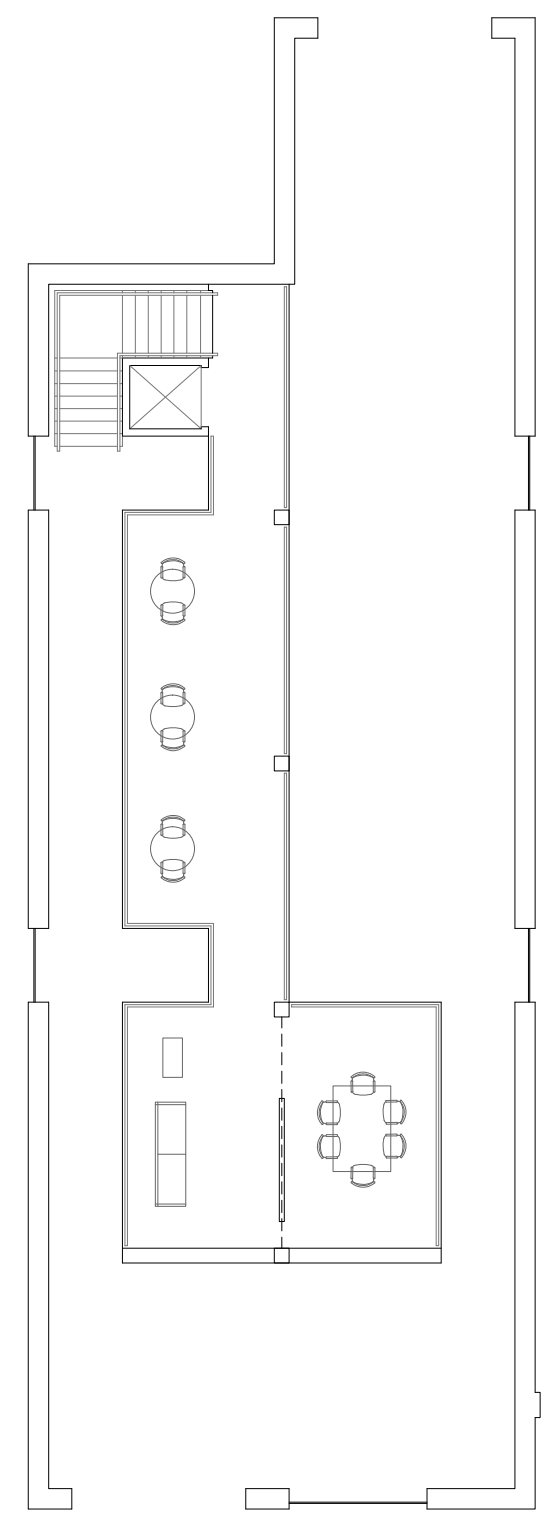

FIGURE 110 // FLOOR PLANS : UPPER LEVEL 


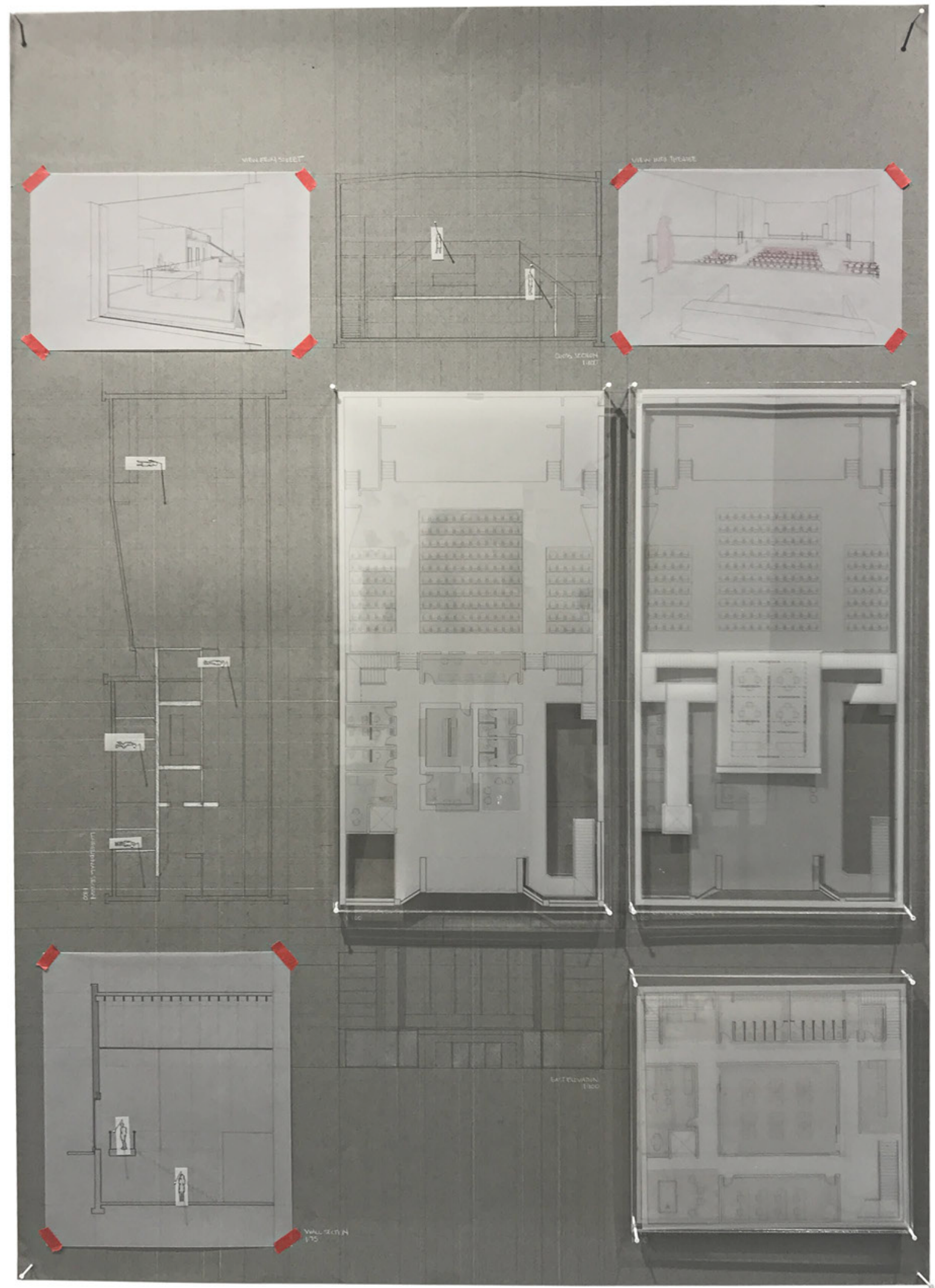




\section{gore street theatre}

The size and style of the Princess Theatre makes it an iconic symbol of the Gore Street street-fronts. The building remains identifiable but efforts have been made to make it more welcoming. Visitors arrive at the main entry on the East side and are greeted by four glass doors and curtain wall that frames the building's two front corners. The original doors have been changed to glass to reinforce the concept of transparency between program (inside) and community (outside). Upon entering one will find that the entry of the original building has been reconfigured. What was once an empty entry hall is now a three-storey space that houses the functional medical program and offers visual cues to the building's alternate spaces. Upon entry you will arrive at the building's core and main waiting area which sits between two atrium spaces. It is located at the front centre of the building to act as a division between the entry, theatre space and additional program, much like Gore street does for the rest of the city. The core holds everything together. At this location, all of the medical detox program is located within and just off of the core. If circulating on the North corridor you will find a prominent staircase within a double height space leading to the lower level, and washrooms equipped with examination resources. Just past this is an entry point into the main theatre, a new stair leading to the upper level counselling loft, and an existing staircase leading to the lower level. If entering the South corridor of the building you will find the building's elevator next to a two-storey atrium, a counselling room, the pharmacy and safe injection spaces. Just past this is another entry into the main theatre and additional stairs leading to the upper and lower levels. The atrium's have been created on either side of the entry space to provide natural light to the lower level, layer space and create cues that emphasize the importance of the lower level. The prominent staircase has been designed to hug the interior of the North corner facade. The Northeast corner of the building has been changed to curtain wall intended to spark the curiosity of people in passing and suggest the importance of the lower level.

As you enter the lower level you are greeted by two storey social space. The wall that separates the social entrance space and the rest of the additional program beyond is a communal art wall. As you circulate through the East corridor you will find entry to the main workshop and classrooms. Just beyond that is another two storey social pocket that overlooks the social space. Next to the elevator is another counselling room and office which is created for front-line workers and educators to share. Just past this is access to one of the existing staircases leading up to the theatre. This sits next to a small seating area, storage and main washroom facilities. The second existing staircase sandwiches these washroom facilities. Taking this staircase brings you back onto the main level where you will enter the grand theatre space comprised of seating and a stage that runs the length of the West facade. 
FIGURES 112 \& 113 // SPATIAL SKETCHES GORE STREET THEATRE
FIGURES $114 \& 115 / /$ SECTION SKETCHES

GORE STREET THEATRE
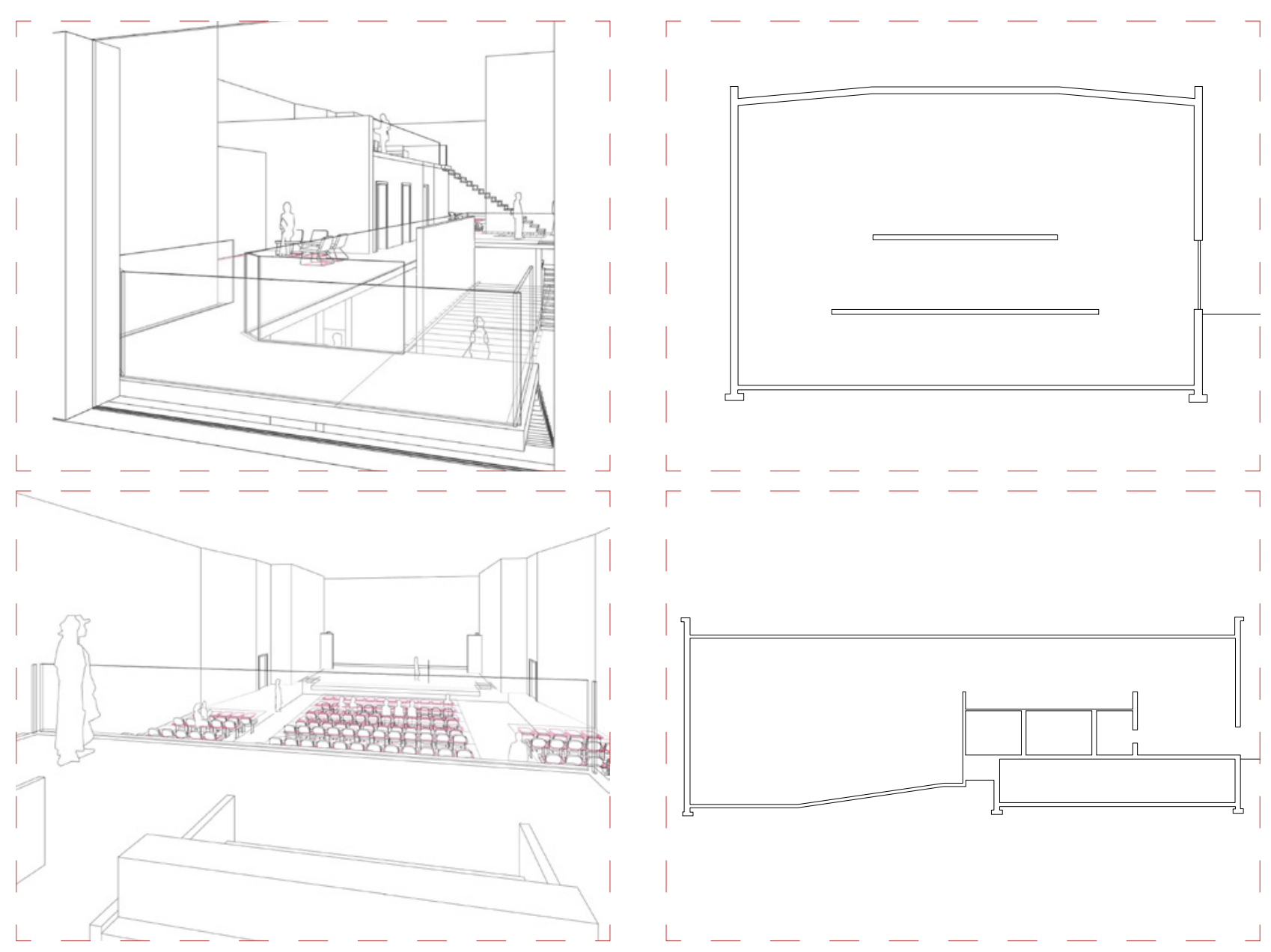

The Gore Street Theatre is designed in a way that creates curiosity for the users / occupants. Due to its location within the city, there must be levels of both transparency and opaqueness.

The wall section exposes a situation where people passing are able to experience the spaces within the building. The added transparent facade allows one to see into a space that connects 3 levels. Although one can see into the space, only a certain level of trans parency is revealed, giving subtle hints for one to circulate through the building to discover more.

Throughout the drawings, the users are strategically placed in spaces where they have the choice to be a part of social atmos pheres but also private and self contained.

The drawings exclude exterior doors to conceptually represent circulation between interior and extertor space.

FIGURE 116 // WALL SECTION

GORE STREET THEATRE

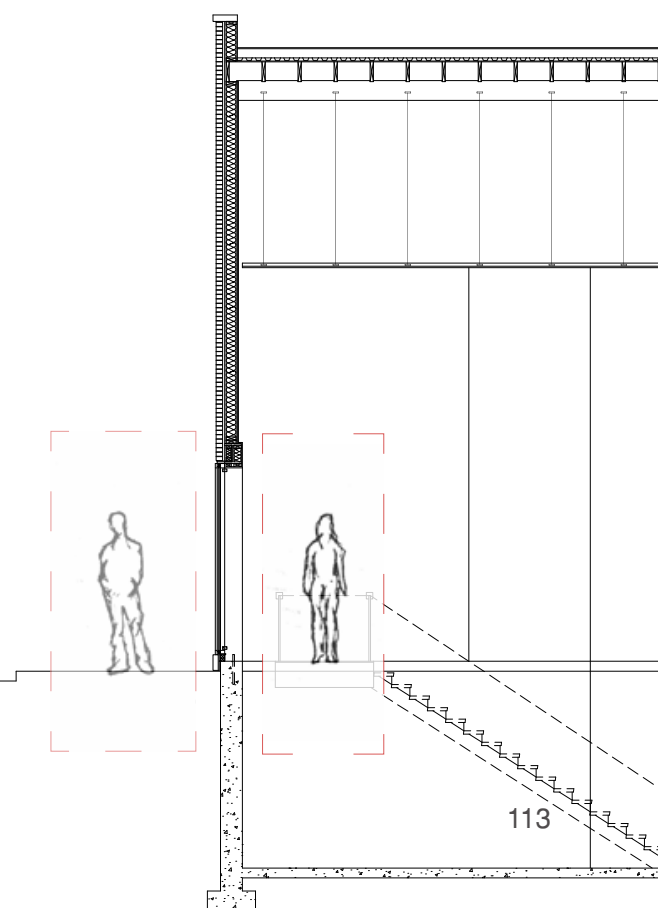




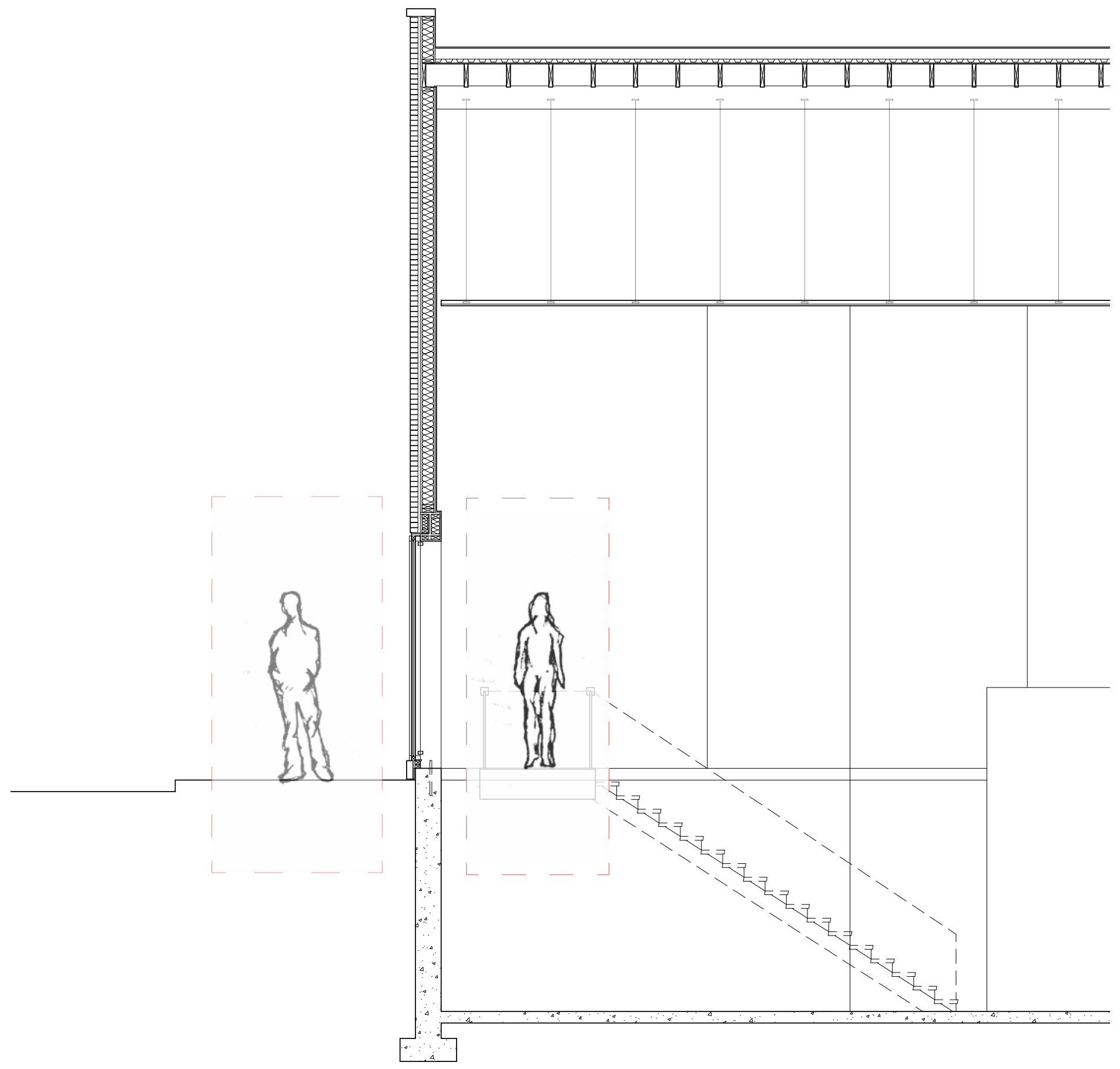




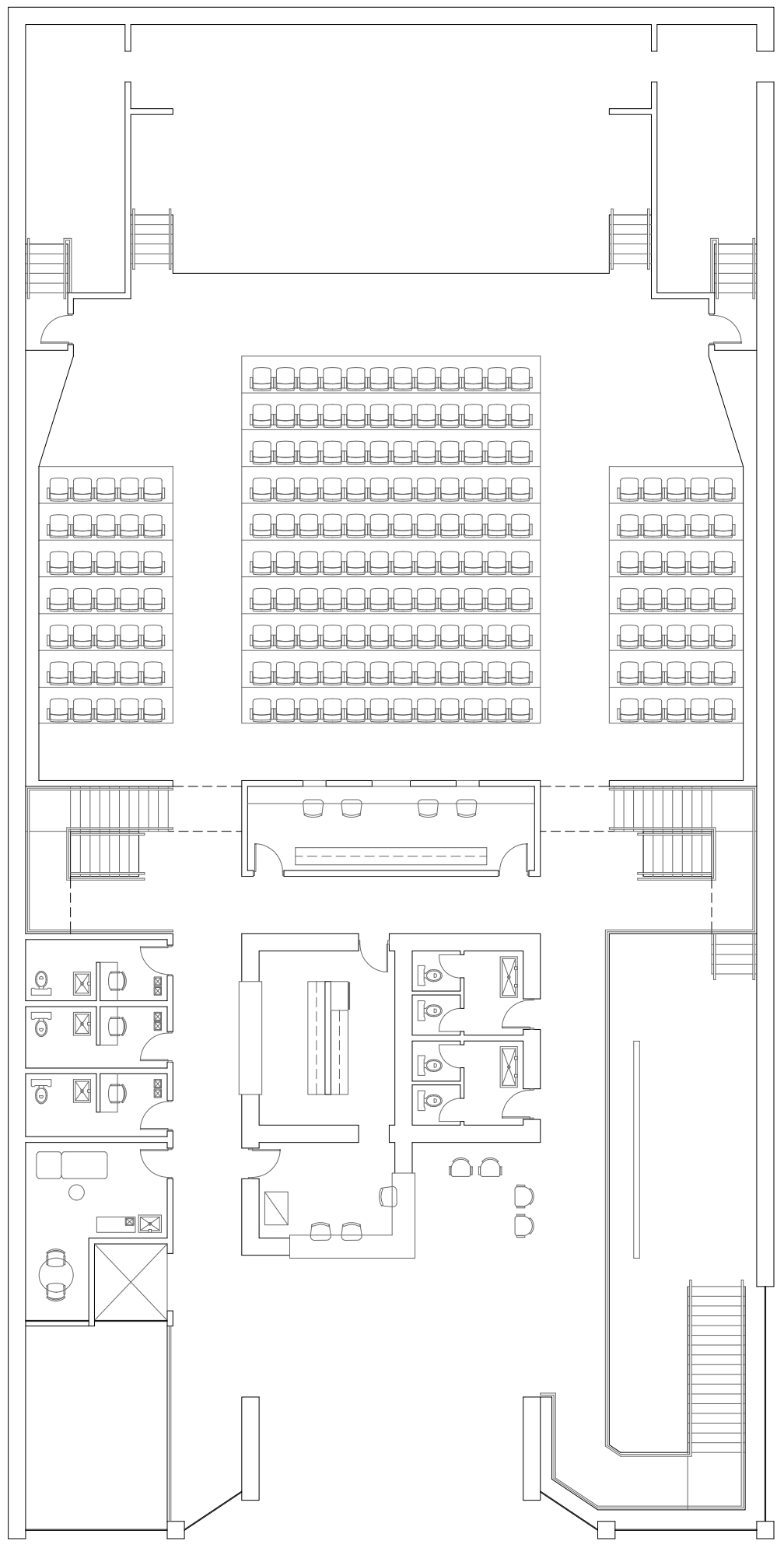




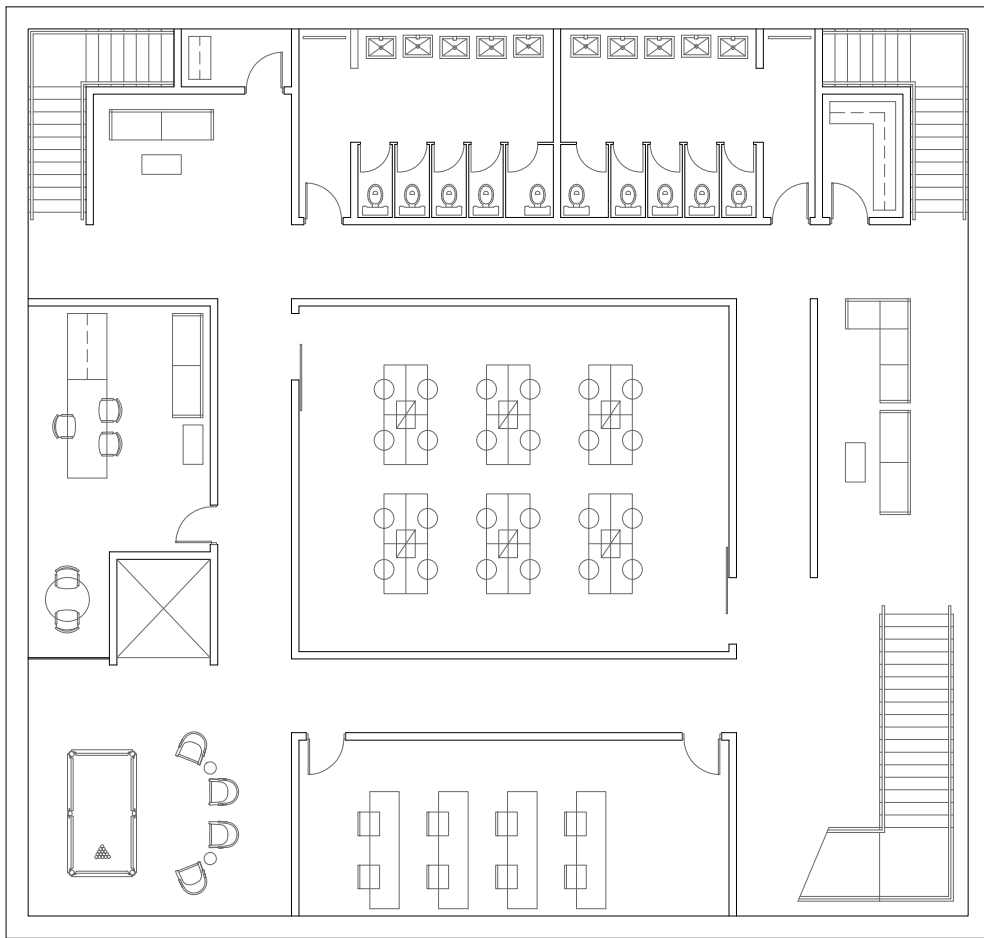




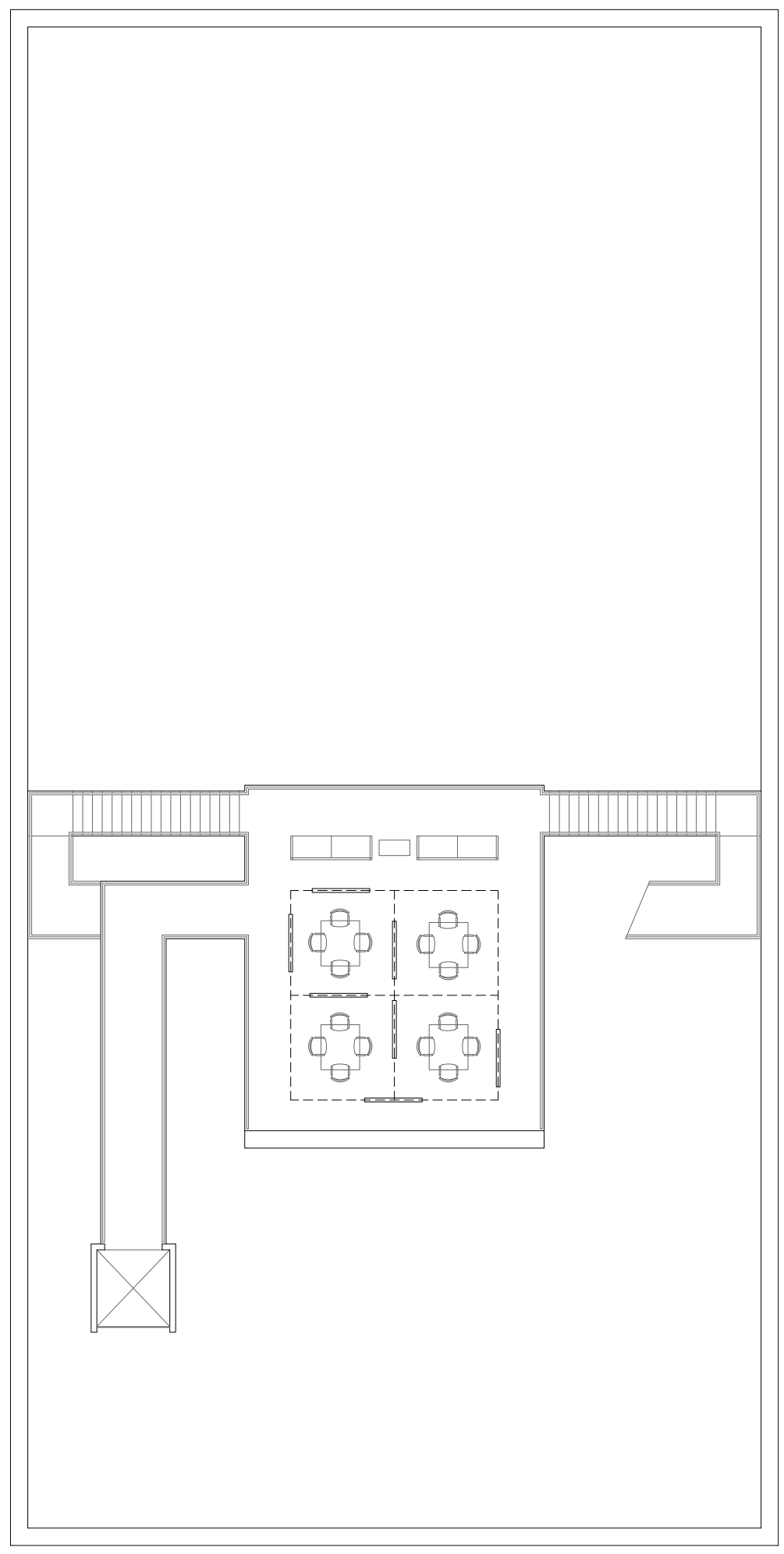

FIGURE 120 // FLOOR PLANS : UPPER LEVEL GORE STREET THEATRE 


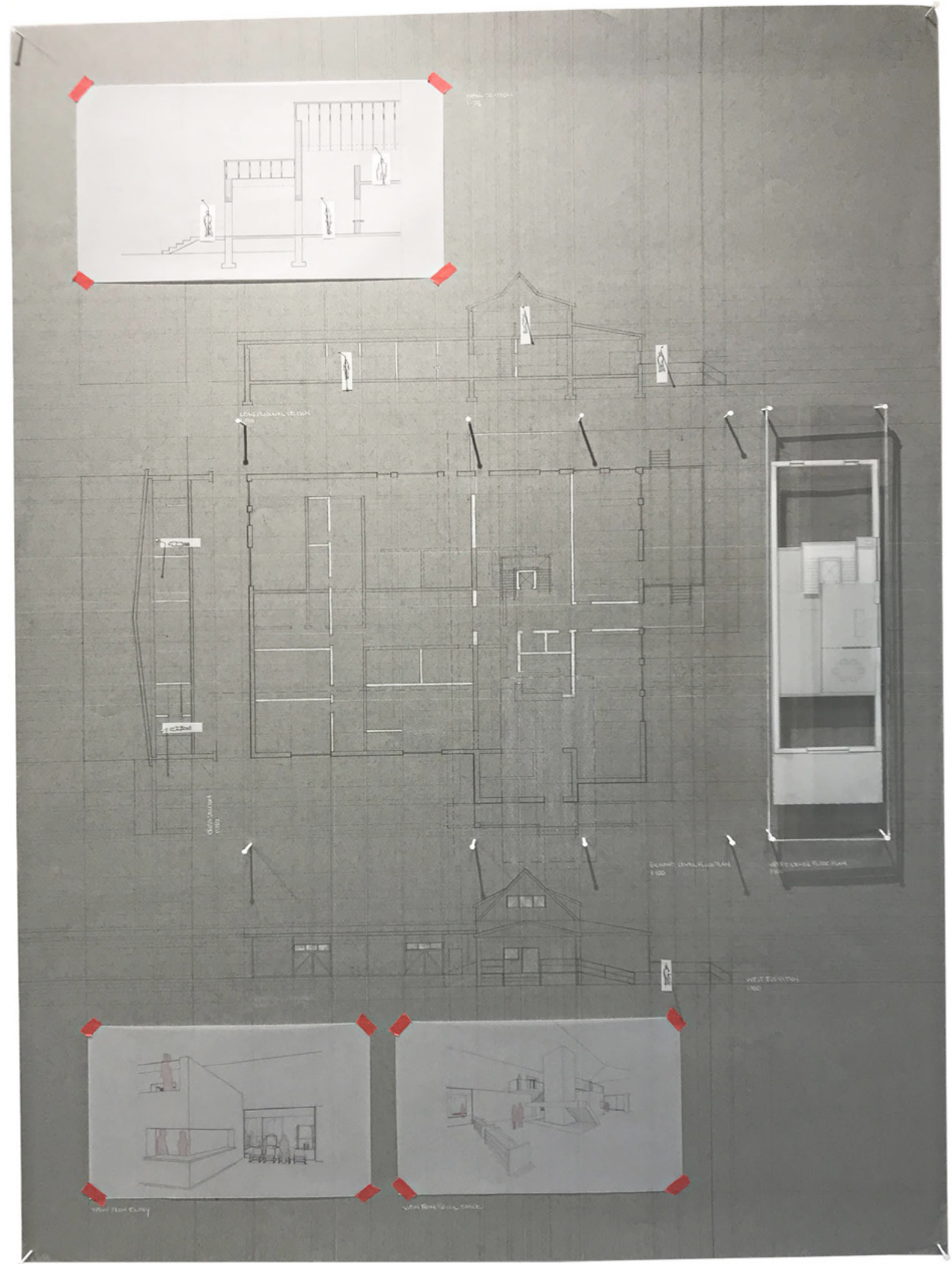

FIGURE 121 // FINAL DRAWING COMPOSITION

COUNTRY CLUB WELLNESS 


\section{country club wellness}

Entering the Country Club site you are greeted by an immense parcel of green space and the existing building. The original parking lot has been redesigned to a much smaller scale and to incorporate a landscape design that directs you to the buildings entrance. As you approach the building you will enter onto an existing porch that has new seating. The original doors have been replaced with glass doors to reiterate the concept of transparency. The entry of the building has been reconfigured from its original layout. Upon entry you will walk into a two-storey entrance space. Within this space is the main core, waiting and visual connections into the physical rehabilitation space, social spaces and the main stair and elevator. Entering into the corridor on the North will bring you to the medical detox program. First you will find the pharmacy and than make your way into a corridor that gives you access to medical examination rooms, change rooms equipped with washroom facilities, an office for front-line workers to share, a large counselling room and some additional storage. This corridor circulates back into the main entrance wing. Considering the size of the building, social pockets have been created between spaces. Between the medical detox and additional program you will find a two storey social space around the vertical circulation core. The additional physical rehabilitation program hugs the waterfront side of the building on the South. This is where you will find a physical and vocational rehabilitation space. Between the two is access to the existing exterior deck. The outdoor deck has been expanded to accommodate more exterior space overlooking the waterfront.

The main stair and elevator located in the centre of the social space brings you to the upper level where you will find more counselling services. Once you have entered the upper level you will find a large open counselling space that overlooks the entry and social space located on the lower level, as well as the waterfront. 
FIGURES $122 \& 123$ // SPATIAL SKETCHES COUNTRY CLUB WELLNESS
FIGURES 124 \& 125 // SECTION SKETCHES WEST END COMMUNITY KITCHEN

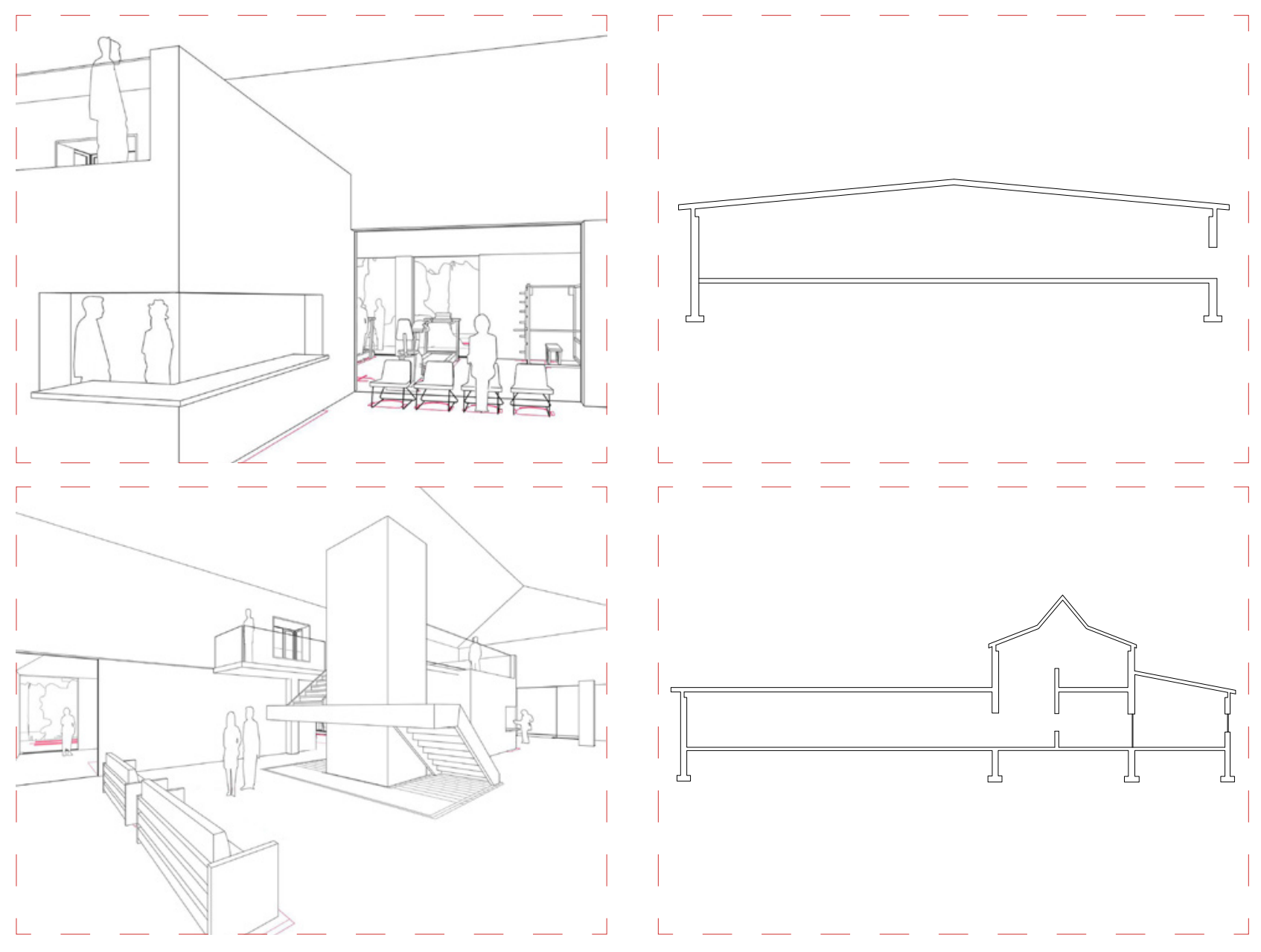

FIGURE 126 // WALL SECTION

COUNTRY CLUB WELLNESS

Located in a more private part of town. The Country Club Wellness facility must have an entry that feels warm and welcoming but also maintain a level of opaqueness. This is achieved by using transparent materials for the door while also creating a longer journey between the door and entry core.

An upper level has been designed to allow the users to experience the building in a variety of ways. This vertical overlap of space(s) creates both public and private experiences for the occupants.

Throughout the drawings, the users are strategically placed in spaces where they have the choice to be a part of social atmospheres but also private and self contained.

The drawings exclude exterior doors to conceptually represent circulation between interior and exterior space.

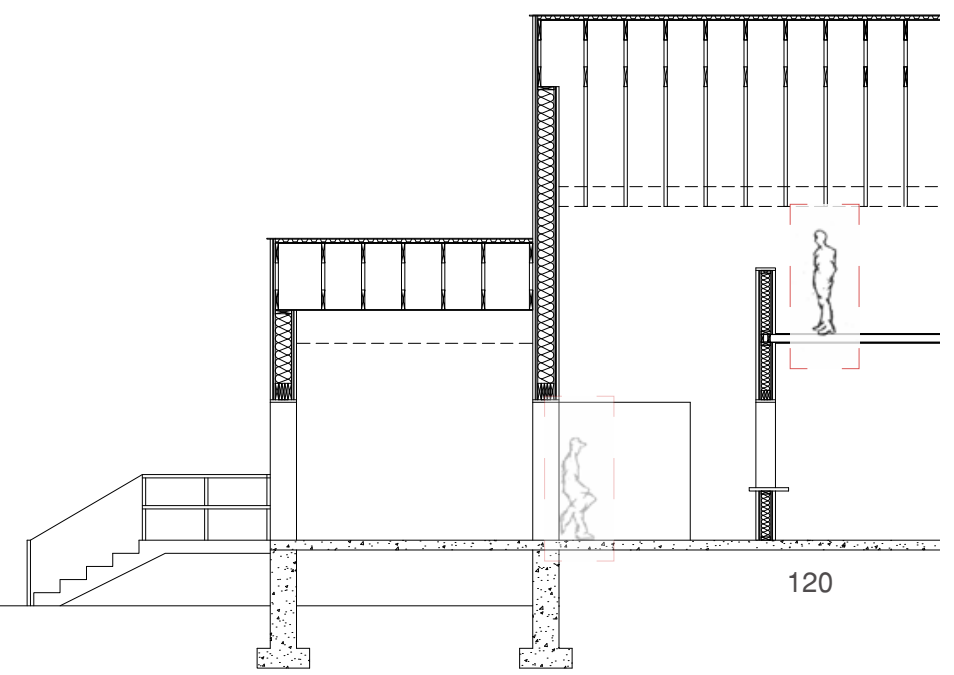




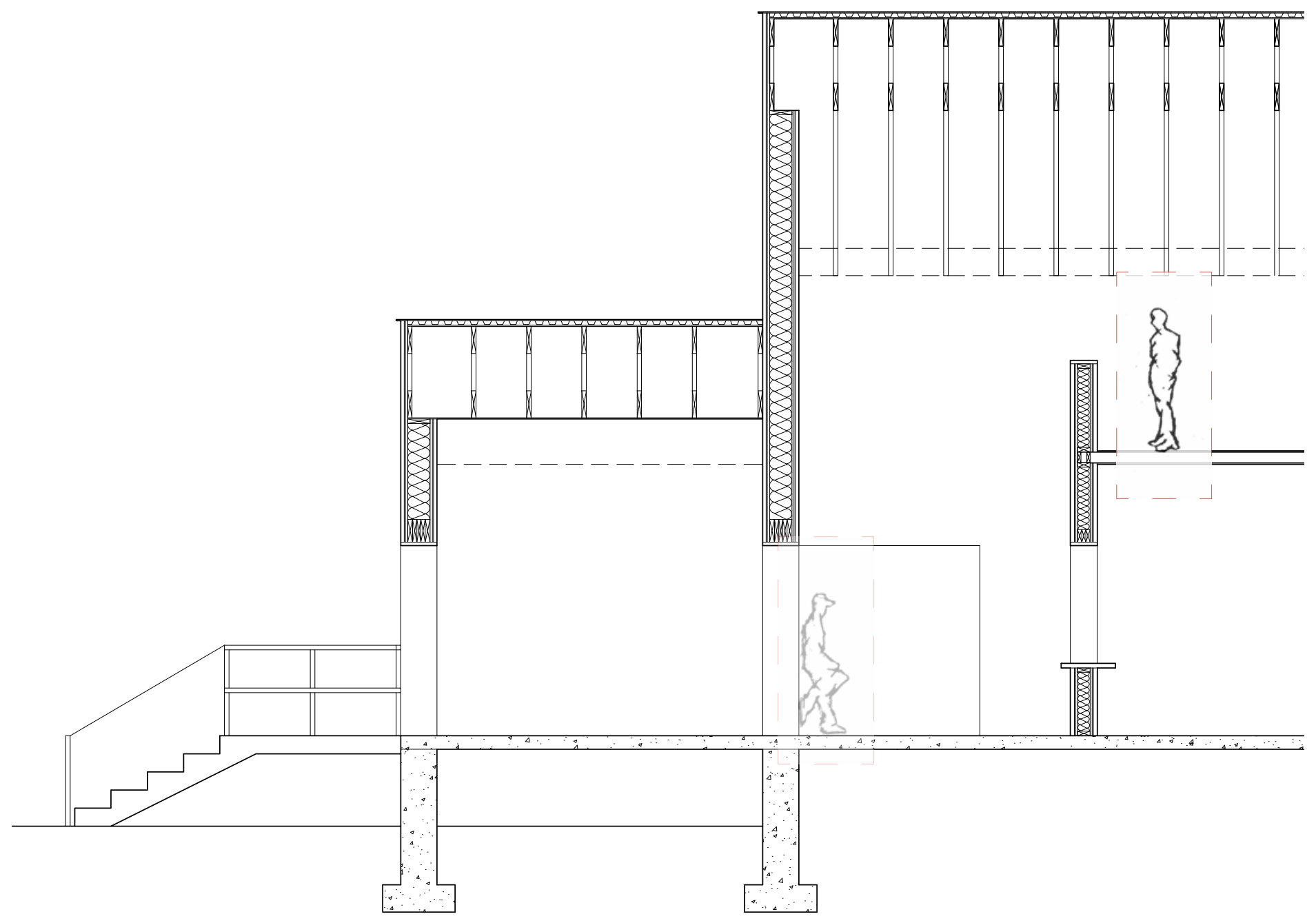




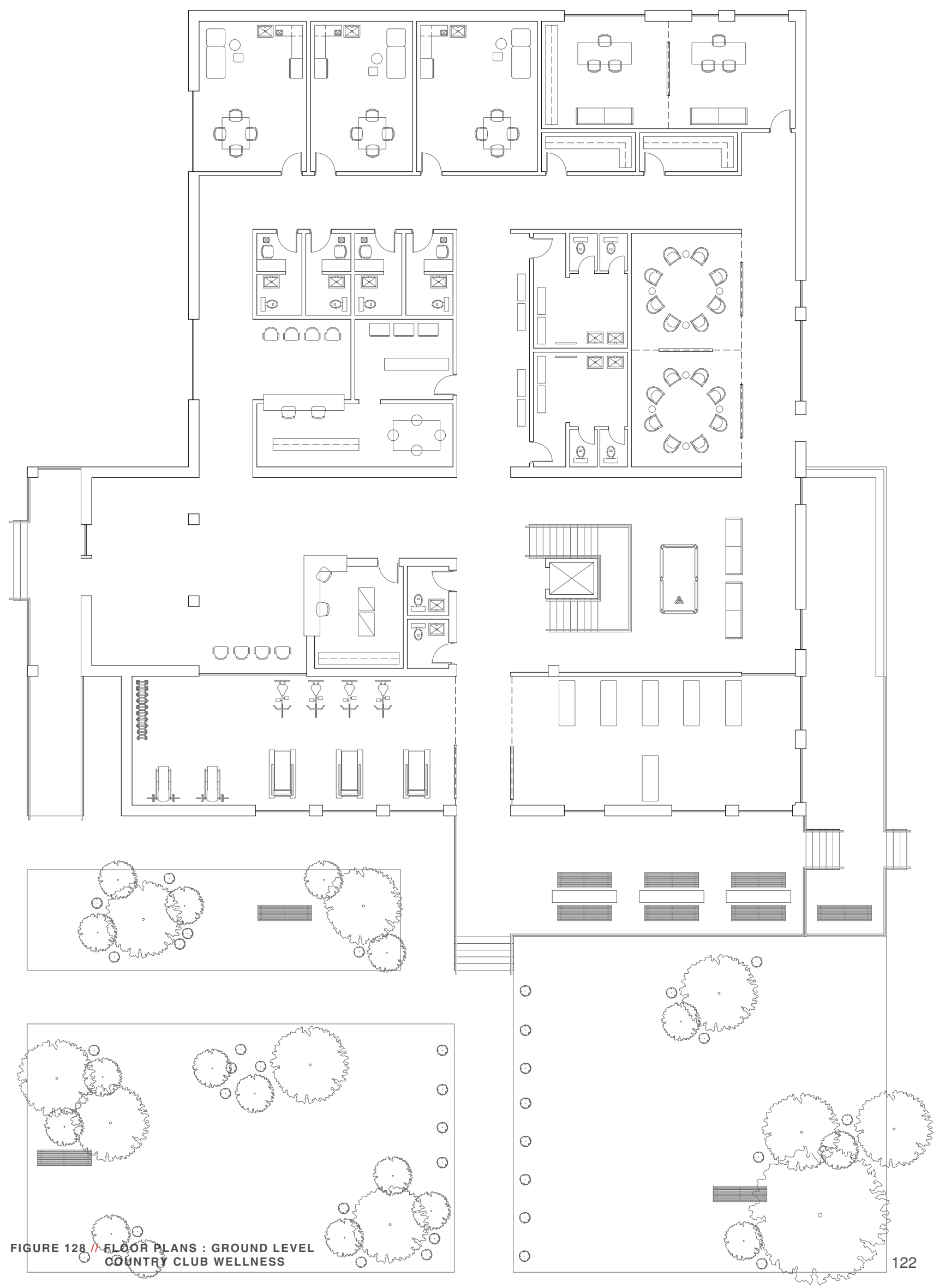




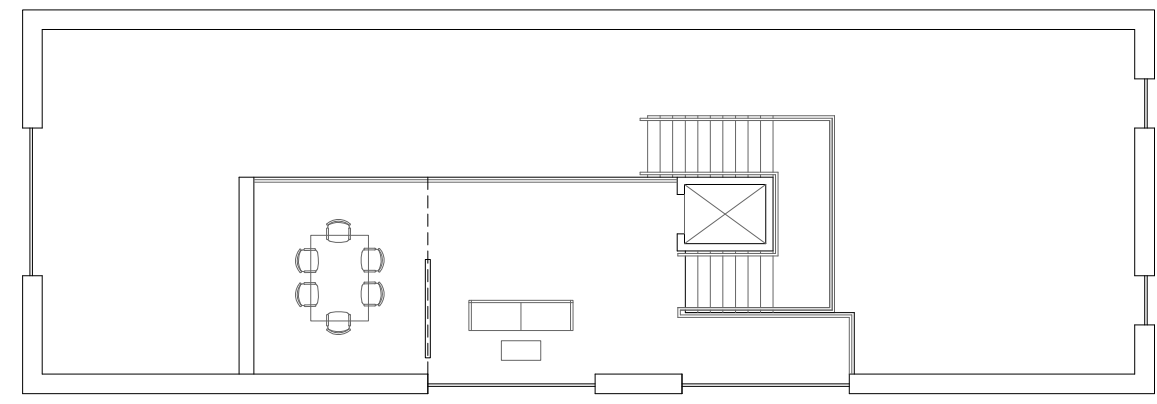

FIGURE 129 // FLOOR PLANS : UPPER LEVEL

COUNTRY CLUB WELLNESS 


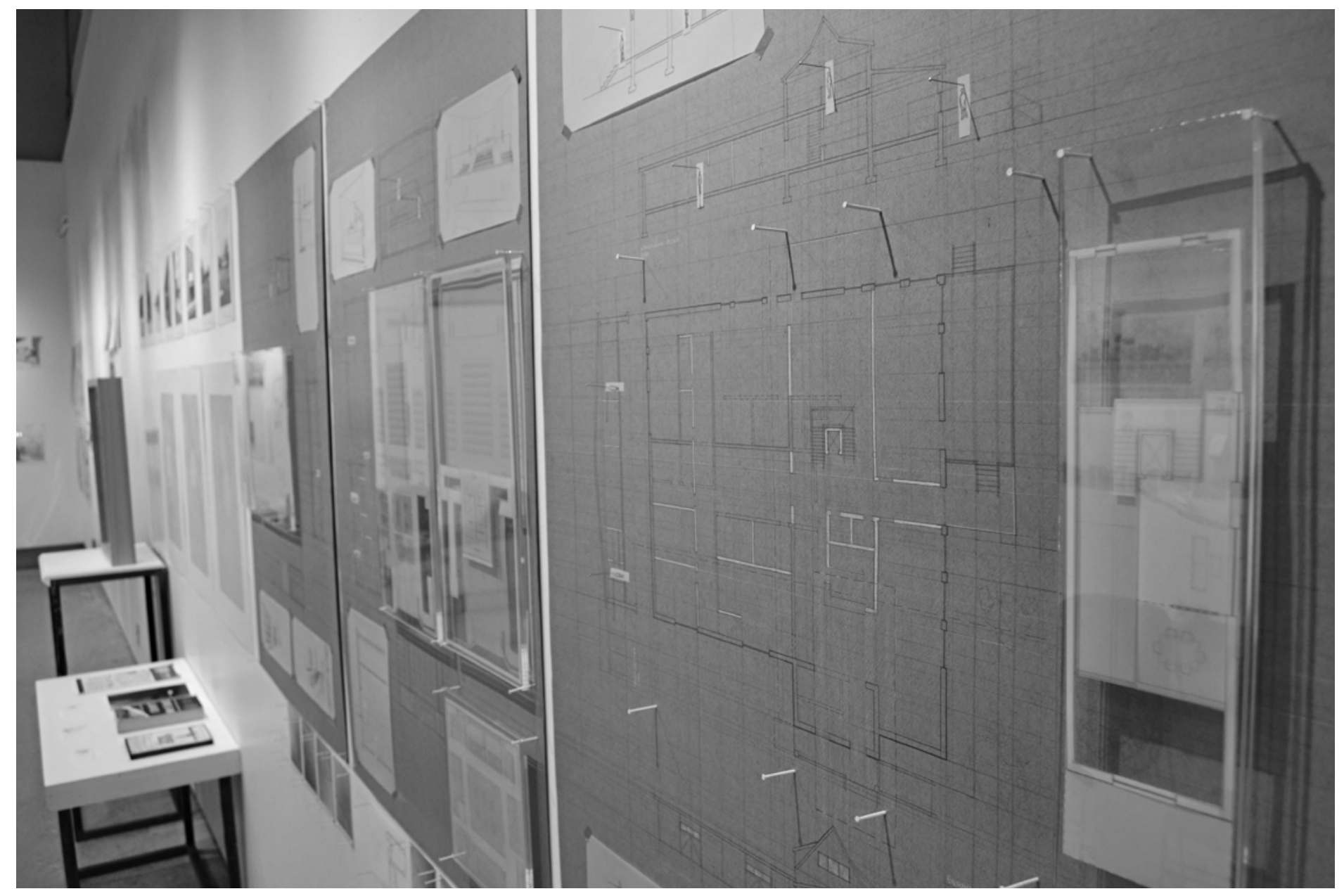




\section{CONCLUSIONS}

This thesis has been quite a journey for me. It started with some vague idea that I wanted to help my hometown of Sault Ste. Marie recover the vibrancy that it once had when I was young. In doing research on the current state of the city, I was shocked to discover that apart from the standard Rust Belt problems of a diminished economic base, the opioid epidemic was taking a radical toll on the health and vitality of the downtown core and the city as a whole. It occurred to me that until this issue was addressed, no amount of cosmetic work would overcome the negative atmosphere associated with the poorly serviced addicted population.

Research into opioid addiction led me to understand that addiction is a disease. It has been poorly resourced because of the negative stigma associated with addiction, but the reality is that in many cases, addicts are no more at fault than diabetics or cancer patients are for their diseases, and we should treat them with the same respect and kindness that we treat other patients. Like diabetes, addiction is a treatable disease. When controlled with substitute medications, addicts can lead healthy and productive lives. So I asked myself, was there a way that I could turn addressing the opioid crisis into a positive thing? Specifically, I wondered what architectural interventions could be made that could simultaneously improve the lives of addicts and the life of the community?

I have answered these questions with a design proposal for a network of community facilities that will help to rehabilitate both addicts and buildings that are abandoned or have lost their purpose. My research into addiction revealed a carefully staged strategy for treatment of addicts, leading to recovery. My thought was to use similar strategies to rehabilitate the fabric of the city by attending to the rehabilitation of significant individual sites in the city that had, like addicts, fallen on tough times. Key to the addiction rehabilitation strategy is the acknowledgement that there is a person of value inside the person who, due to his/her disease, is no longer functioning appropriately in society. A series of therapeutic steps allows this person to shed the negative influences in their lives and once again become contributing members of society.

I developed specific design proposals for three key sites in the city with the idea that similar strategies could be used for other neighbourhoods. My thinking is that if enough thoughtfully designed sites get developed in the city, the negative stigma attached to addiction can be reversed with neighbourhood institutions that offer services and focus on recovery in a more holistic and community building way. 

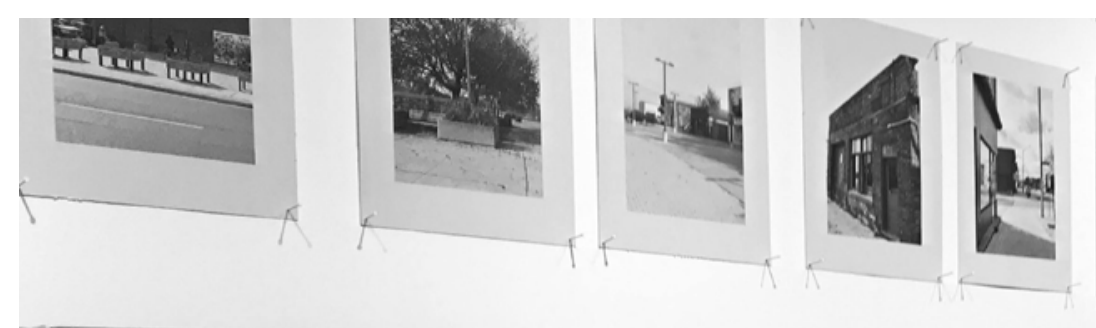

․ㅡㅂ몬

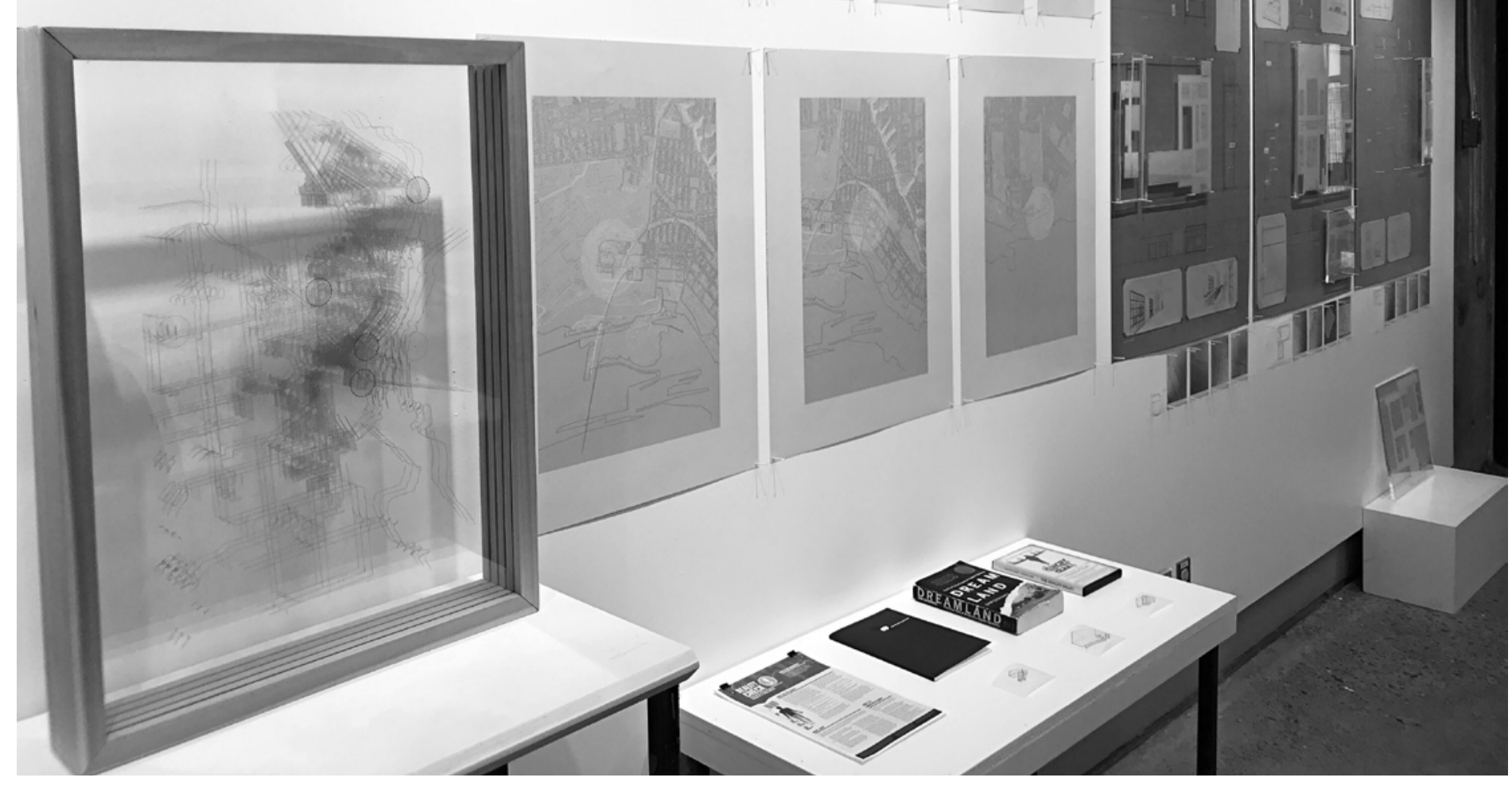


The CTV documentary on addiction put Sault Ste. Marie on the map in a negative way. Ultimately my goal would be to prove that demonstrating a positive attitude towards recovery could instead make Sault Ste. Marie a model for other cities that are experiencing similar issues with the opioid epidemic.

I therefore began the rehabilitation of the three sites in Sault Ste. Marie by treating them as if they were patients seeking treatment. In order to make this real for me, I decided to document the existing buildings (patients) drawing by hand on a heavy grey paper that could tolerate being worked on over time. The return of the building to a useful and viable place in the city (treatment) happened in successive stages on this paper over the course of the semester. The final design is not only a proposal for three neighbourhood rehabilitation centres in the city, but documents and pays tribute to the recovery process as well.

What became apparent during this process was the strong connection that I developed with these drawings. By hand-drawing each component, I was able to take ownership of each design move. As the drawings evolved I became more and more protective of the compositions of skins and layers that I had worked so hard to create. These were my drawings, my designs, my process. They were not simply detached design proposals for a series of sites. This was not about finding the most functional or economical solution to the design problem. While these were factors to be considered, the experience had much more to do with personal investment in an idea. This is the most important lesson that I have learned during the course of this thesis: the idea of ownership is crucial to success.

This new-found appreciation of the value of a sense of ownership suggests a logical next step for this thesis. Why not apply this idea when considering, not just the design, but also the construction of the rehabilitation centres? One of the areas for vocational retraining in the rehabilitation centres could actually be focused around construction and project management activities of the centres themselves. Involving recovering addicts in the construction of these spaces would allow them to have a vested interest in the success of the project and in its survival into the future, thus increasing their own sense of value and belonging. The facility in which they get help is a space that wouldn't be possible without their input. The sense of ownership becomes a sense of pride. I believe this is the key to finding good in a bad situation; in taking lemons and turning them into lemonade. 


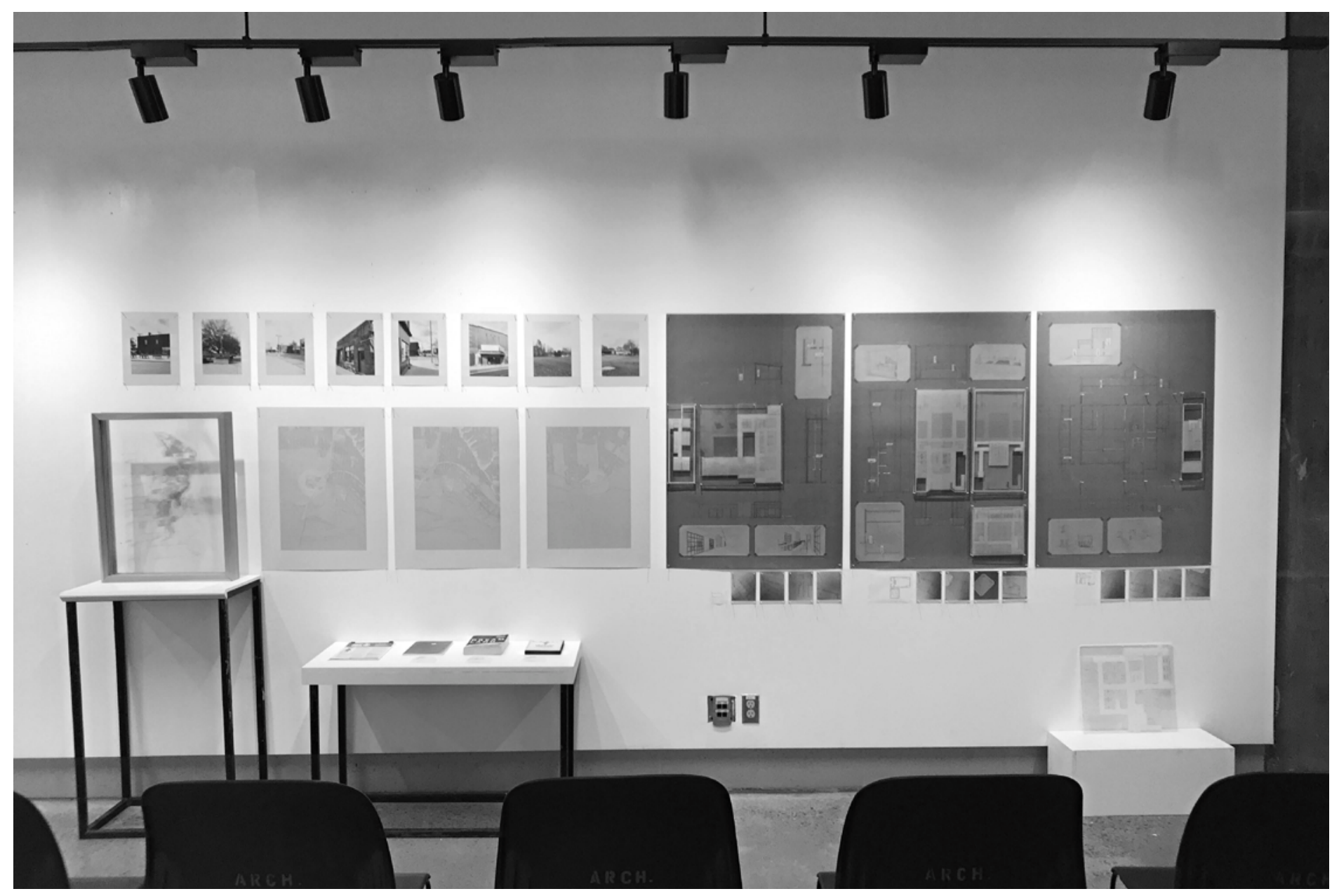




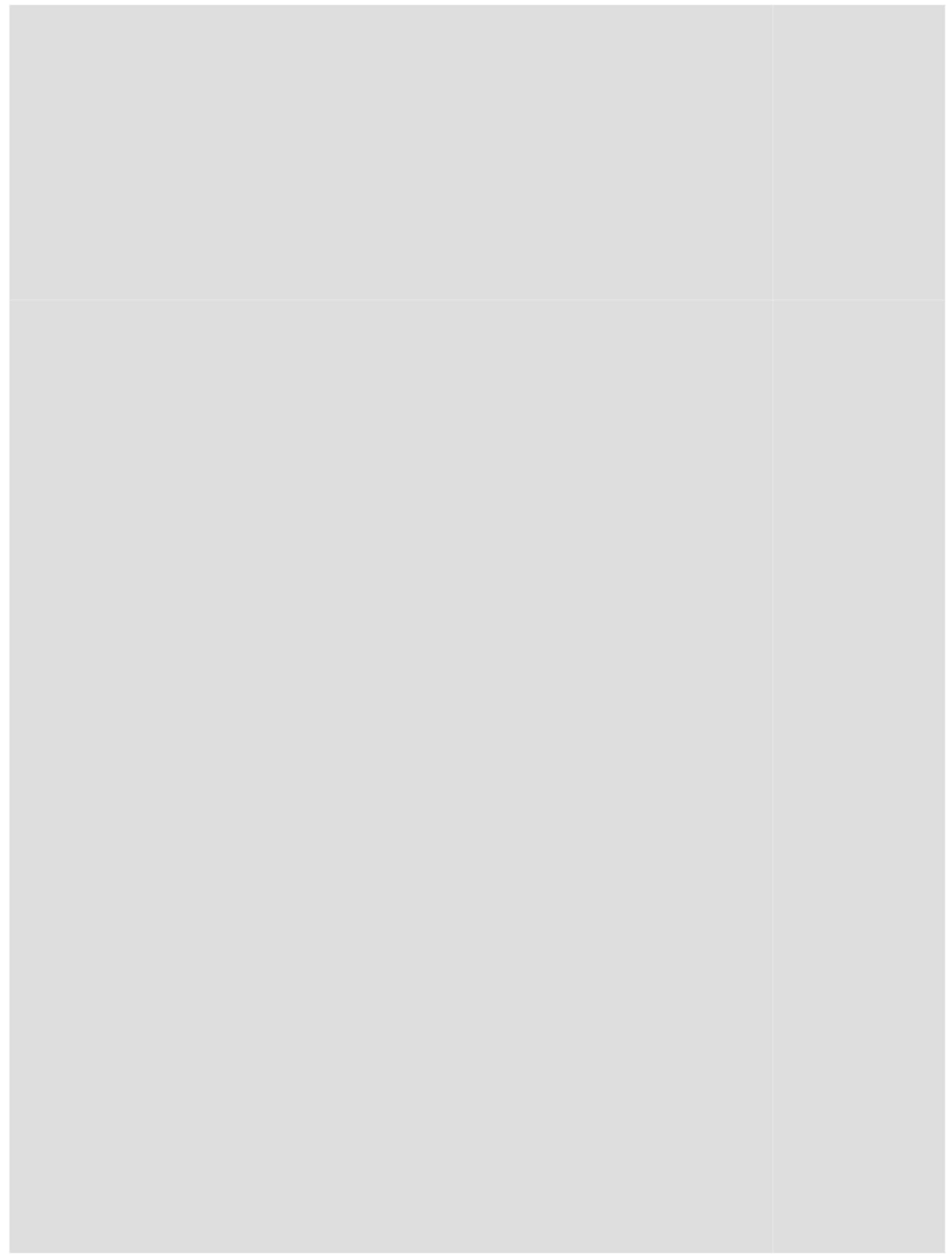




\section{BIBLIOGRAPHY}

\section{TEXT CITATIONS}

Connors, Gerald J. Donovan, Dennis M. and DiClemente, Carlo C. Substance Abuse Treatment and the Stages of Change: Selecting and Planning Interventions. New York: Guilford, 2001.

Crosier, Stephanie. "Opioid Drug Abuse on the Rise Locally". Sault Star, August 29, 2017. Accessed October 02, 2017.

http://www.saultstar.com/2014/08/27/opioid-drug-abuse-on-the-rise.

"Flint, Michigan Master Plan". National Endowment for the Arts. Accessed November 12, 2017.

https://www.arts.gov/exploring-our-town/imagine-flint-master-plan

Glory Wang. Rehabilitation Strategies: The Case of Vancouver Downtown Eastside. Master's Thesis. Carleton University, 2004.

Kelly, Brian. "Drug Overdoses Climbing”. Sault Star, March 18, 2017. Accessed October 02, 2017. http://www.saultstar.com/2017/03/18/drug-overdoses-climbing-group-chair.

Kemp, D. D. "Sault Ste Marie”. The Canadian Encyclopedia. Accessed March 03, 2018. http://www.thecanadianencyclopedia.ca/en/article/sault-ste-marie/

Ougler, Jeffrey. "Sault Ste. Marie and Area Drug Strategy Committee begins Planning Strategy to ensure those who need treatment most know where to get it". Sault Star, January 31, 2017. Accessed October 02, 2017. http://www.saultstar.com/2017/01/31/sault-ste-marie-and-area-drug-strategy-committeebegins-plan ning-strategy-to-ensure-those-who-need-treatment-most-know-where-to-get-it.

"Reality Check”. Future: Sault Ste. Marie. Accessed August 15, 2017.

http://www.futuressm.com/. 
Merriam-Webster Dictionary: America's most-trusted online dictionary. Accessed March 02, 2018.

https://www.merriam-webster.com/

“Östra Hospital Acute Psychiatry Ward”. White Arkitekter. Accessed November 12, 2017.

http://whitearkitekter.com/project/ostra-hospital-emergency-psychiatry-ward/

“Östra Psychiatry Hospital”. Architizer. Accessed November 12, 2017.

https://architizer.com/projects/oestra-psychiatry-hospital/

"Remember This? When James Street Was Bustling". Soo Today. December 06, 2015. Accessed March 18,

2018.

https://www.sootoday.com/columns/remember-this/remember-this-when-james-street-was-bus tling-185021

The Hungry Heart. Documentary. Directed by Bess O'Brian. Released September 21st 2013. DVD. http://thehungryheartmovie.org/about-the-film/blog/

"Sault Ste. Marie Golf Club Overview". Sault Ste. Marie Golf Club Course. Accessed March 23, 2018. http://www.saultgolfclub.ca/course.html

Steeltown Down. Documentary. Produced and Directed by Vice Canada. Released February 10, 2018. https://www.ctvnews.ca/video?clipld=1323609

\section{IMAGE CITATIONS}

"Algoma Steel". Hive Mind. Accessed March 18, 2018.

https://hiveminer.com/Tags/algomasteel,sunset

Photograph by David Helwig. "Downtown Gets Another Methadone Clinic". Soo Today, March 29, 2016. Accessed March 16, 2018.

https://www.sootoday.com/local-news/downtown-gets-another-methadone-clinic-271067

Flint Institute of Arts. Accessed November, 122017.

https://www.flintarts.org

"Flint, Michigan Master Plan". National Endowment for the Arts. Accessed November 12, 2017.

https://www.arts.gov/exploring-our-town/imagine-flint-master-plan 
Google Earth. Accessed October 14, 2017.

"Gore Street". City of Sault Ste. Marie. Accessed September 15, 2017.

http://saultstemarie.ca/City-Hall/City-Departments/Community-Development-Enterprise-Services/

Planning-Enterprise-Services/Strategic-Long-Range-Planning/Downtown-Development/Gore-Street. aspx

“New Psychiatric Clinic". Competition Online. Accessed November 12, 2017.

https://www.competitionline.com/en/projects/51317

"Princess Theatre, Sault Ste. Marie". Ontario Jewish Archives. Accessed March 15, 2018.

http://search.ontariojewisharchives.org/Permalink/descriptions273853

"Reality Check". Future: Sault Ste. Marie. Accessed August 15, 2017.

http://www.futuressm.com/.

"Remember This...". Soo Today. November 23, 2014. Accessed March 15, 2018.

https://www.sootoday.com/columns/remember-this/remember-this-lets-all-be-glad-its-not-the-1930s-

anymore-177213

"Remember This? When James Street Was Bustling". Soo Today. December 06, 2015. Accessed March 18,

2018.

https://www.sootoday.com/columns/remember-this/remember-this-when-james-street-was-bus tling-185021

"Sault Ste. Marie Golf Club Overview". Sault Ste. Marie Golf Club Course. Accessed March 23, 2018.

http://www.saultgolfclub.ca/course.html

Steeltown Down. Documentary. Produced and Directed by Vice Canada. Released February 10, 2018. https://www.ctvnews.ca/video?clipld=1323609

The Corporation of The City of Sault Ste. Marie Archives. Sault Ste. Marie, Ontario Canada.

The Hungry Heart. Documentary. Directed by Bess O'Brian. Released September 21st 2013. DVD.

http://thehungryheartmovie.org/about-the-film/blog/ 


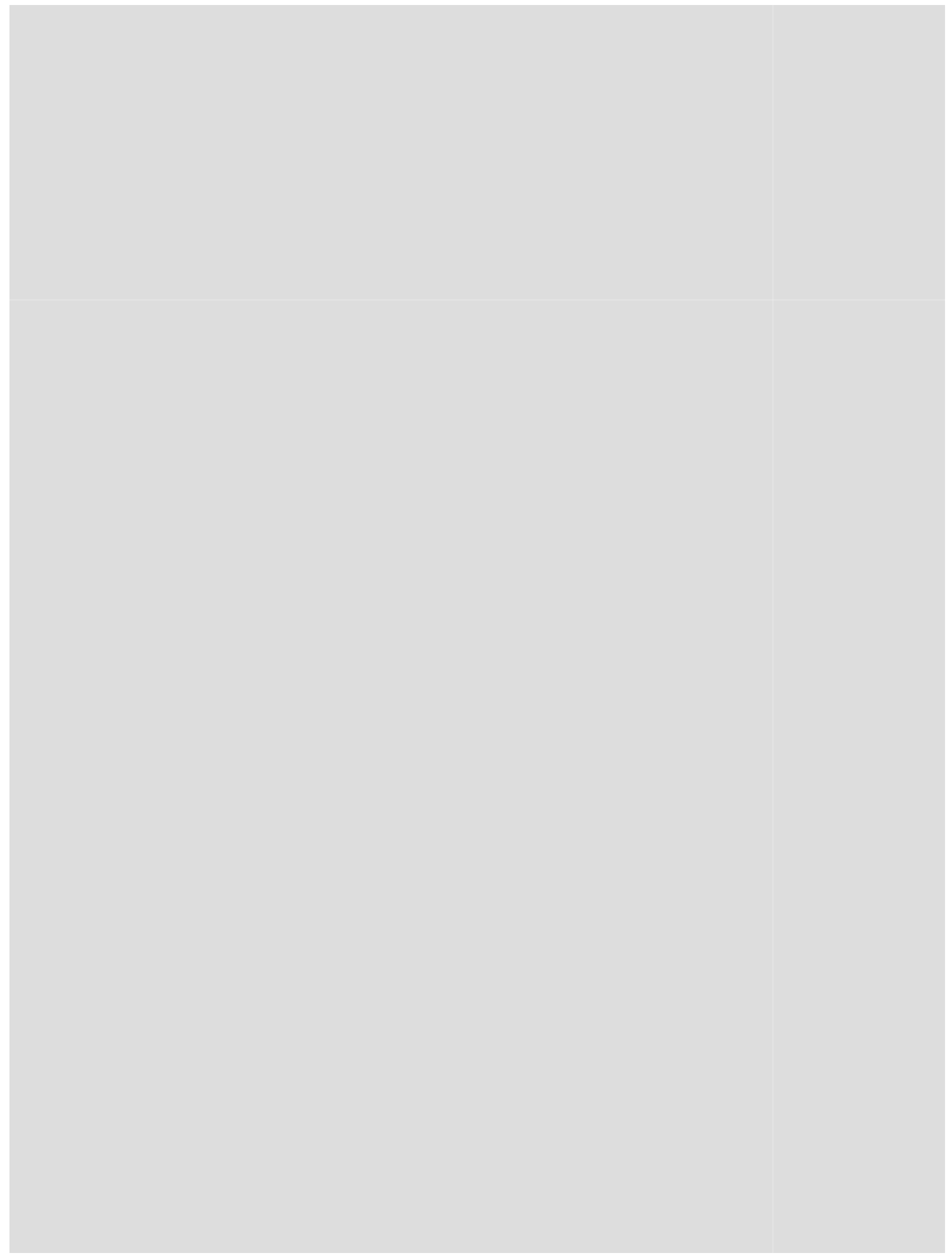




\section{APPENDICES}

\section{APPENDIX A // DRAWING PROCESS PHOTOGRAPHS}
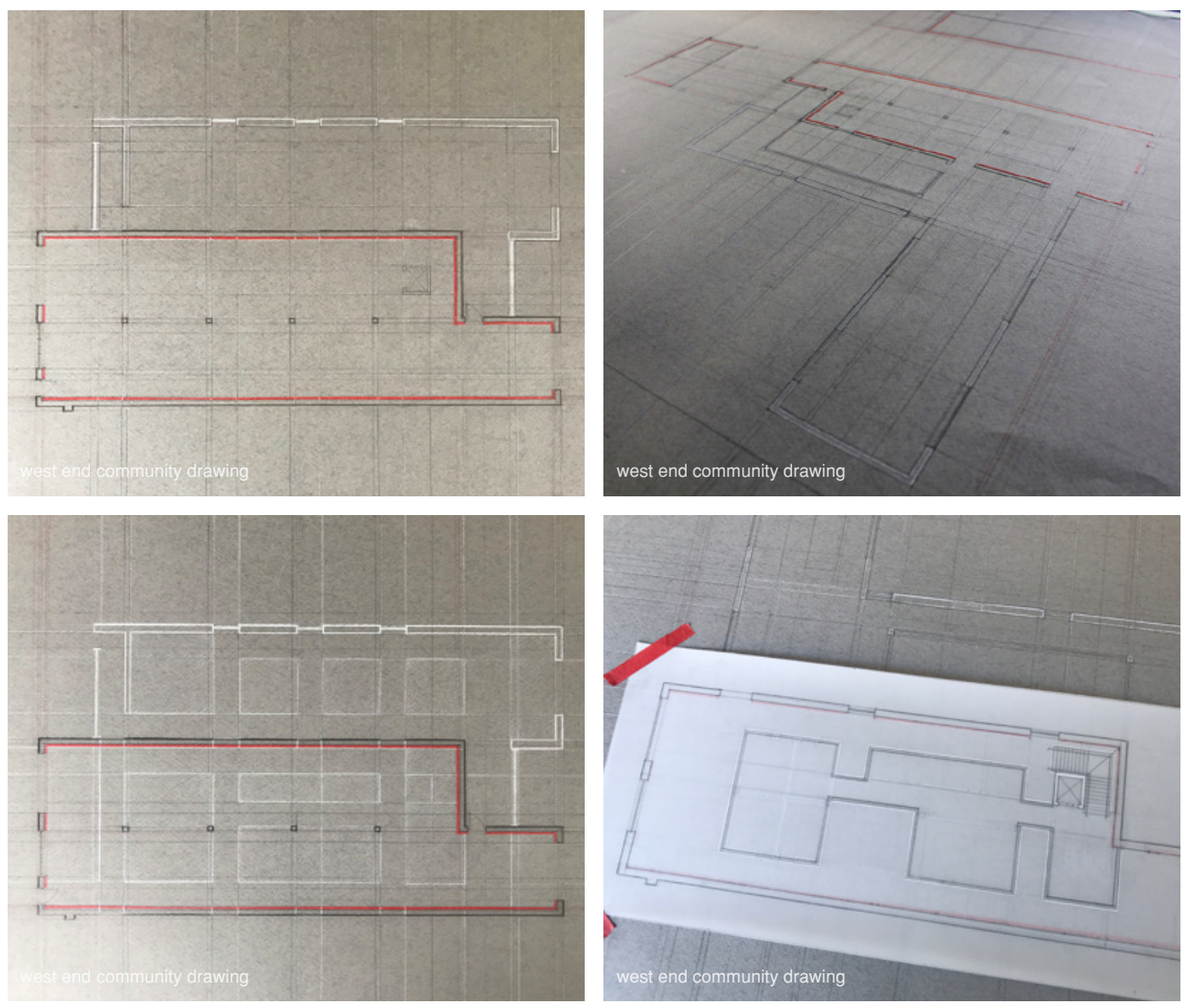

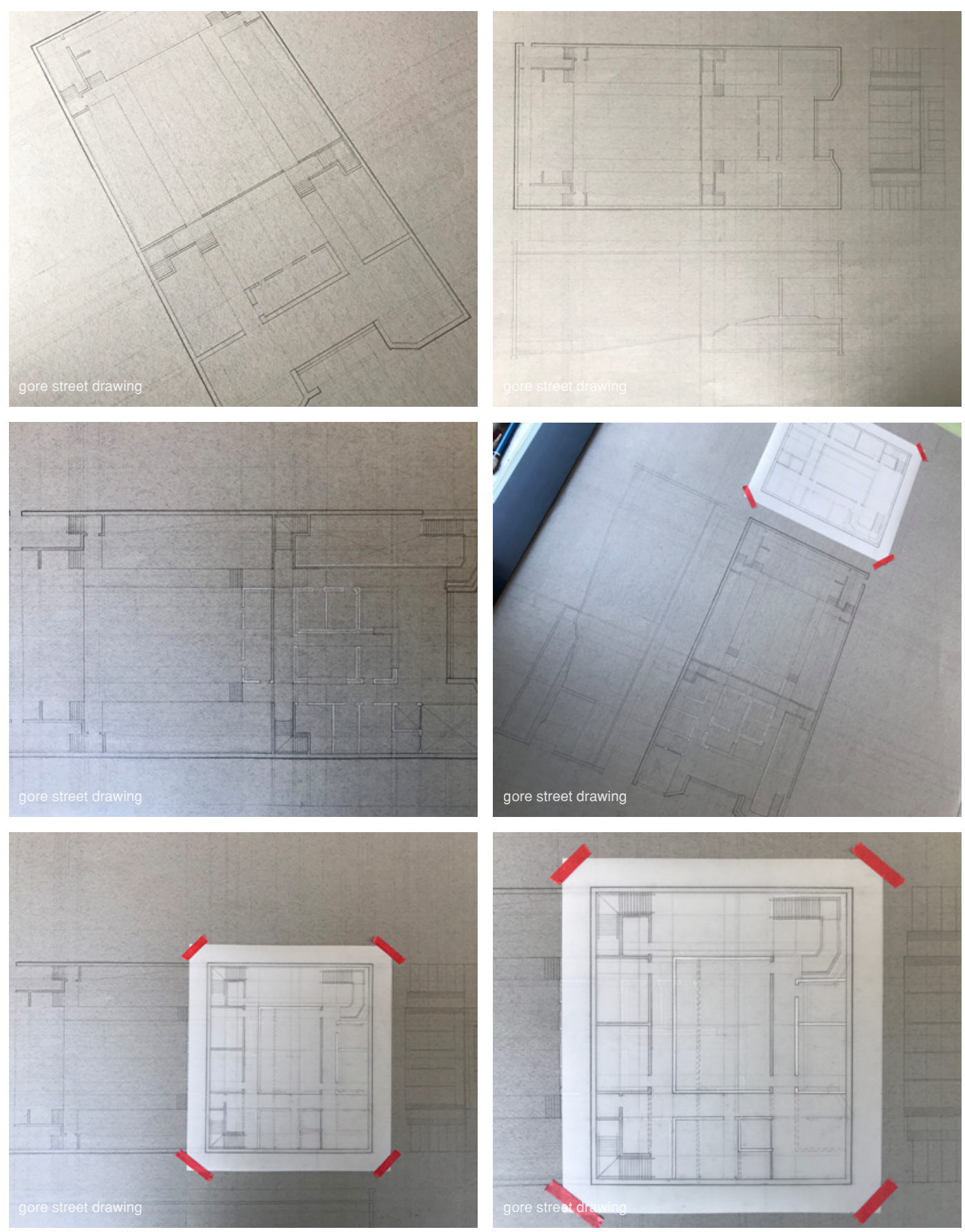

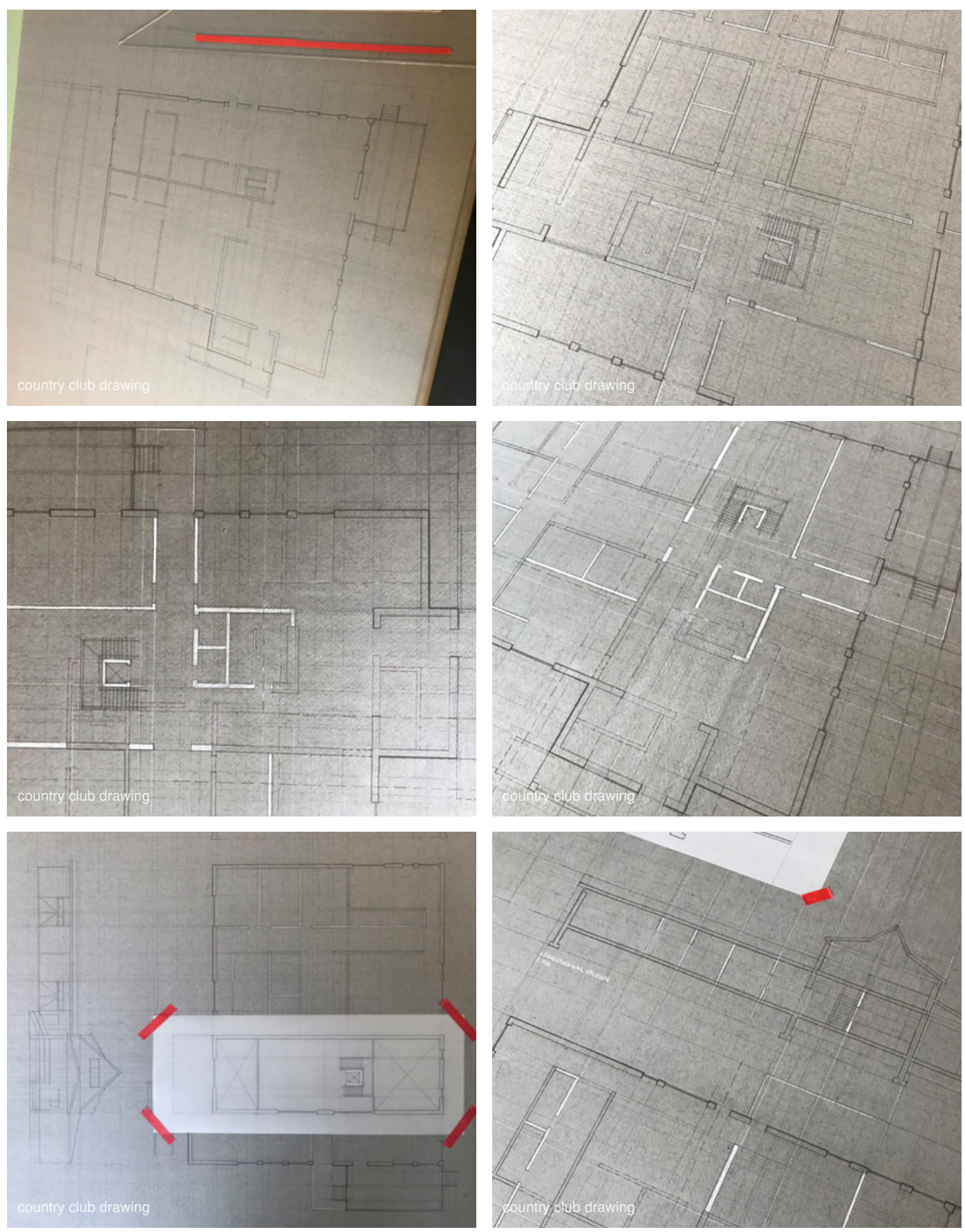


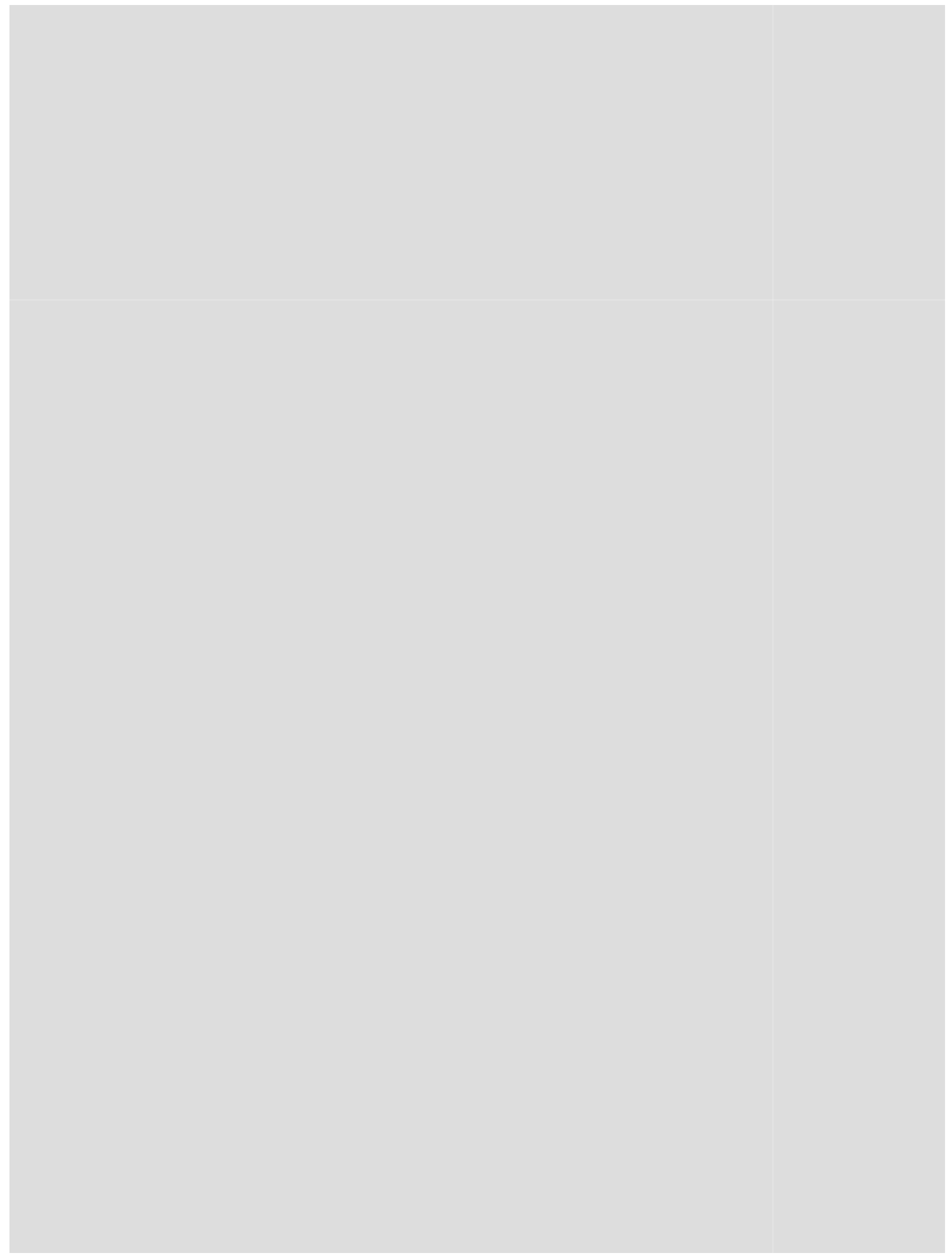


Thank you 
Catrina Pastore

When Life Hands You Lemons, Make Lemonade

Thesis Publication

Master of Architecture

(C) 2018

Carleton University

Azrieli School of Architecture \& Urbanism

Ottawa, Ontario 